\title{
WestVirginiaUniversity
}

THE RESEARCH REPOSITORY @ WVU

Graduate Theses, Dissertations, and Problem Reports

2010

\section{Aerogel nanocomposites for energy applications}

\author{
Yuan Li \\ West Virginia University
}

Follow this and additional works at: https://researchrepository.wvu.edu/etd

\section{Recommended Citation}

Li, Yuan, "Aerogel nanocomposites for energy applications" (2010). Graduate Theses, Dissertations, and Problem Reports. 2142.

https://researchrepository.wvu.edu/etd/2142

This Thesis is protected by copyright and/or related rights. It has been brought to you by the The Research Repository @ WVU with permission from the rights-holder(s). You are free to use this Thesis in any way that is permitted by the copyright and related rights legislation that applies to your use. For other uses you must obtain permission from the rights-holder(s) directly, unless additional rights are indicated by a Creative Commons license in the record and/ or on the work itself. This Thesis has been accepted for inclusion in WVU Graduate Theses, Dissertations, and Problem Reports collection by an authorized administrator of The Research Repository @ WVU. For more information, please contact researchrepository@mail.wvu.edu. 


\title{
Aerogel Nanocomposites for Energy Applications
}

\author{
Yuan Li \\ Thesis submitted to the \\ College of Engineering and Mineral Resources \\ At West Virginia University \\ In partial fulfillment of the requirements \\ For the degree of \\ Master of Science \\ In \\ Chemical Engineering
}

R. Lloyd Carroll, Ph.D., Committee Chair

Department of Chemistry

Dady Dadyburjor, Ph.D.

Charter D. Stinespring, Ph.D.

Department of Chemical Engineering

Morgantown, West Virginia

2010

Keywords: Sol-gel, Aerogel, Metal nanoparticles, $\mathrm{CO}_{2}$ emission reduction, TGA, Chemical-Looping Combustion (CLC) 


\section{ABSTRACT}

\section{Aerogel Nanocomposites for Energy Applications}

\section{Yuan Li}

Efficient use of petroleum, coal and natural gas resources requires the use of novel materials and developing technologies. Aerogel-supported nanoparticles are materials with great potential in development of new technologies in energy generation, fuel processing, and by-product remediation. Aerogels represent one of the highest surface area materials known, providing an excellent support for catalytic reactions, including those important in the reformation of petroleum resources. The properties and capabilities of these materials may be modified by tuning the porosity, controlling the size and nature of nanoparticles on the support, and varying the reaction conditions. Our focus in this work is the development of oxygen carriers (aerogel with metal nanoparticles) for application in a Chemical Looping Combustion (CLC) system, a process by which the energy is generated from fuel oxidation where the fuel and oxidant are not in direct contact. The structure and composition of the produced materials in our lab was characterized by X-ray Diffraction, Scanning Election Microscopy, Transmission Electron Microscopy, BET, X-ray Photoelectron Spectroscopy, and Inductively Coupled Plasma Mass Spectrometry. Thermogravimetric Analysis was then employed to optimize the reaction conditions and determine which materials presented the greatest potential for CLC. 


\section{ACKNOWLEDGEMENT}

I would like to express my sincere appreciation to my research advisor Dr. R. Lloyd Carroll, for his patience, guidance and great support for my research and graduate studies. He provided me with opportunities to learn many new techniques along with a plethora of new experiences. I would additionally like to thank the other members of my committee, Dr. Dady Dadyburjor and Dr. Charter D. Stinespring for their excellent instruction and enlightening discussions.

I would also like to thank all the professors and staff involved with WV-Nano, who patiently and kindly trained me on their instruments and techniques. Especially I would like to thank Dr. Andy Woodworth, Dr. Kolin Brown, Eric Shires, Dr. Vin Berry, Dr. M. S. Seehra, they helped me a lot on my research.

I would like to give a great thank you to all my fellow lab mates, especially Victor Abdelsayed, Shengrong Ye and Aaron Routzahn. They helped me to become familiar with the lab and expand my ideas for my research. It was really great to work with them.

This work is supported by the University Research Initiative with the National Energy Technology Laboratory, through the Department of Energy Grant \# [41817M215341817M21000].

I would like to thank Todd Gardner, James Poston, Edward Kachur, Daniel Hill and Mechelle Perters at NETL, for the great support I received in my work there.

I would also like to thank my families and friends, who supported me in my study and research. They have witnessed my growth, and supported me through all my successes and failures. 


\section{TABLE OF CONTENTS}

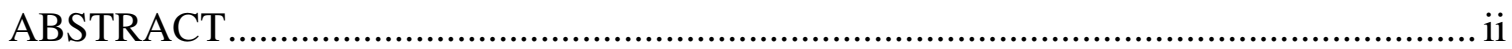

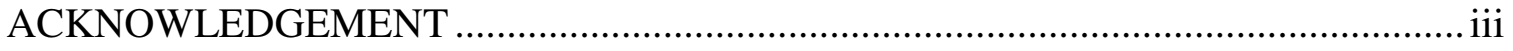

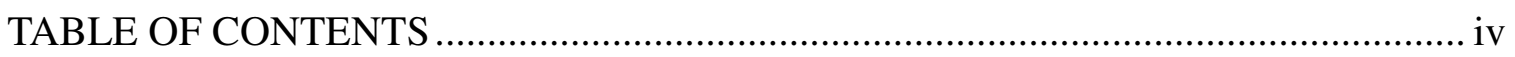

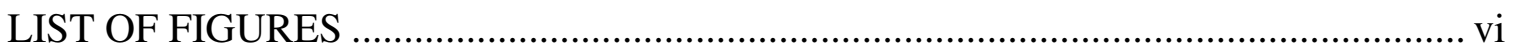

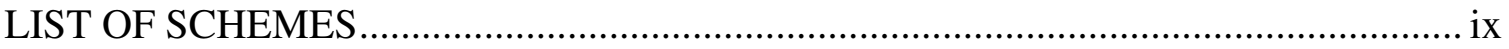

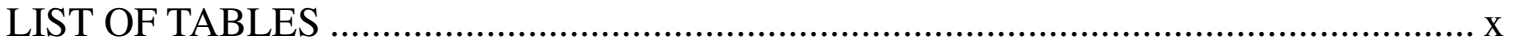

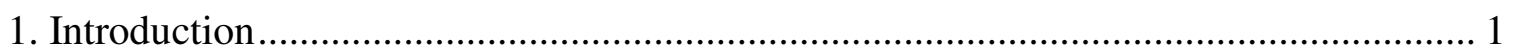

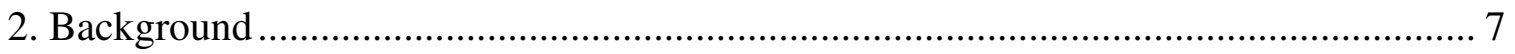

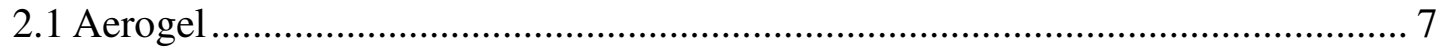

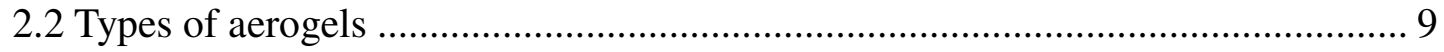

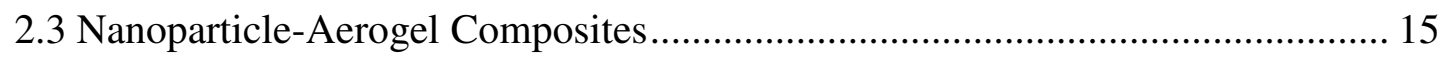

2.4 Thermally Stable Aerogel-Nanoparticle Composites ........................................ 17

2.5 Characterization Methods of Aerogels Structure ............................................ 19

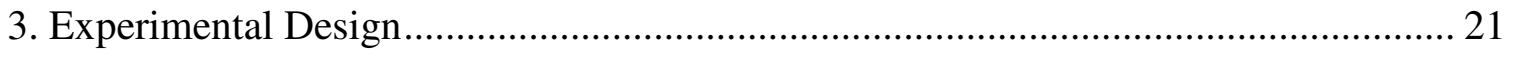

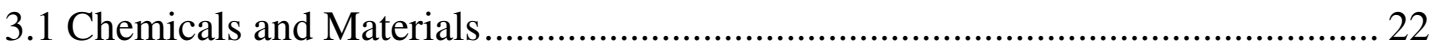

3.2 Silica-Modified Alumina Gel.................................................................... 22

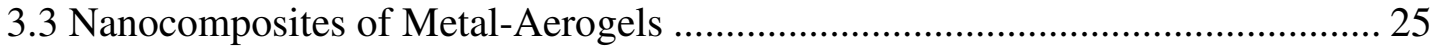

3.4 Estimation of Metal Concentration in Aerogel ............................................... 27

3.5 Characterization of Aerogel Samples.......................................................... 28

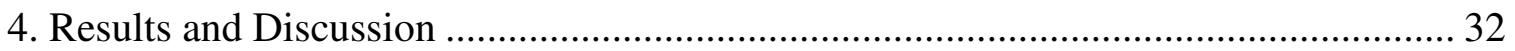

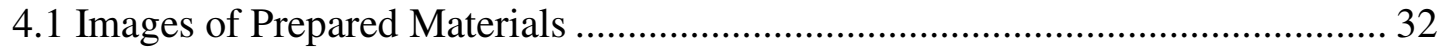

4.2 Structure and Composition of Aging Aerogels ................................................ 33

4.3 Aerogels Containing Iron and Cobalt ........................................................ 40

4.4 Thermal Analysis of Iron-containing Aerogel .............................................. 56 




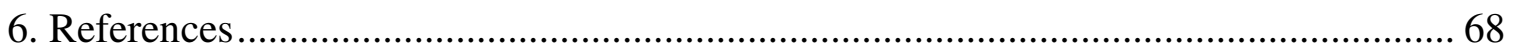




\section{LIST OF FIGURES}

Figure 1-1. Keeling Curve- $\mathrm{CO}_{2}$ concentration in the Earth's atmosphere from

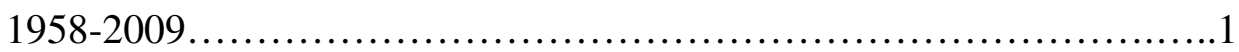

Figure 1-2. Global energy usage details ........................................

Figure 1-3. IGCC power plants .................................................

Figure 1-4. Chemical-Looping Combustion System..................................

Figure 2-1. General scheme for preparing aerogels by sol-gel processing .................8

Figure 2-2. Changes in surface area of alumina with heating temperature. (०) Alumina obtained by decomposition of boehmite. (•) silica $2.5 \mathrm{wt} \%$, (•) silica $5 \mathrm{wt} \%$,

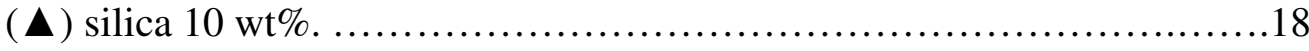

Figure 3-1. Metal particles loaded aerogel synthesis procedure $\ldots \ldots \ldots \ldots \ldots \ldots \ldots \ldots \ldots . \ldots \ldots \ldots$

Figure 3-2. Gel in Iron precursor and Octyl Ether mixer...............................26

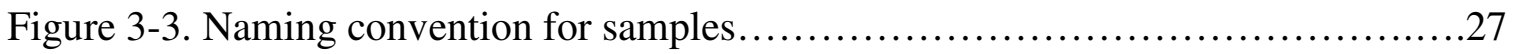

Figure 4-1. Pictures of pure aerogel and aerogel with metal particles.......................32

Figure 4-2. XRD patterns from aged aerogels. a) After indicated alumina aging times; boehmite peak pattern at bottom. b) After indicated TEOS aging times

Figure 4-3. Surface area of aerogel as TEOS aging increases...........................37

Figure 4-4. SEM images of alumina-silica aerogel before (a) and after (b) 24hrs TEOS

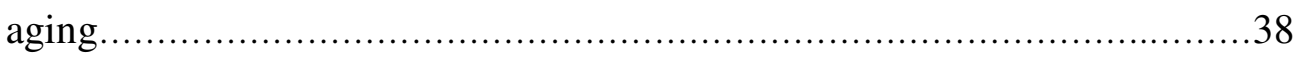

Figure 4-5. TEM image of alumina-silica aerogel f.................................. 38

Figure 4-6. XPS spectra for aerogel. The figure shows a comparison between no TEOS

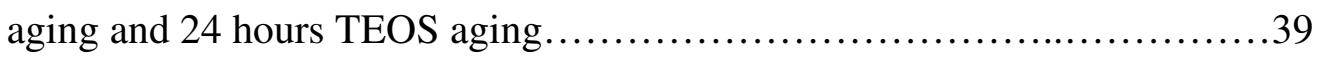

Figure 4-7. XRD patterns for gel undergoing alumina aging (boehmite) - TEOS aging (Boehmite/ Silica)- adding Fe particles (Fe/Boehmite/Silica)- calcined at 800 
Figure 4-8. Aerogel with deposited iron. Cobalt-containing aerogels have the same general appearance. As is clearly observable from the image, the aerogel pieces have much higher metal concentration on the surface

Figure 4-9. SEM image of aerogel with Iron loading (Fe250, ground, (a)) and Cobalt

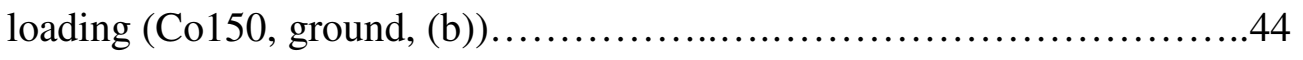

Figure 4-10. EDX image of aerogel with Iron loading (Fe250, ground).................45

Figure 4-11. EDX image of aerogel with Cobalt loading (Co150, ground).............46

Figure 4-12. EDX for Fe250 surface (cross section)...........................47

Figure 4-13. SEM-EDX result for Co150 surface (cross section) ...................47

Figure 4-14. TEM image of alumina-silica aerogel after iron deposition...............47

Figure 4-15. XPS survey scan for aerogel with and without deposition of iron............48

Figure 4-16. High resolution XPS spectrum for Iron peak..........................49

Figure 4-17. XPS survey scan for Co150..................................49

Figure 4-18. For Fe250 (a) XPS SXI showing linescan locations, (b) XPS Line-Scan distribution curves, and (c) XPS Mapping image.....................53

Figure 4-19. For Co150 (a) XPS linescan SXI showing linescan locations, (b) XPS linescan distribution curves, (c) XPS Mapping SXI, and (d) XPS Mapping

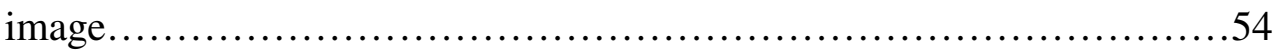

Figure 4-20. TPR spectra for Fe-aerogel......................................57

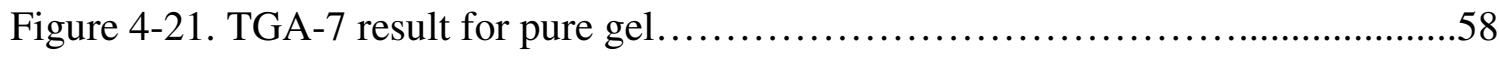

Figure 4-22. TGA-7 result for Fe250 reduction-reoxidation........................60

Figure 4-23. TGA-7 result for Fe250cal reduction-reoxidation.....................60

Figure 4-24. TGA-7 result for Co150 reduction-reoxidation......................62

Figure 4-25. TGA-7 result for Co150cal reduction-reoxidation....................62

Figure 4-26. Cyclic cycles TGA test for Fe50 (left) and Co150 (right)...............64 
Figure 4-27. One oxidation-reduction cycle in cyclic TGA system.................65

Figure 4-28. XRD pattern for Co150 after TGA........................................................65 


\section{LIST OF SCHEMES}

Scheme 2-1. Chemical reaction for the sol-gel process of alkoxysilanes..................11

Scheme 2-2. Alumina phase changes as temperature increasing..................... 14

Scheme 4-1. Loss reactions in iron-gel formation................................55 


\section{LIST OF TABLES}

Table 2-1. Typical Methods for Aerogel's Characterization..........................20

Table 3-1. Metal Concentration Estimations Based on the Precursor Concentration.......28

Table 4-1. Surface Area of Aerogel with Varying Metal Deposition....................43

Table 4-2. Elemental Composition of Iron-containing Aerogels by XPS and ICP-MS....50

Table 4-3. Elements concentrations for aerogel samples with different amounts of ironcomparison from XPS and ICP-MS 


\section{Introduction}

In the development of novel energy technology, we must consider the possible impacts of the work. As it stands now, fossil fuel use is implicated as a major source of $\mathrm{CO}_{2}$ emission, resulting in increase in the green house effect and hence global warming.

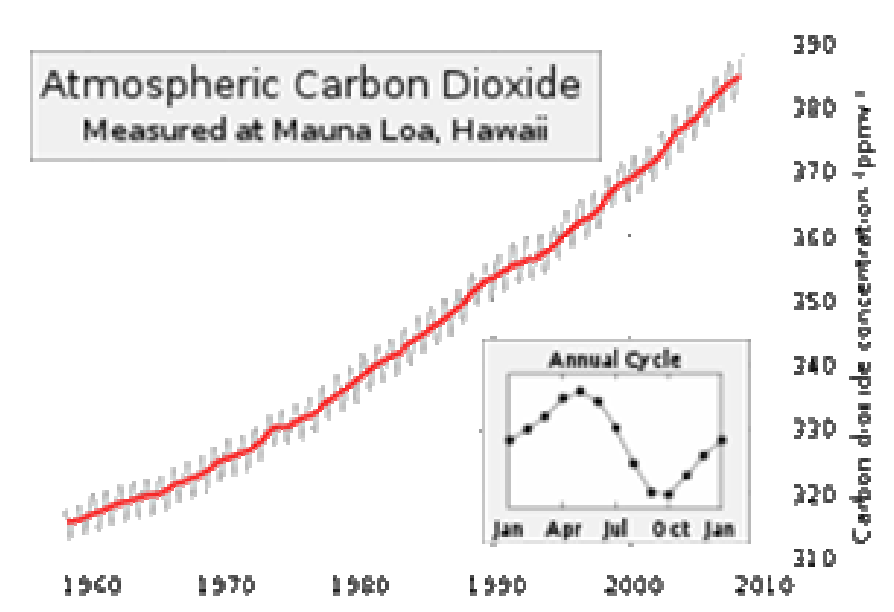

Figure 1-1. Keeling Curve - $\mathrm{CO}_{2}$ concentration in the

Earth's atmosphere from 1958-2009 (Reported from reference 1).

The increase in atmospheric $\mathrm{CO}_{2}$ due to emissions from human sources is strongly supported by ongoing research. The Keeling Curve (Figure 1-1) $)^{2}$ shows the history of atmospheric carbon dioxide concentrations from 1958-2009, as measured at Mauna Loa, Hawaii. It is an essential piece of evidence showing increases in greenhouse gases due to industrialization. This is the longest continuous direct measurement of $\mathrm{CO}_{2}$ in the world. The approximately linear increase from 315 ppmv (part per million by volume) in 1958 to 387 ppmv in 2009, amounts to an average increase of $1.3 \mathrm{ppmv} / \mathrm{year}$.

While it may be possible to propose the capture and sequestration of existing $\mathrm{CO}_{2}$ in the atmosphere, it is currently economically and technically impossible with existing technologies. It then becomes necessary to focus on methodologies to effectively reduce $\mathrm{CO}_{2}$ emission. Given that fossil fuels represent a ready source of energy for the foreseeable future, we must consider ways to reduce the emission of $\mathrm{CO}_{2}$ from their use. With current technologies (such as direct combustion of fossil fuels), $\mathrm{CO}_{2}$ capture and sequestration are possible, but technically and economically challenging. In a study 
carried out by the DoE in $2006^{3}$, the cost involved in retro-fitting a single existing coal-burning power plant for capture of $90 \%$ of $\mathrm{CO}_{2}$ from flue gas was $\$ 400,000,000$, resulting in an increase in energy costs of $50-100 \%$ per kilowatt hour. Therefore, the most economically and technically feasible alternative is to identify alternative energy generation techniques using fossil fuels, that allow the capture and sequestration of $\mathrm{CO}_{2}$. We will describe one such technique, known as Chemical Looping Combustion (CLC) , below.

The twentieth century has seen a rapid increase in the use of fossil fuels. Between 1980 and 2006, the worldwide annual growth rate was $2 \%$. In 2008 , total worldwide energy consumption was 474 exajoules $\left(5 \times 10^{20} \mathrm{~J}\right)$ with $80-90 \%$ derived from the combustion of fossil fuels, and for which coal provides $25 \%$ of this ${ }^{5}$, as shown in Figure 1-2. The carbon emissions from power generation account for $25-30 \%$ of all global $\mathrm{CO}_{2}$ emissions. Under the current demands for energy, reliance on fossil fuels for the generation of power is unavoidable. However, this is an important problem that should be addressed. With the techniques we have now, $\mathrm{CO}_{2}$ emissions can not be avoided, but they can be reduced to a considerably lower level.

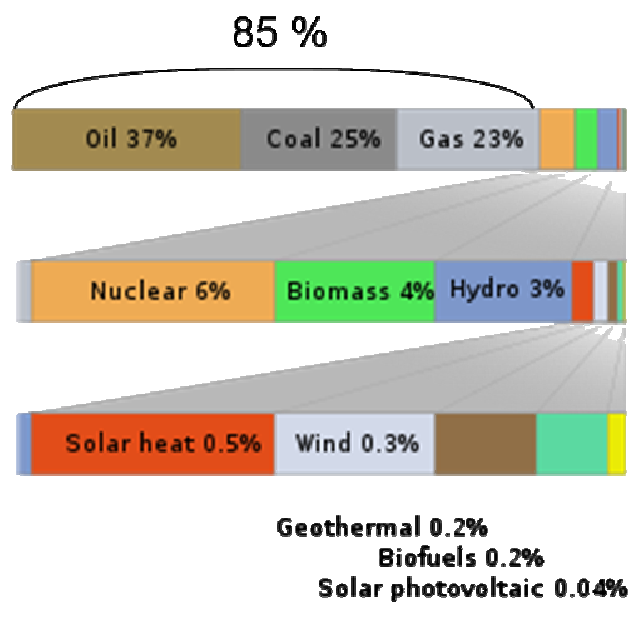

Figure 1-2. Global energy usage details (Reported from reference 5)
CLC can potentially lead to a significant impact on the use of fossil fuels and reduction of the emission of carbon dioxide. Thus, the goal of our work is to develop materials that improve the effectiveness of oxygen carriers in CLC. This will result in more efficient generation of power from fossil fuels and important improvements in this field. 
Coal is used for about $50 \%$ of United States' electricity needs ${ }^{6}$. New technologies to generate power from fossil fuels have focused on improved efficiency, removal of contaminants, and the capture and sequestration of $\mathrm{CO}_{2}$. In industry, Integrated gasification combined cycle (IGCC) is used to convert coal into synthesis gas (or syngas), which is a mixture of $\mathrm{H}_{2}$ and $\mathrm{CO}$. Contaminants, such as sulfur and heavy metals, which generate environmental pollutants or reduce the efficiency of the power generation process, should be removed from the syngas before combustion. This design results in reducing the emission of sulfur dioxide, particulates, and mercury, cadmium, and arsenic. Excess heat from the primary combustion is passed to a steam cycle, similar to a combined cycle gas turbine. Comparing with conventional pulverized coal, IGCC definitely improved the combustion efficiency. The lower emissions allowed for by IGCC will become an important consideration in the future as emission regulations tighten due to growing concern of the impact pollutants have on the environment and the globe ${ }^{6}$. Figure 1-3 is a schematic flow diagram of IGCC plants ${ }^{7}$.

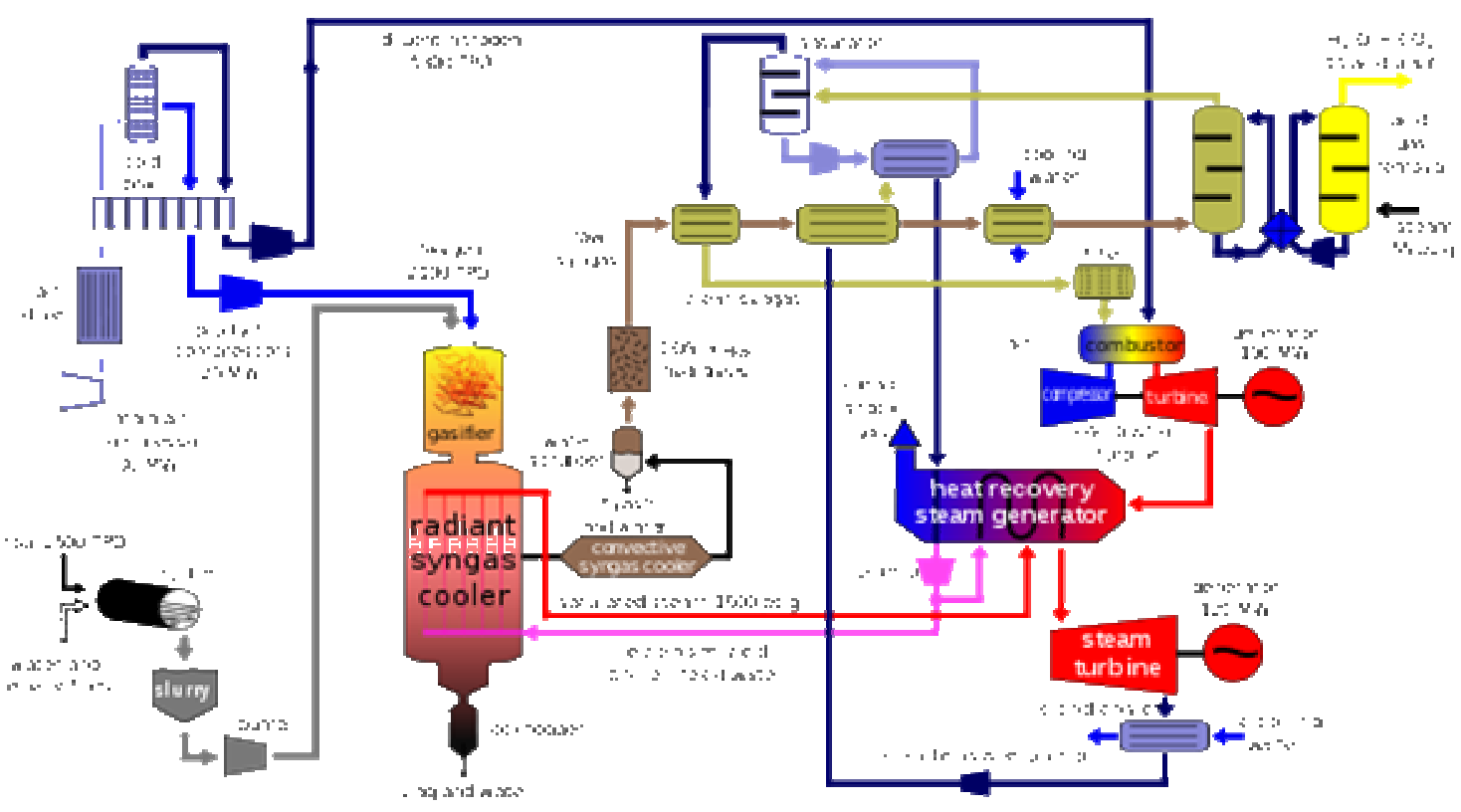

Figure 1-3. IGCC power plants (Reported from reference 6) 
The IGCC process converts coal to syngas $\left(\mathrm{CO}\right.$ and $\mathrm{H}_{2}$ ), which may then be directly combusted to generate power. An alternative high efficiency power generation method using syngas is called Chemical-Looping Combustion (CLC) ${ }^{8}$. CLC is a promising combustion technology, which removes the direct combustion step of syngas in IGCC.

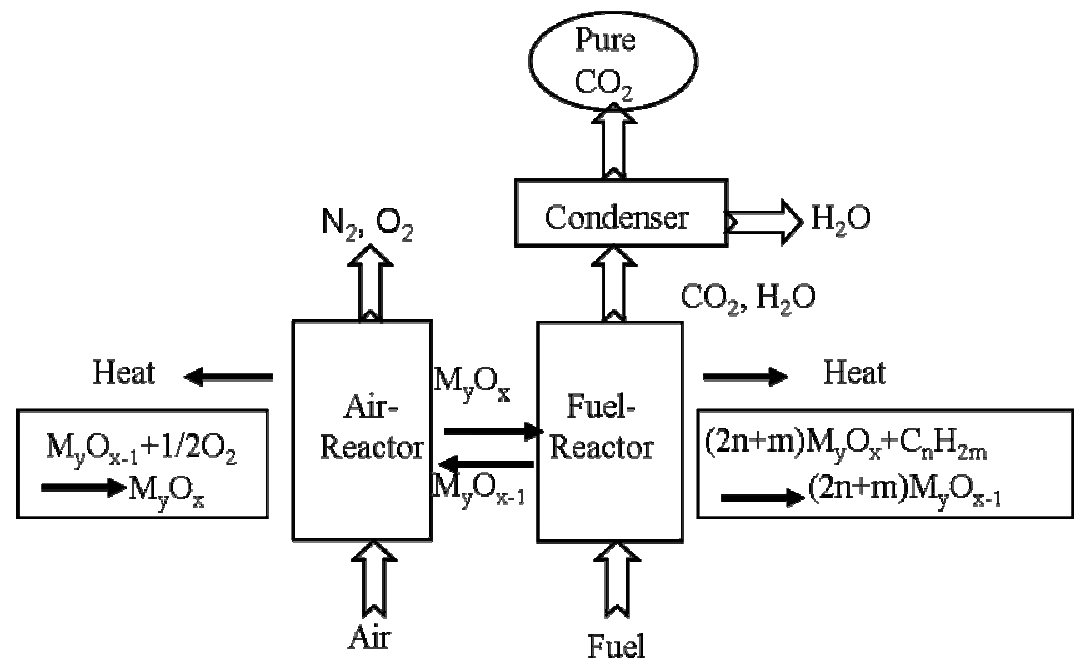

Figure 1-4. Chemical-Looping Combustion System

CLC is a two-stage process (Figure 1-4). In the first stage, fuel, such as syngas, is passed over heated metal oxides. Metal oxides act as oxygen carriers, supplying the stoichiometric oxygen necessary for oxidation of fuels to $\mathrm{CO}_{2}$ and water, but without $\mathrm{N}_{2}$ (which is present in air) which can lead to $\mathrm{NO}_{\mathrm{x}}$ formation and dilution of the product gas stream. In the process of providing the oxygen for the combustion of the fuel, the metal oxide is reduced. In the second stage, these reduced metal particles are reoxidized with air, to be reused as oxygen carriers in the next fuel oxidation cycle. Formation of $\mathrm{NO}_{\mathrm{x}}$ is significantly reduced, and the product stream consists of the products of oxidation $\left(\mathrm{CO}_{2}\right.$, $\mathrm{H}_{2} \mathrm{O}$ ) as well as unoxidized fuel. Unoxidized fuel can then be recaptured and recycled, and $\mathrm{CO}_{2}$ and $\mathrm{H}_{2} \mathrm{O}$ can be further separated by condensation processes, resulting in a relatively pure $\mathrm{CO}_{2}$ stream. CLC facilitates the separation of $\mathrm{CO}_{2}$ from the product stream, for subsequent reuse or sequestration, without the costly and difficult removal of 
flue gas.

Good oxygen carriers meet two important criteria: the carrier must have high reactivity with the fuel gas, and the reduced carrier must be easily reoxidized upon contact with oxygen. Typically, an oxygen carrier is composed of a metal oxide which provides oxygen storage, and an inert binder or support, which increases the mechanical strength for the catalyst, both of which are important factors for real industrial application ${ }^{9}$. In general, the metal oxides combined with the inert in synthesis process as a bulk. The inert acts as the porous support providing a higher surface area for reaction, as a binder to increase the mechanical strength and attrition resistance, additionally, as an ion conductor to enhance the ion permeability in the bulk structure ${ }^{10,11}$. Different metal oxides-based have been proposed in previous work $^{12-19}$ as possible candidates for CLC process: $\mathrm{CuO}, \mathrm{CdO}, \mathrm{NiO}, \mathrm{Mn}_{2} \mathrm{O}_{3}, \mathrm{Fe}_{2} \mathrm{O}_{3}$, and $\mathrm{CoO}$. These materials are well known, and thus a variety of precursors can be chosen and used in the synthesis. Several different materials have been used as the support for metal oxides in CLC system as well. Depending on the kinds of metals, the cost and the sources, the support materials have many choices as well ${ }^{16}$, such as $\mathrm{Al}_{2} \mathrm{O}_{3}$, sepiolite $\left(\mathrm{Mg}_{4} \mathrm{Si}_{6} \mathrm{O}_{15}(\mathrm{OH})_{2} \cdot 6 \mathrm{H}_{2} \mathrm{O}\right), \mathrm{SiO}_{2}, \mathrm{TiO}_{2}$, and $\mathrm{ZrO}_{2}$. These supports must be stable at high temperature due to the nature of the system. However, as far as we can tell, aerogels, which have high porosity, surface area, and thermal stability, have not been considered in CLC. So in this work, we have developed aerogel-supported metal oxide nanoparticles for study as oxygen carriers in CLC.

Other groups have investigated aerogel assembles for matrix ${ }^{20}$, catalyst ${ }^{21}$ or for support $^{22,23}$ of metals acting as advanced sensors and catalytic materials. The unique structures and properties of aerogel determine whether it can serve as a framework onto which a more desirable support metal may be deposited. This approach could be advantageous in situations where the more desirable support is either costly, or does not form a reasonable aerogel-like structure on its own. Several conditions combine to determine the activity of the aerogel-supported metals ${ }^{24-28}$, such as the metal precursor, the method used to prepare the metal nanoparticle-aerogel composite, the loaded metal nanoparticle size and surface area, and the porosity and structure of the aerogel itself. Co 
and $\mathrm{Co} / \mathrm{Ru}$ nanoparticles supported on silica aerogel ${ }^{29,30}$ have been studied in the Fischer-Tropsch process showing efficiency improvement. In addition, Iron oxide $\left(\mathrm{Fe}_{2} \mathrm{O}_{3}\right)$ dispersed on silica aerogel ${ }^{31}$ exhibits a catalytic activity at the steady state in the Fischer-Tropsch synthesis which is about 300 times higher (per g of iron) than the activity of the conventional fused iron reduced catalyst. All of them have shown an improvement compared with the existing catalyst system. This is a promising way to continue.

Some metal/metal oxides have been studied as oxygen carriers in CLC. Cu-based oxygen carrier prepared by impregnation on alumina to be used in a CLC system, which exhibited high reactivity in both reduction and oxidation with times for complete conversion lower than $40 \mathrm{~s}$ at $1073 \mathrm{~K}$. Another example of such a system is $\mathrm{NiO}$ supported on $\mathrm{NiAl}_{2} \mathrm{O}_{4}{ }^{18}$. This support material helps the particles maintain their structure during the recycling reactions, and preserving the reactivity of the material.

This project will focus on the employment of silica-alumina aerogel as the support for nanoparticles of metals/metal oxides, specifically Fe and Co. These metal-oxides will act as the oxygen carriers in the CLC system, transporting oxygen to syngas, avoiding the direct contact between syngas and air. The high surface area and porosity of the aerogel will provide rapid syngas access to the oxygen carriers, resulting in greater efficiency of energy generation. The use of a hybrid aerogel, composed of alumina and silica, will stabilize the morphology of the oxygen carrier nanoparticles at elevated temperatures, increasing the durability and longevity of the composite as an oxygen carrier. The preparation of these composite aerogel materials by a novel in-situ method has not previously been demonstrated, and the resulting materials are extensively characterized. 


\section{Background}

\subsection{Aerogel}

Aerogels are solid materials having high porosity and extremely low density (bulk density $\left.0.004-0.005 \mathrm{~g} / \mathrm{cm}^{3}\right)^{1}$. The aerogel has a continuous open pore network structure formed by the sol-gel process. These pores commonly have an irregular structure. Through the drying process, the liquid in pores of the gel is replaced with air. Several methods can be used to dry the wet gel (special precaution is taken to make sure that the aerogel is continuously immersed in solvent - this is referred to as "wet gel"), such as supercritical drying, freeze drying or ambient pressure drying ${ }^{1}$.

While aerogels have been known since $1931^{32}$, sol-gel technology using oxide materials, including glass and ceramics, has developed primarily in the last 30 years. Sol-gel chemistry is used mainly to produce metal oxides, but production of carbides ${ }^{32}$, nitrides $^{32}$, and sulfides ${ }^{32}$ is also possible through this route. Metal oxides can be synthesized directly in the initial chemical reaction, or a metal hydroxide may form which can be heated to yield the oxide. The general techniques of sol-gel chemistry have been extensively employed in preparation of gels.

The four general steps involved in aerogel preparation are: (1.) Reaction of the appropriate chemical precursors to form colloidal particles; (2.) Aggregation of particles to form a gel; (3.) Drying of the gel; (4.) Heating to induce phase transformations and/or densification. The initial aim in the sol-gel technique is to convert a chemical precursor into particles, producing a sol, which is a suspension of solid colloidal particles in a liquid. To form gels, the growth process is extended, allowing rapid nucleation of new particles within the sol. The colloidal particles grow in solution, and eventually connect to form a gel, a 3-dimensional solid network having high porosity and high specific surface area where the interior of the interconnected network is filled with liquid. The gel may not have the chemical composition of the desired end-product, and chemistry can be 
carried out on the system at a suitable time during the reaction ${ }^{1}$. Figure $2-1$ shows the general scheme for preparing aerogels by sol-gel process.
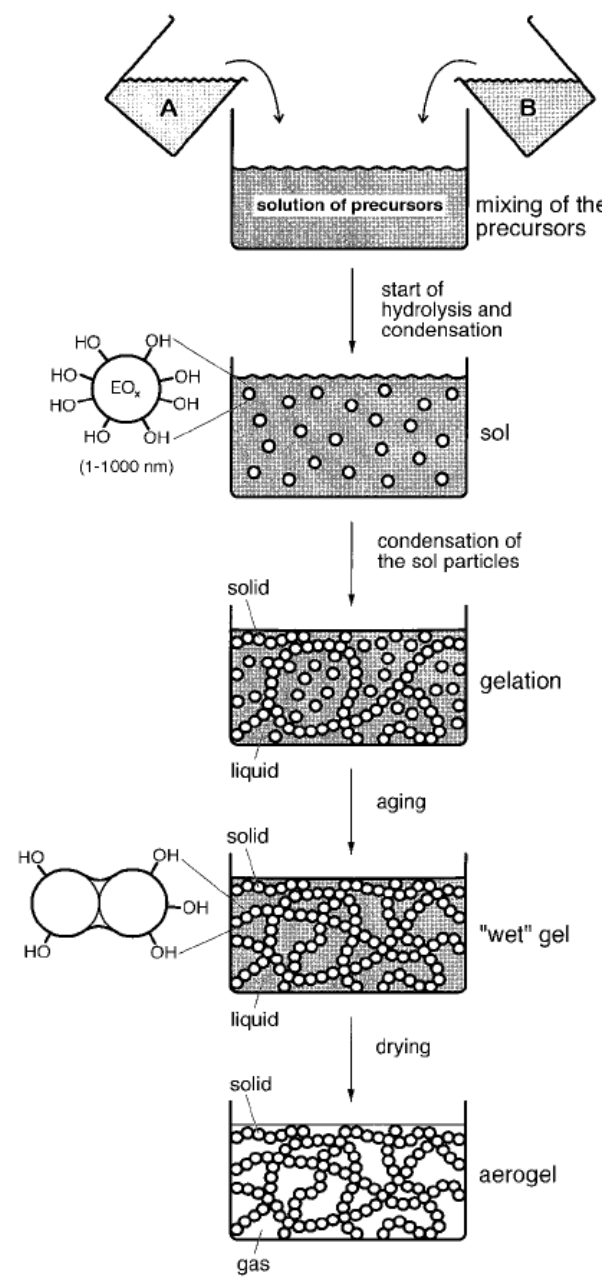

Figure 2-1. General scheme for preparing aerogels by sol - gel processing (Reported from reference 20)

Gels contain liquid within their pore structure. In ordinary drying methods, liquids are directly evaporated from capillaries (pores). Due to surface tension, which is always greater than zero, liquid-vapor menisci exist until pores are completely dried. Inside a pore, a meniscus exerts a force on the pore walls, called capillary stress, which can induce pore collapse. Therefore, after ordinary drying, the surface area of the sol-gel network due to its pore structure is typically dramatically decreased. Such materials are referred to as xerogels. In order to avoid pore collapse during the drying step, two physical drying methods are available: sublimation (or freeze drying), to produce cryogels, and supercritical drying, which produces aerogels. In the sublimation process, 
the solvent-wetted gel is frozen, and the solvent is removed by sublimation in a low pressure environment, leaving behind an uncollapsed pore structure. The process of relevance in this work is that of supercritical drying.

There are two main types of supercritical drying - supercritical ethanol ${ }^{33}$ (critical point: $280{ }^{\circ} \mathrm{C}$ and $15 \mathrm{MPa}$ ) and carbon dioxide ${ }^{34}$ (critical point: $35^{\circ} \mathrm{C}$ and $8.5 \mathrm{MPa}$ ). Due to the potential hazards from supercritical ethanol, supercritical drying with liquid carbon dioxide is the selected method chosen to deal with our wet gels. In comparison with supercritical ethanol method, this process has the advantage of operating at a low critical temperature and moderate pressure. This makes the process much safer since $\mathrm{CO}_{2}$ is non-flammable, non-explosive and almost totally chemically inert under the applied conditions.

In supercritical $\mathrm{CO}_{2}$ drying, the liquid within the pores of the gel is replaced with a solvent that is miscible with liquid $\mathrm{CO}_{2}$, such as ethanol or acetone. Prior to drying, solvent exchange from, for instance, water to absolute ethanol, is necessary. Generally, absolute ethanol is used prior to the drying. During the drying, the ethanol is replaced with liquid $\mathrm{CO}_{2}$. The temperature and pressure are then increased, causing the liquid $\mathrm{CO}_{2}$ to undergo a supercritical transition, where the liquid-vapor interface, and therefore the capillary force, is not present. The supercritical $\mathrm{CO}_{2}$ can be slowly leaked out of the system, preserving the network structure of the gel without shrinkage due to capillary effects.

The high surface area and open pore structure gives the aerogel a dual purpose in catalysis applications. Nanoparticles can be hosted in aerogel pores to provide higher number density of these materials. The pores within the gel then act as nanoreactors during the process for which the material has been prepared. The gel structural characteristics depend on the preparation conditions. The type and concentration of the precursors, solvent, $\mathrm{H}_{2} \mathrm{O}$ /alkoxy ratio, type of catalyst, $\mathrm{pH}$, temperature, duration of aging, and drying method, each affect the structure of the gel.

\subsection{Types of aerogels}


Aerogels have been prepared from many different types of materials including metals, metal oxides, etc. depending on the desired application. Titania, zirconia, and niobia aerogels were prepared from alcoholic metal alkoxide solutions ${ }^{35}$ to determine the effect of the acid content used in the sol-gel synthesis for pore size distribution. Iron (III) oxide akaganeite aerogel $^{36}$ synthesized from ethanolic Fe (III) salt solutions were much stiffer than the silica and alumina ones with the same densities. Nickel- and cobalt-doped carbon aerogel $^{37}$ had a significant impact on the physical properties of the resulting gel, such as conductivity and mechanical properties, comparing with the pure aerogel. Colloidal gold on silica aerogel ${ }^{38}$ demonstrated that no significant structural changes occurred to the aerogel structure due to the presence of small amounts of gold colloid, but the surface of the Au colloid is accessible for further modification by introducing other functional reagents. A vast range of diverse properties and compositions of aerogel have been made and investigated.

In this work, silica-alumina aerogels were chosen to act as supports for metal nanoparticles, for possible catalytic applications and as oxygen carriers in CLC. In this regard, the supports must be thermally and chemically stable under the conditions of high temperature environment. Silica and alumina aerogels have been used under a wide range of experimental conditions, and are perhaps the most widely used as supports. For the applications described, each has advantages and disadvantages and neither is well-suited to the proposed purposes alone; the combination of the two into a hybrid material exploits the advantages and mitigates the disadvantages of each, as described in Section 2 below.

Silica aerogels are easily formed and have been used extensively since the first aerogels prepared by Steven S. Kistler in $1931^{32}$ in an effort to prove that a "gel" contained a continuous solid network of the same size and shape as the wet gel. The obvious way to demonstrate this was to replace the liquid from the wet gel with air without damaging the solid component. However, if the gel was simply dried, it was found to shrink, accompanied by severe cracking. Finally, Kistler discovered the key for aerogel production: the solvent should be transformed into a supercritical phase above the critical temperature and pressure, and thus allowed to convert into a gas directly without two phases having been present at any time. 
Silica aerogels are primarily composed of silicon dioxide and related hydrates. The $\mathrm{SiO}_{2}$ and related gels have the composition $\mathrm{SiO}_{x}(\mathrm{OH})_{y}$ or, if they are prepared from alkoxides, $\mathrm{SiO}_{x}(\mathrm{OH})_{y}(\mathrm{OR})_{z}$, where the values of $y$ and $z$ can be rather high ${ }^{1}$. Large surface area, small pores, good transparency, and good electrical, acoustic and thermal insulation $^{39}$ properties allow silica aerogels to be employed as insulators, catalysts, nanoparticle detection devices, liquid storage, etc. The major drawback of these aerogels is their fragile and brittle nature though special efforts can be made to improve the mechanical properties ${ }^{40}$.

Silica gels are produced primarily through acid-catalyzed or base-catalyzed hydrolysis of silicon alkoxides. The most commonly used precursors are tetramethoxysilane (TMOS) or tetraethoxysilane (TEOS). The chemical reactions hat occur during the sol-gel process are displayed in Scheme 2-1. In the hydrolysis step, water reacts with alkoxides to form alcohol and the reactive silanol groups which can form links between hydrolyzed alkoxides. Once silanol groups begin forming, they can condense through two different routes: water condensation or alcohol condensation, forming connective silicon-oxygen-silicon bridges in either process. Thus condensation can occur, even if not all the alkoxide groups are hydrolyzed. This is a slow process, but it can be accelerated by a number of different chemical routes to catalyze the formation of silanols. By controlling the formation of the sol, then catalyzing the formation of links between colloidal particles, silica aerogels can be produced with a wide range of different properties.

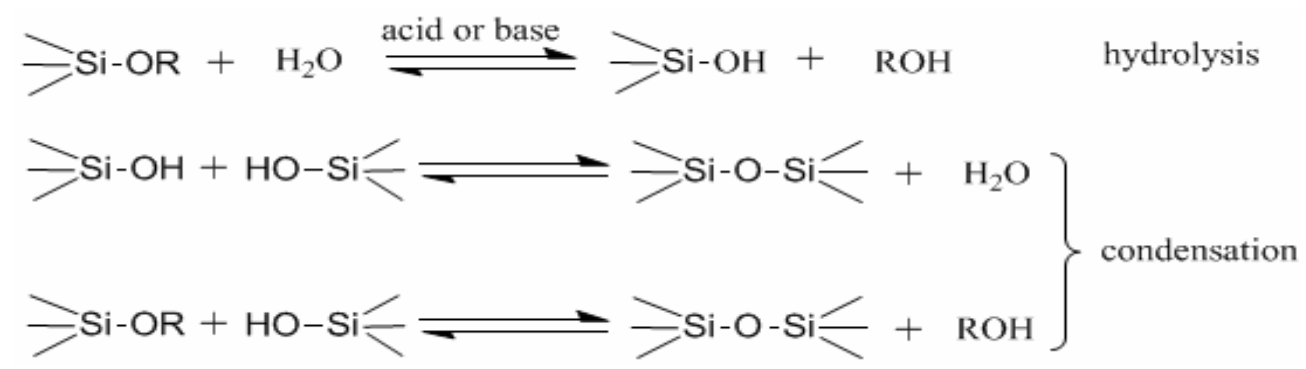

Scheme 2-1. Chemical reaction for the sol-gel process of alkoxysilanes (Reported from reference 1)

Because of the control possible in the formation of the silica gel system, silica 
aerogels carry a number of superlatives. Extremely low density silica aerogels $(0.003$ $\mathrm{g} / \mathrm{cm}^{3}$ ) were first produced in large quantities by the Hrubesh group at Lawrence Livermore National Laboratory (LLNL) ${ }^{32}$; these materials were only three times the density of air. Other specially formulated silica aerogels have led to world records: lowest density solid $\left(0.0011 \mathrm{~g} / \mathrm{cm}^{3}\right)$; lowest dielectric constant from 3-40 GHz (1.008); lowest speed of sound through a material $(70 \mathrm{~m} / \mathrm{s})$; lowest thermal conductivity $\left(0.016 \mathrm{~W} \mathrm{~m}^{-1}\right.$ $\mathrm{K}^{-1}$ ); lowest optical index of refraction (1.002).

Silica aerogels have been used in some notable applications. Very low density silica aerogels, nicknamed "Blue Smoke", have been utilized by NASA in the Stardust project to catch comet dust without damage. When high-speed cometary particles, even smaller than a grain of sand, strike the aerogel, they bury themselves into the sponge-like material, creating a carrot-shaped track up to 200 times its own length, rapidly decelerating without damage to the particle. From the track, NASA scientists can find the tiny target for in depth analysis. In another application, Aspen Aerogel Company has patented processes to produce and market aerogels as extremely efficient insulators for use in residential and commercial buildings, as well as outdoor apparel. It has the advantages of highest insulating performance; minimum weight and thickness; thin profile to enable more fashion and design options; strong and flexible for demanding outdoor conditions; easy to install. Other research, commercial and industrial applications are under investigation, some of which are described below.

Without specific efforts to strengthen them, silica aerogels are mechanically weak and brittle. This can prove to be a major drawback for industrial applications. Various approaches have been used to strengthen gels, including reinforcement with carbon nanotubes (which additionally makes the aerogel conductive) ${ }^{41}$; coating gel structure with polymer ${ }^{42-44}$ to increase the stiffness; and chemically reinforcing the particle network to produce a flexible, hydrophobic material ${ }^{45}$. However, a simpler approach to strengthen silica (and other) aerogels is to increase the connection between particles in the network through an aging process ${ }^{46}$. This will be discussed in detail in the Experimental section.

Alumina aerogels have also been used extensively as supports for catalytic 
materials. Alumina aerogels are also formed from acid or base-catalyzed hydrolysis of aluminum alkoxides. The composition of various aluminum oxides and hydroxides can be very complicated. $\alpha-\mathrm{Al}_{2} \mathrm{O}_{3}, \gamma-\mathrm{Al}_{2} \mathrm{O}_{3}, \gamma-\mathrm{Al}(\mathrm{OH})$ (boehmite), $\theta-\mathrm{Al}_{2} \mathrm{O}_{3}$, and $\delta-\mathrm{Al}_{2} \mathrm{O}_{3}$ are the primary stable structures at varying temperatures, differing from one another in bonding structure and surface charge ratio. Boehmite (aluminum oxyhydroxide, $\gamma-\mathrm{Al}(\mathrm{OH})$ ) is an important precursor material for aluminum oxides from sol-gel processes ${ }^{47}$. The formation of boehmite depends on the starting aluminum-oxygen compound (such as the alkoxides) and the specific reaction conditions. However, in general, boehmite is the preferential form of alumina produced from the hydrolysis of aluminum-oxygen compounds in an aqueous environment at temperatures in the range of $30{ }^{\circ} \mathrm{C}$ to $150{ }^{\circ} \mathrm{C}$. During the hydrolysis, the aqueous phase may contain high aluminum hydrate content, which can deposit as boehmite during hydrothermal aging at temperatures from $60{ }^{\circ} \mathrm{C}$ to $240{ }^{\circ} \mathrm{C}$. Boehmite is stable at temperatures below $200{ }^{\circ} \mathrm{C}$ above this temperature to $300{ }^{\circ} \mathrm{C}$, the structure will show a shift in composition from boehmite to $\lambda-\mathrm{Al}_{2} \mathrm{O}_{3}{ }^{48}$. As more heat is applied to boehmite structures (such as those forming a gel), the material undergoes a recrystallization from amorphous structures to those with increasing crystallite size, including shifts to other alumina phases including to $\gamma-, \delta-, \theta-\mathrm{Al}_{2} \mathrm{O}_{3}$, and finally to $\alpha-\mathrm{Al}_{2} \mathrm{O}_{3}$ at $1000-1200{ }^{\circ} \mathrm{C}^{47,48}$, as shown in Scheme 2-2. The transformation from boehmite to $\lambda-\mathrm{Al}_{2} \mathrm{O}_{3}$ as temperature increases leads to a dramatic decrease in surface area, limiting the usefulness of purely alumina aerogels to low temperature processes. 


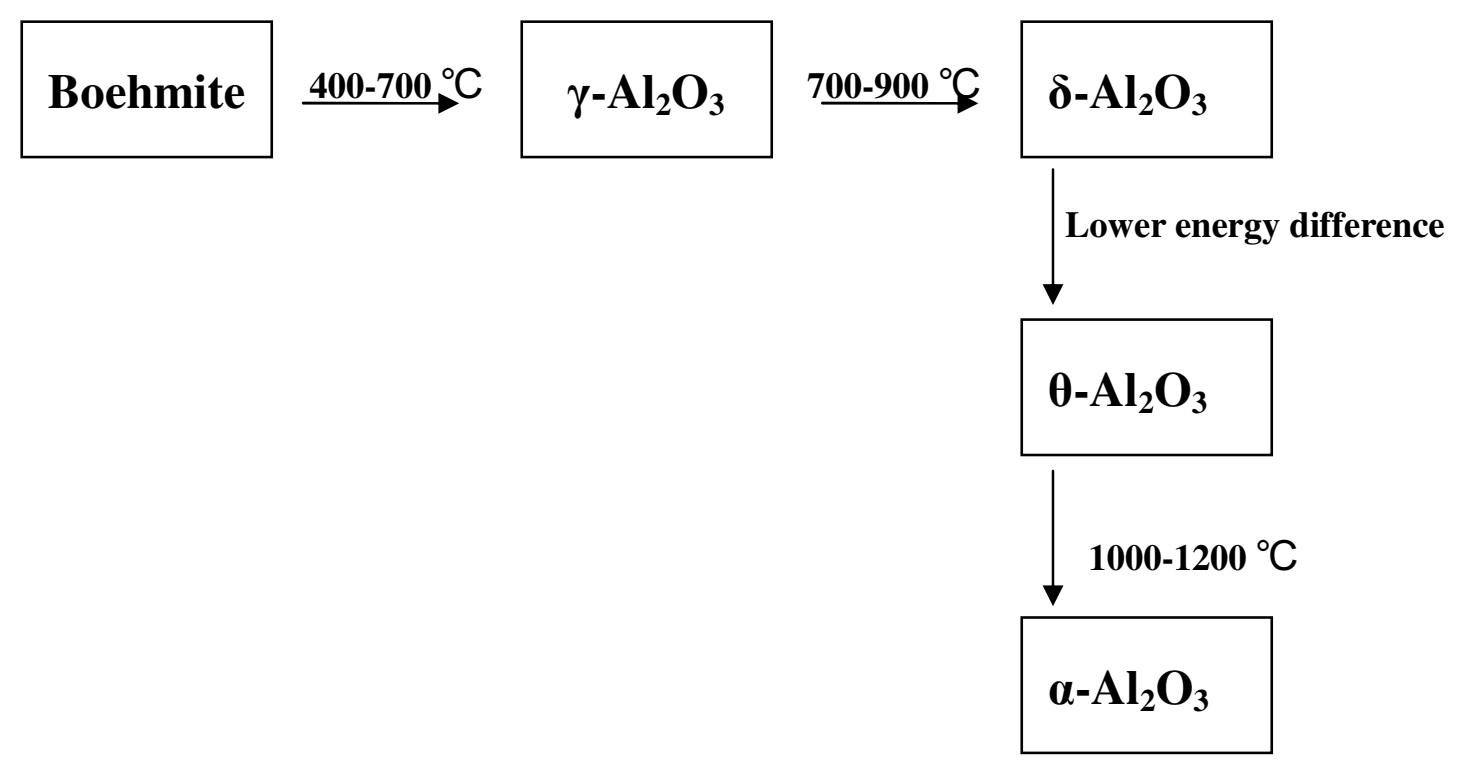

Scheme 2-2. Alumina phase changes as temperature increasing

Similar to silica aerogels, alumina aerogels have high porosity, high surface area, and low density. The network structure of an alumina aerogel is made by dense boehmite particles through random interactions ${ }^{49}$. Though these materials may form particles with sizes to hundreds of nanometers, the interparticle bonding is not a covalent polymeric structure as occurs in silica aerogel. The bonding between particles in alumina is achieved by weak hydrogen bonds. Thus, alumina aerogels are typically more brittle than silica aerogels.

Alumina aerogel has many potential applications, including acting directly as a catalyst $^{21}$, catalyst supports ${ }^{50}$, porous membranes ${ }^{51}$ and thermal insulators ${ }^{37}$. The study of the alumina aerogel as a catalyst is a potential area to focus on. Alumina aerogel was prepared and applied as a catalyst for NO reduction by hydrocarbon ${ }^{50}$. In addition, it is compared with xerogel which is a kind of gel dried directly in air. Alumina aerogel had almost the same catalyst activity with xerogel at $550{ }^{\circ} \mathrm{C}$, but did a better job at $600{ }^{\circ} \mathrm{C}$. The microstructure and surface area also exhibited more stability than xerogel by annealing up to $700{ }^{\circ} \mathrm{C}$. Surface area is one factor for the catalytic activity of the gels, 
and can also be affected by the drying process $^{21}$.

\subsection{Nanoparticle-Aerogel Composites}

Nanoscale materials have a wide range of interesting properties due to their extremely small size. Nanoparticles have shown useful catalytic, electronic, and optical properties, leading to their use in development of many different kinds of devices. Aerogels provide an excellent platform for applications of nanoparticles, due to their open porous structure, extremely high surface area, and limited optical absorbance. Combining the capabilities of nanoparticles with a suitable aerogel support can produce exciting new composite materials with a wide array of desirable properties. In this section, three routes of nanoparticle-aerogel composite formation that have been used by others will be described and contrasted with the novel approach used in this work.

"Just-in-time" Gelation": The Rolison group at the Naval Research Laboratory has pioneered an approach to form nanoparticle aerogel composites in which low-density nanoscale mesoporous composites could be synthesized by adding a colloidal or dispersed solid to a sol that is about to gel. The sol can "glue" a range of chemically and physically diverse particles into the three-dimensional silica network formed upon gelation. As the colloidal silica gels through condensation reactions, it incorporates all of the dispersed second phase (the nanoparticles) into the three-dimensional (3D) network formed by the original parts. It was shown that after the gelation procedure, neither repeated washings (using fresh solution to replace the liquid within the pores) nor supercritical drying would flush the immobilized particles out of the silica structure even particles as small as $2 \mathrm{~nm}$ were retained in the gel.

This approach has a number of drawbacks, however. Choosing the exact reaction time to add the nanoparticle phase just before gelation requires extensive experimentation with gelation conditions, and may not be perfectly reproducible, especially as reactions 
are scaled up. In addition, stirring is avoided during the gelation process to protect the fragile structure of gel, leading to uneven distribution and possible overgrowth of the added nanoparticle phase within the gel structure. This causes the complete encapsulation of some of the nanoparticles in the gel, decreasing the total activity of the composite.

Simultaneous Composite Formation: In this approach, a precursor mixture of alkoxides (for aerogels) and nitrates (for nanoparticles) are combined and subjected to the same reaction conditions, producing the nanoparticles at the same time as the gel. In this process, both the aerogel precursor and nanoparticle precursor undergo the same reaction conditions, such as high temperature and pressure. This technique for the growth of nanoparticles and gels has been used to produce $\mathrm{FeCo}-\mathrm{SiO}_{2}$ nanocomposite aerogels ${ }^{53}$ with different supercritical drying conditions, which have a strong influence on the formation of the FeCo alloy nanoparticles ${ }^{53}$. One of the drawbacks to this approach is that the possible products are somewhat limited, since both materials must be able to tolerate specific reaction conditions. Unfavorable reaction conditions for one of the components could lead to the formation of complexes and compounds other than those desired. In addition, overgrowth of nanoparticles is likely if the gel is grown after particles nucleate, reducing the overall activity of the system.

Nanoparticle Formation in Supercritical Alcohol: Thermal formation of nanoparticles in supercritical alcohol is another way to deposit target metals onto aerogel $^{54}$. In this approach, the wet gel was synthesized first, and then the solution inside the wet gel was replaced by an ethanolic solution of metal precursors. The gel was subjected to supercritical conditions for ethanol (critical point: $280{ }^{\circ} \mathrm{C}$ and $15 \mathrm{MPa}$ ), during which the nitrates decomposed, and the metal oxide was formed in the aerogel. This process has been used extensively by the Eyring group at the University of Utah to produce materials for Fischer-Tropsch catalysis. This method provides good control over the gel and the nanoparticle materials, but the major drawback is the use of supercritical 
ethanol. This reaction system can be difficult to control, and the high temperature and high pressure, combined with the potential explosiveness of vapor-phase ethanol make this system challenging to use.

These three methods each have benefits and drawbacks. The just-in time approach has shown great flexibility, and has been used for many different types of materials, but it is time-consuming to find the ideal reaction conditions, and the lack of reproducibility was a problem. The thermal approaches have the advantage that nanoparticles are formed in the gel, but the simultaneous process runs the risk of burying the nanoparticles, and the supercritical ethanol process was judged to hazardous to use. The method employed in our work is similar in some aspects to the thermal processes in that we form particles in-situ. However, because we will separate the gelation and nanoparticle generation steps, we will have good control over both materials. In our approach, aerogel synthesis and metal nanoparticle formation are carried out at different times. The aerogel is produced first, including an aging process, producing a stiffer, more robust material. Metal nanoparticles are then deposited through thermolytic techniques within the aerogel, providing improved control over the resulting material. The goal for this work is to produce nanoparticles that are attached on the interior pore surface of the aerogel. We anticipate that this will produce the most highly active materials, leading to high efficiency as an oxygen carrier in the CLC process.

\subsection{Thermally Stable Aerogel-Nanoparticle Composites}

For the application of aerogels as supports for nanoparticles in areas such as automotive catalysts and other high temperature processes (including CLC), stability of both the active nanoparticles and the aerogel support is absolutely essential. The proposed system consists of metal/metal oxide nanoparticles on the aerogel acting as the oxygen carriers in CLC, requiring that the nanoparticles maintain high activity and stability at temperatures as high as $800{ }^{\circ} \mathrm{C}$. However, many studies have shown that 
supported metal nanoparticles tend to sinter at elevated temperatures ${ }^{55-57}$. In addition, as described above, alumina coarsens at elevated temperature. Finally, silica is vulnerable to reactions that occur in high temperature steam in reducing conditions ${ }^{58}$, such as those in CLC. These drawbacks may seem overwhelming; however, recent work has shown that while individual components may not be stable at the desired conditions, composites of the materials easily meet the requirements of the system.

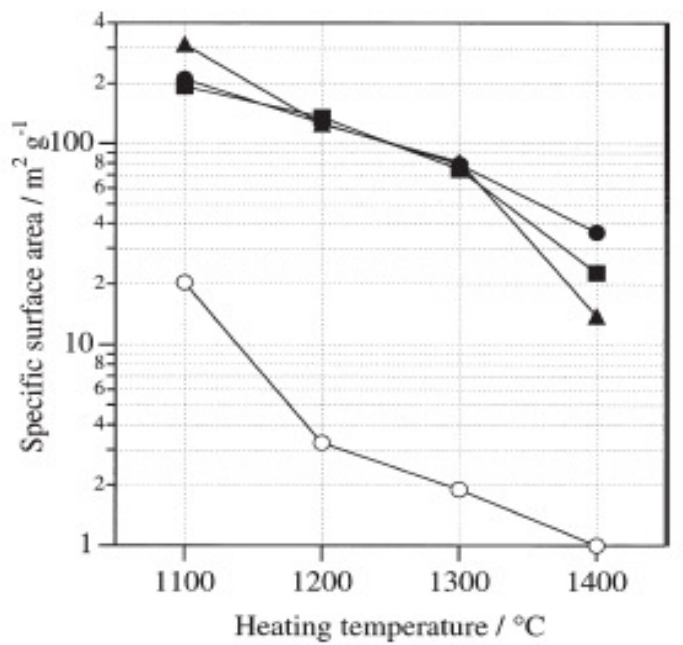

Figure 2-2. Changes in surface area of alumina with heating temperature. ( 0 ) Alumina obtained by decomposition of boehmite. (ロ) silica $2.5 \mathrm{wt} \%,(\bullet)$ silica 5 $\mathrm{wt} \%,(\boldsymbol{\Delta})$ silica $10 \mathrm{wt} \%$. (Figure from reference 60 )
Although silica aerogels are known to sinter above $700{ }^{\circ} \mathrm{C}$ leading to densification, shrinkage, and cracking, work with silica-alumina aerogels at temperatures as high as $900{ }^{\circ} \mathrm{C}$ has shown that sintering in $\mathrm{Al}_{2} \mathrm{O}_{3}$-containing silica aerogels was strongly retarded compared with the pure $\mathrm{SiO}_{2}$ aerogels at the same temperature $^{59}$. Similarly, recent work has shown that alumina gels with deposited silica exhibit increased thermal stability of the aerogel, maintaining the $\theta-\mathrm{Al}_{2} \mathrm{O}_{3}$ phase at temperatures where pure alumina had completely converted to the low surface area $\alpha-\mathrm{Al}_{2} \mathrm{O}_{3}{ }^{60}$. High thermal stability was achieved through the synergistic effect of silica addition and the ultra-low bulk density (aerogel). Figure 2-2 shows the variation of BET surface area of with the heating temperature. As a control sample, the ordinary alumina aerogel surface area is only about $20 \mathrm{~m}^{2} / \mathrm{g}$ at $1100{ }^{\circ} \mathrm{C}$ and $1 \mathrm{~m}^{2} / \mathrm{g}$ at $1400{ }^{\circ} \mathrm{C}$. But the silica-modified alumina aerogel maintains $100 \mathrm{~m}^{2} / \mathrm{g}$ below $1200{ }^{\circ} \mathrm{C}$, and $80 \mathrm{~m}^{2} / \mathrm{g}$ at $1300{ }^{\circ} \mathrm{C}$. The optimal silica content $(5$ $\mathrm{wt} \%$ ) to maintain the thermal stability of the alumina gel was explained as the appropriate ratio of silica to interact with the surface of the alumina, while minimizing sintering of silica itself, which occurs at higher concentrations. 
Nanoparticles on pure silica aerogels tend to rapidly sinter, aggregate, and decrease activity, which is because the surface tension between nanoparticles are smaller than nanoparticles with silica. Especially at high temperature, the nanoparticles getting more energy could not be fixed at the aerogel surface. Once aggregation happening, dispersion of the nanoparticles leads to a distinct decrease on surface area, which will directly result in reducing the activity efficiency. That is why silica aerogel is mixed with other compounds commonly.

Nanoparticles on alumina aerogel do not have the above factors as silica, but alumina itself is not stable enough at high temperature. As we all know that, porosity and surface area are very important feathers for catalyst support materials. Maintaining large surface area and mesopores structure for alumina aerogel during annealing, avoiding phase transformation from high surface area phase $\gamma-\mathrm{Al}_{2} \mathrm{O}_{3}$ to lower one $\alpha-\mathrm{Al}_{2} \mathrm{O}_{3}{ }^{61}$ is the major challenge for alumina aerogel applications. In addition, further heating may also result in pore coarsening and a loss of the surface area. Adding additives ${ }^{61}$ or combining with other hard template have been studied as effective ways to control the surface area, transformation temperature and maintain mesopores structure.

\subsection{Characterization Methods of Aerogels Structure}

Each aerogel has its own structural characteristics, which depend on the preparation conditions and precursor reagents. The size scale for an aerogel is large, ranging from nanometers to micrometers. No single method can give comprehensive information on the aerogel structure, and each method has its advantages and disadvantage. In most cases, a combination of several methods is used to obtain the required information. Following is the most common methods people used to characterize the aerogel structure (Table 2-1). 
Table 2-1. Typical Methods for Aerogel's Characterization ${ }^{1}$

\begin{tabular}{|c|c|c|}
\hline Method & Structural information & Comments \\
\hline $\begin{array}{c}\text { Transmission Electron } \\
\text { Microscope(TEM), } \\
\text { Electron microscope } \\
\text { Scanning Electron } \\
\text { Microscope (SEM), } \\
\text { Scanning Transmission } \\
\text { Electron Microscope } \\
\text { (STEM) }\end{array}$ & $\begin{array}{c}\text { Particle size, } \\
\text { Morphology of samples }\end{array}$ & $\begin{array}{l}\text { High energy from electron beam } \\
\text { as the source from microscopes } \\
\text { would sinter the samples. }\end{array}$ \\
\hline $\begin{array}{l}\text { Small Angle Neutron } \\
\text { Scattering (SANS) }\end{array}$ & $\begin{array}{c}\text { Surface area of fractal } \\
\text { dimensions }\end{array}$ & $\begin{array}{l}\text { Provide the sample information } \\
\text { ranging from the Angstrom to the } \\
\text { micrometer }\end{array}$ \\
\hline Mercury Porosimetry & Pore volume & $\begin{array}{l}\text { Compression of the network by } \\
\text { the applied pressure instead of } \\
\text { penetration of Mercury into the } \\
\text { matrix }\end{array}$ \\
\hline $\begin{array}{l}\mathrm{N}_{2} \text { adsorption and } \\
\text { desorption (BET) }\end{array}$ & $\begin{array}{c}\text { Surface area } \\
\text { information, Pore size } \\
\text { distributions }\end{array}$ & $\begin{array}{l}\text { Pores which are accessible to } \mathrm{N}_{2} \\
\text { could be measured; the result is } \\
\text { accurate for samples whose } \\
\text { structure would not be affected by } \\
\text { the } \mathrm{N}_{2} \text { pressure during the } \\
\text { measurement }\end{array}$ \\
\hline $\begin{array}{c}\text { Light scattering Small } \\
\text { Angle X-ray Scattering } \\
\text { (SAXS) }\end{array}$ & Particle and cluster sizes & $\begin{array}{l}\text { Reverse relation of the scattering } \\
\text { vector and the structural } \\
\text { dimension }\end{array}$ \\
\hline Helium Pyknometry & $\begin{array}{c}\text { Density of sample } \\
\text { skeleton }\end{array}$ & \\
\hline $\begin{array}{c}\text { Atomic Force } \\
\text { Microscopy (AFM) }\end{array}$ & Surface atomic structure & 3-dimensional surface profile \\
\hline $\begin{array}{l}\text { Nuclear Magnetic } \\
\text { Resonance (NMR) }\end{array}$ & $\begin{array}{l}\text { Structure evolution from } \\
\text { the molecular precursors } \\
\text { to the gel stage pore } \\
\text { diameters or fractal } \\
\text { dimensions }\end{array}$ & \\
\hline
\end{tabular}




\section{Experimental Design}

Our experimental design encompasses the preparation of the hybrid aerogel support, composed of alumina and silica, followed by generation of the nanoparticles in the aerogel through in-situ thermal decomposition of organometallic precursors. The gel is then dried using supercritical techniques, and further prepared for testing in CLC and other processes. The schematic diagram in Figure 3-1 summarizes the process, and will be referred to in the detailed description below.

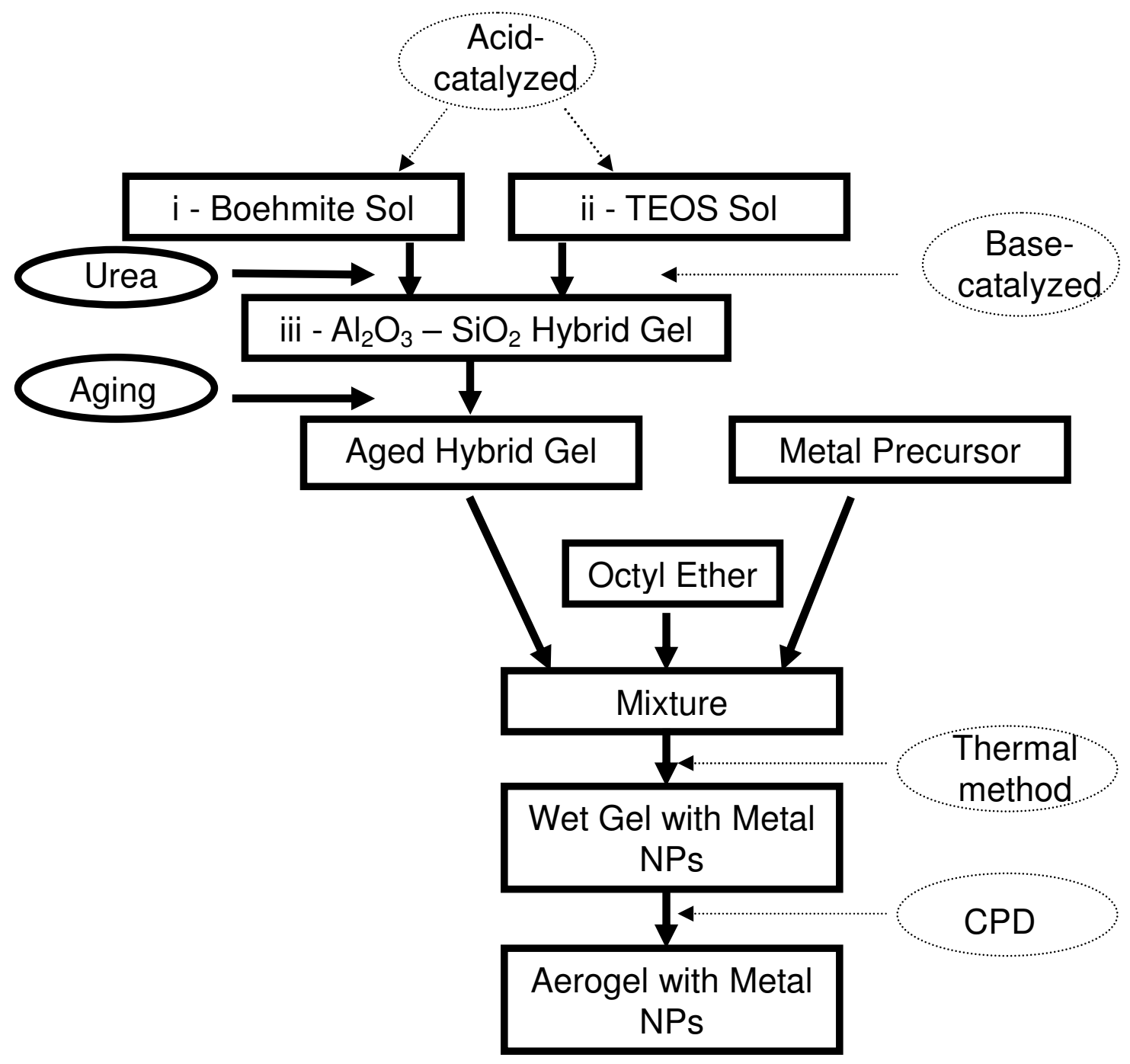

Figure 3-1. Metal particles loaded aerogel synthesis procedure 


\subsection{Chemicals and Materials}

Iron(0) pentacarbonyl $\left(\mathrm{Fe}(\mathrm{CO})_{5}, 99.999 \%\right)$, octyl ether $\left(\left(\mathrm{CH}_{3}\left(\mathrm{CH}_{2}\right)_{7}\right)_{2} \mathrm{O}, 99 \%\right)$, tetraethyl orthosilicate (TEOS, $\mathrm{Si}\left(\mathrm{OC}_{2} \mathrm{H}_{5}\right)_{4}, \geq 99.0 \%$ ), and urea (ACS reagent, 99.0-100.5\%) were purchased from Sigma Aldrich. Dicobalt octacarbonyl $\left(\mathrm{Co}_{2}(\mathrm{CO})_{8}\right.$, 95\%) and aluminum isopropoxide (AIP, 98+\%) were purchased from Acros Organics. Absolute-200 proof ethanol from Aaper and ultrapure deionized water (DI, $\geq 18 \mathrm{M} \Omega$ ) were used. All chemicals were used without any further purification.

\subsection{Silica-Modified Alumina Gel}

The procedure developed by Horiuchi et al. ${ }^{60}$ was followed for the synthesis of alumina aerogels. The labels refer to sections of the process schematic above. Boehmite and silica sols are initially produced by acid-catalyzed hydrolysis of their respective alkoxides (Figure 3-1). In a typical reaction to form boehmite sol (i), $0.1 \mathrm{~mol}(20.4 \mathrm{~g}$ ) of AIP was hydrolyzed with $80 \mathrm{~mL}$ hot water $\left(80^{\circ} \mathrm{C}\right)$ with vigorous stirring to yield a turbid white solution. An oil bath was used to maintain constant temperature. To this solution 10 $\mathrm{mL}$ of $1 \mathrm{M}$ nitric acid was added and refluxed for one hour. Concurrently, TEOS sol (ii) was prepared by hydrolyzing $1.14 \mathrm{~g}$ TEOS with $10 \mathrm{~mL}$ of $1 \mathrm{M}$ nitric acid under stirring at room temperature for one hour forming "ii - TEOS sol". In iii, the TEOS sol was added to the boehmite sol along with $2 \mathrm{~g}$ urea and thoroughly mixed stirring for the first half an hour. The mixture was refluxed. As the reaction progressed, the viscosity of the sol increased, until it finally formed a white gel.

This process is a two-step process - acid catalysis initially formed the sols of boehmite (i) and silica (ii) as shown in Figure 3-1. This is then followed by a base-catalyzed gelation with urea acting as the catalyst. In this two-step acid-base-catalyzed sol-gel procedure, the role of urea is to allow rapid gelation to occur. 
The urea decomposes in acidic aqueous solution to give ammonia and carbonate ions, ultimately neutralizing the nitric acid, and releasing hydroxide ions that catalyze the gelation process of the composite gel. The process is as following:

i - boehmite sol (at $\left.90^{\circ} \mathrm{C}\right)$ :

$$
\begin{gathered}
\mathrm{Al}\left(\mathrm{i}-\mathrm{OC}_{3} \mathrm{H}_{7}\right)_{3}+\mathrm{H}_{2} \mathrm{O} \longrightarrow \mathrm{Al}(\mathrm{OH})_{3}-\mathrm{H}_{2} \mathrm{O} \longrightarrow \mathrm{AlOOH} \\
\text { Formation of boehmite }
\end{gathered}
$$

ii - TEOS sol (stirring at RT) :

$$
\begin{gathered}
\left(\mathrm{H}_{5} \mathrm{C}_{2} \mathrm{O}\right)_{3}-\mathrm{Si}-\mathrm{O}-\mathrm{C}_{2} \mathrm{H}_{5}+\mathrm{H}_{2} \mathrm{O} \underset{\text { Hydrolysis }}{\longrightarrow}\left(\mathrm{H}_{5} \mathrm{C}_{2} \mathrm{O}\right)_{3}-\mathrm{Si}-\mathrm{OH}+\mathrm{H}_{5} \mathrm{C}_{2} \mathrm{OH} \\
\left(\mathrm{H}_{5} \mathrm{C}_{2} \mathrm{O}\right)_{3}-\mathrm{Si}-\mathrm{OH}+\mathrm{HO}-\mathrm{Si}-\left(\mathrm{OC}_{2} \mathrm{H}_{5}\right) \longrightarrow\left(\mathrm{H}_{5} \mathrm{C}_{2} \mathrm{O}\right)_{3}-\mathrm{Si}-\mathrm{O}-\mathrm{Si}-\left(\mathrm{OC}_{2} \mathrm{H}_{5}\right)_{3}+\mathrm{H}_{2} \mathrm{O}
\end{gathered}
$$

\section{Condensation}

\section{$\left(\mathrm{H}_{5} \mathrm{C}_{2} \mathrm{O}\right)_{3}-\mathrm{Si}-\mathrm{O}-\mathrm{C}_{2} \mathrm{H}_{5}+\mathrm{HO}-\mathrm{Si}-\left(\mathrm{OC}_{2} \mathrm{H}_{5}\right)_{3} \longrightarrow\left(\mathrm{H}_{5} \mathrm{C}_{2} \mathrm{O}\right)_{3}-\mathrm{Si}-\mathrm{O}-\mathrm{Si}-\left(\mathrm{OC}_{2} \mathrm{H}_{5}\right)_{3}+\mathrm{H}_{5} \mathrm{C}_{2}-\mathrm{OH}$}

\section{Condensation}

As produced, gels are very soft, weak, and fragile. After drying, they are brittle and break easily. To strengthen the gel, a common technique used is that of aging. Aging is a way to optimize the gel structure. The effects of aging vary over a wide range of

structural and textural properties ${ }^{62,63}$. As aging time increases, physical changes or chemical reactions may occur to the wet gel which contribute to the strengthening of the gel's structural framework. Such changes may include an increase in bonding between the particles of the original structure, shifting of particles to increase contact area, or the deposition of a new thin layer deposited onto the existing surface and bridging particles. Aging is often carried out in the original solution, where more material can be added to the existing structure, but the process may also occur in pure solvents, where strengthening is likely due to dissolution and redeposition processes. In general, aging has been shown to be an effective method to increase the strength and stiffness of gels ${ }^{41}$, 64.

In order to optimize the structure of our aerogel and increase the stiffness, two 
aging processes were used. The first aging step was alumina aging. The gel was left in the original AIP/TEOS solution at room temperature for two days, allowing time to fully form the structural skeleton. To this aged gel, a second TEOS aging process was performed $^{46}$. TEOS provided a source of additional silica, the deposition of which should increase the stability of aerogel at high temperature. To carry out this second aging step, the gel was washed with $20 \mathrm{vol} \% \mathrm{H}_{2} \mathrm{O} / \mathrm{EtOH}$ for $24 \mathrm{hrs}$ at $60^{\circ} \mathrm{C}$ to remove the original growth solution present in the pores. This solution was then replaced with an aging solution $(70 \mathrm{vol} . \% \mathrm{TEOS} / \mathrm{EtOH})$ at $70{ }^{\circ} \mathrm{C}$ for varying times $(6,12$ and $24 \mathrm{hrs})$. The volume ratio of gel: washing/aging solution was 1:3. After TEOS aging, the stiffness of the wet gel was notably increased. The wet gel was further washed in absolute ethanol (at least three changes of $3 \mathrm{x}$ gel volume) in three days to ensure removal of the aging solution.

Many methods ${ }^{64-68}$ have been used to dry the wet gel. In this research, a critical point drying (CPD) system was used to dry the gel without shrinkage or structural deformation of the materials. $\mathrm{EtOH}$ is miscible with liquid $\mathrm{CO}_{2}$ and may act as an intermediate solvent. The wet gel was dried under supercritical conditions for $\mathrm{CO}_{2}\left(31^{\circ} \mathrm{C}\right.$ and $73.8 \mathrm{MPa}$, though the chamber can reach $40{ }^{\circ} \mathrm{C}$ and $98 \mathrm{MPa}$ ). After the washing process, such that only ethanol remains in the pore volume, wet gels were quickly transferred into the CPD chamber which contained enough absolute ethanol to maintain the ethanol level 2-3 mm higher than the wet gel. The CPD chamber has a small window in the side to aid in this process, and to observe the critical transition that occurs upon heating. The chamber was sealed, and the ethanol exchanged with liquid $\mathrm{CO}_{2}$. After the chamber was filled with liquid $\mathrm{CO}_{2}$, the solution was allowed to remain undisturbed for 10 minutes so that the ethanol could diffuse out of the gel, and $\mathrm{CO}_{2}$ could diffuse into the gel. The $\mathrm{CO}_{2}$-ethanol mixture solution was then replaced with fresh $\mathrm{CO}_{2}$. A total of five exchanges were carried out, each tie making sure that when discharging the mixed solution, the wet gels were covered by the solution. After the ethanol was totally replaced by liquid $\mathrm{CO}_{2}$, the temperature was increased to $40{ }^{\circ} \mathrm{C}$. As the chamber heated up slowly over 45 minutes, 
the pressure increased to $\sim 9.8 \mathrm{MPa}$ which exceeds the critical point of $\mathrm{CO}_{2}\left(31.1^{\circ} \mathrm{C}, 7.38\right.$ $\mathrm{MPa}$ ). The transformation of the liquid $\mathrm{CO}_{2}$ to supercritical $\mathrm{CO}_{2}$ is accompanied by a loss of the liquid-gas interface, which can be seen through window in the CPD chamber. After reaching the programmed temperature, a needle valve is opened which allows the supercritical $\mathrm{CO}_{2}$ to slowly leak out of the chamber, over 40-50 minutes, to reach atmospheric pressure. The chamber was opened, and the dried aerogel was quickly transferred into a clean, dry sealed container for storage. The white monoliths of alumina/silica aerogels were obtained while retaining the shape of the original wet gels.

\subsection{Nanocomposites of Metal-Aerogels}

In-situ thermal decomposition of organometallic precursors was employed to deposit metal nanoparticles into the aerogel pores. The general procedure is outlined in Fig. 3-1. Two metals, iron and cobalt, were chosen for deposition. Iron oxides are frequently used in CLC and other catalytic processes, and cobalt is an important catalyst, particularly in the Fischer-Tropsch process. These two metals will be deposited into the same parent gel for more direct comparison to one another. The process that we are using to deposit the metal into the gel is similar in some respects to that used to produce nanoparticles by thermal decomposition of organometallic compounds ${ }^{69}$. In the production of nanoparticles, however, surfactants are used to control the size of the resulting nanoparticles as well as provide stabilization of the partiles from aggregation. No surfactant is used in our system because we are not producing free nanoparticles, and the amount of organometallic precursor available within the pore volume limits the possible size of any nanoparticle growth.

To deposit metal nanoparticles within the gel, a measured volume of the wet gel was carefully transferred into a flask with octyl ether. The metal precursor was added into the octyl ether, either by syringe in the case of iron pentacarbonyl, or as a weighed powder for dicobalt octacarbonyl. Figure 3-2 shows the wet gel in octyl ether with iron pentacarbonyl. The concentration of metal carbonyls was varied while maintaining a constant volume ratio of gel to solution of 1 to 3 . Four samples were prepared with a 
range of metal concentrations. Iron pentacarbonyl was added to produce gels with concentrations ranging from $5-\sim 28 \mathrm{wt} \%$ iron. Cobalt samples with approximately the same weight percents as the iron-containing gels were attempted, but the solubility of the cobalt precursor was too low to be certain that all the precursors were dissolved. In the cobalt samples, the concentration of the precursors was cut in half compared to the iron-containing gels to produce $5-\sim 16 \mathrm{wt} \%$ cobalt in the gel. The metal carbonyl and gel reaction mixtures were prepared under an argon atmosphere and kept at room temperature for at least 24 hours to allow for complete diffusion of the metal carbonyl into the porous structure of the gel. To induce the formation of nanoparticles in the gel, the flask was heated to $250{ }^{\circ} \mathrm{C}$ for 1 hour. The color of the solution and the gel changed to dark brown or black, indicating the decomposition of the organometallic precursor into nanoparticles. After cooling to room temperature, the gel was then transferred into $50 \mathrm{ml}$ of ethanol and the solvent changed every 24 hours for 3 days to exchange the octyl ether with ethanol. The gel was then dried under supercritical conditions in a CPD before calcination in air for one hour at $800{ }^{\circ} \mathrm{C}$ using a tube furnace (Lindburg/Blue $\mathrm{M}$ TF55035A) with a ramp rate of $200{ }^{\circ} \mathrm{C} / \mathrm{hr}$.
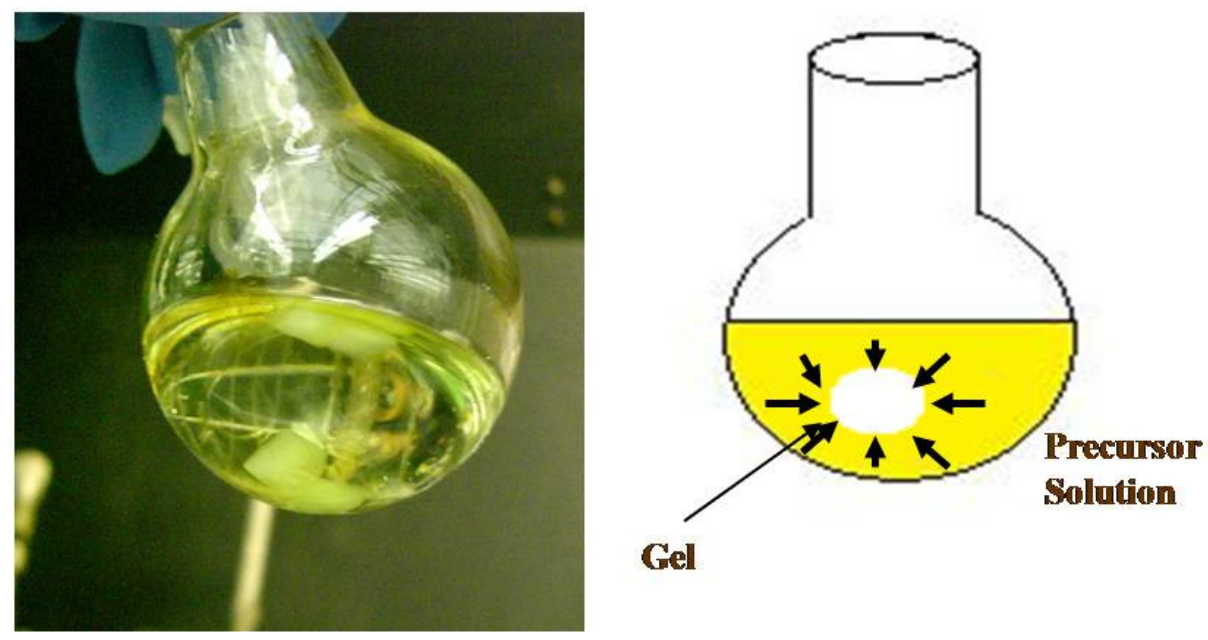

Figure 3-2. Gel in Iron precursor and Octyl Ether mixer

For simplicity, when discussing these samples, we have adopted the following nomenclature for nanoparticle-aerogel composite samples: the atomic symbol of the 
deposited metal followed by the concentration of the precursor in the reaction vessel (and therefore, in the gel) (Figure 3-3). Since iron pentacarbonyl is volatile liquid, but dicobalt octacarbonyl is solid, the concentrations in Fe-containing samples refer to the microliters of $\mathrm{Fe}(\mathrm{CO})_{5}$ per milliliter of reaction volume (octyl ether + gel). The concentrations in Co-containing samples refers to the milligrams of $\mathrm{Co}_{2}(\mathrm{CO})_{8}$ per milliliter of reaction volume (octyl ether + gel). The names of comparison, $1 \mu \mathrm{L}$ of iron pentacarbonyl represent $7.5 \times 10^{-3}$ moles and $0.42 \mathrm{mg}$ of iron, while $1 \mathrm{mg}$ of dicobalt octacarbonyl represents $0.32 \mathrm{mg}$ of cobalt. This distinction is expanded upon in the next section.

\section{$\mathrm{Fe}(\mathrm{CO})_{5}(\mathrm{I})$ $\mathrm{Co}_{2}(\mathrm{CO})_{8}(\mathrm{~s})$

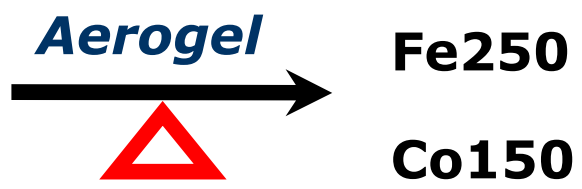 \\ Metal \# = Metal precursor concentration in Octyl Ether, $\mu \mathrm{l}($ or $\mathrm{mg}) / \mathrm{ml}$}

Figure 3-3. Naming convention for samples

\subsection{Estimation of Metal Concentration in Aerogel}

The concentration of the precursor was used to estimate the maximum amount of metal that could be deposited into the aerogel. These estimations are tabulated in Table 3-1. Dicobalt octacarbonyl was not completely soluble in octyl ether; it is anticipated that this may lead to significant deviation from the theoretical yield. This also assumes that there is a uniform distribution of the metal throughout the gel. The maximum average weight percentages for the metals are $27.85 \%$ and $15.88 \%$ for $\mathrm{Fe} 250$ and $\mathrm{Co} 150$ respectively.

Aerogel or aerogel with metal nanoparticles after supercritical drying (CPD) are bulk fragile solids. To determine average properties for the sample, each was milled using 
a mortar and pestle to produce a flowing $\sim 0.1 \mathrm{~mm}$ powder for further calcination or other characterizations. "Cal" in the sample name indicates the sample measurement is after calcination. The only samples which were not milled were those samples prepared for XPS mapping and SEM of sample surface.

Table 3-1. Metal Concentration Estimations Based on the Precursor Concentration

\begin{tabular}{|c|c|c|c|}
\hline & & $\begin{array}{c}\frac{\text { Metal }}{\text { Concentration in }} \\
\end{array}$ & $\underline{\text { Ideal Metal }}$ \\
\hline Sample Name & $\frac{\text { Metal Precursor }}{\underline{\text { Concentration }}}$ & $\frac{\text { reaction }}{(\mathrm{mg} / \mathrm{ml})}$ & $\frac{\text { Concentration in Aerogel }}{(\text { wt \%) }}$ \\
\hline $\mathrm{Fe} 5$ & $5 \mu \mathrm{L} / \mathrm{mL}$ & 2.1 & 0.56 \\
\hline $\mathrm{Fe} 20$ & $20 \mu \mathrm{L} / \mathrm{mL}$ & 8.5 & 2.23 \\
\hline $\mathrm{Fe} 50$ & $50 \mu \mathrm{L} / \mathrm{mL}$ & 21.2 & 5.57 \\
\hline $\mathrm{Fe} 250$ & $250 \mu \mathrm{L} / \mathrm{mL}$ & 106.2 & 27.85 \\
\hline $\operatorname{Co5}$ & $5 \mathrm{mg} / \mathrm{mL}$ & 1.6 & 0.53 \\
\hline Co12 & $12 \mathrm{mg} / \mathrm{mL}$ & 3.9 & 1.27 \\
\hline Co30 & $30 \mathrm{mg} / \mathrm{mL}$ & 9.8 & 3.18 \\
\hline Co150 & $150 \mathrm{mg} / \mathrm{mL}$ & 49.1 & 15.88 \\
\hline
\end{tabular}

\subsection{Characterization of Aerogel Samples}

XRD - The X-ray diffraction (XRD) patterns of the powder samples were measured at room temperature with an X'Pert Philips Materials Research Diffractometer, with a $\mathrm{CuK} \alpha$ radiation source within the range of $10-90^{\circ}(2 \theta)$. Samples' preparations are as following: fragile aerogels were ground into powder using the powder stage for testing, so that the metal nanoparticles distribute evenly in the whole sample.

XPS - The X-ray photoelectron spectroscopy (XPS) data was obtained from a Physical Electronics Versa Probe 5000 equipped with an argon sputter ion beam to 
neutralize surface charging and using monochromated aluminum radiation. For each sample, a survey scan was done first to confirm the element composition, then high resolution scans were collected for each relevant element to determine the chemical state. The carbon peak $(284.8 \mathrm{eV})$ (from atmospheric contamination) was used as the reference for peak shift. For normal XPS scan, samples are ground into powder pressed on a carbon tape forming a thin layer. For XPS-Line scan and XPS-Mapping, samples are cross sections keeping the original physical status, gently pressed on the carbon tape.

BET - The surface area of aerogel with and without nanoparticles, was determined using a Micromeritics Chemisorb instrument (Model 2720). The nitrogen adsorption isotherms were used to calculate the BET specific surface area according to the BJH method. The measurements were carried out under a nitrogen flow rate of $1 \mathrm{~mL} / \mathrm{min}$ for all the samples after degassing under nitrogen at a flow rate of $50 \mathrm{~mL} / \mathrm{min}$ at $350{ }^{\circ} \mathrm{C}$. All the samples were ground into powder and loaded into a quartz $U$ tube for testing (around $20 \mathrm{mg})$.

TPR - The temperature-programmed reduction (TPR) data was obtained from a Micromeritics instrument (Model 2720) using a hydrogen flow rate of $50 \mathrm{~mL} / \mathrm{min}$ with the temperature programmed to increase at a rate of $10{ }^{\circ} \mathrm{C} / \mathrm{min}$ from room temperature to $800{ }^{\circ} \mathrm{C}$. Samples preparation is the same as BET.

TEM - Transmission electron microscopy (TEM) was carried out using a Joel JEM-1230 electron microscope operated at $120 \mathrm{kV}$ equipped with a Gatan UltraScan 4000SP 4 K x 4 K CCD camera. Samples for TEM were prepared by placing a droplet of wet gel with nanocomposites suspended in ethanol on a Formvar carbon-coated, 300-mesh copper grid (Ted Pella) and allowed to evaporate in air at room temperature.

SEM - EDX - Hitachi S-4700 field emission scanning electron microscope 
(FE-SEM) was used to get the normal SEM images and elemental distributions. It combines the versatility of PC control with a novel electron optical column to give exceptional performance on large and small specimens. High resolution at $15 \mathrm{kV}$ is guaranteed at the EDX and specimen exchange position of $12 \mathrm{~mm}$ working distance. There are two different way for SEM - EDX samples' preparation. First, to obtain the average information for the whole aerogels or aerogels with nanoparticles, the samples were ground into evenly powder, then pressed on carbon tape for further coating; second, to collect the metal nanoparticles size and distribution only on the surface of aerogel (metal nanoparticles have much higher concentration on the surface than interior), cross section samples were prepared, the surface was kept as it was, then gently pressed on carbon tape for further coating. Our samples are non-conductive, to reduce charging, coating a thin layer of conductive layer is necessary for getting a good SEM image. Au-Pd alloy of around 4-5 nm was sputter-coated on each SEM sample.

ICP - MS - The elemental analysis was carried out using Agilent $7500 \mathrm{cs}$ Inductively Coupled Plasma-Mass Spectrometer (ICP-MS) equipped with a collision/reaction cell. The aerogel nanocomposites were ground into powder, digested in $\mathrm{HNO}_{3}$ at $90{ }^{\circ} \mathrm{C}$ for $4-6$ hours and then diluted $8.7 \times 10^{3}-1.5 \times 10^{4}$ times depending on the samples before introduced into the ICP-MS.

TGA - The thermogravimetric analysis was recorded by Perkin-Elmer TGA-7 Themo Gravimetric Analyzer. Alimel Magnetic standard was used as the calibration reference material. It measures weight changes in sample materials as a function of temperature or time. A sensitive microbalance is used, featuring a null balance design that compensates for weight changes in the sample. Scanning rate is from $0.1{ }^{\circ} \mathrm{C} / \mathrm{min}$ to 200 ${ }^{\circ} \mathrm{C} / \mathrm{min}$, and temperature is ambient to $1000{ }^{\circ} \mathrm{C}$. Samples are ground into powder for testing. 
Cyclic, High pressure TGA - This is a cyclic reduction-reoxidation system. The temperature is gradually increased from room temperature to $800{ }^{\circ} \mathrm{C}$ at the rate of $10{ }^{\circ} \mathrm{C}$ /min. This is kept as an isothermal situation, and then a regiment of synthesis gas (CO $36 \%, \mathrm{H}_{2} 27 \%, \mathrm{He} 25 \%$, and $\mathrm{CO}_{2} 12 \%$ ) - house $\mathrm{N}_{2}$ - house air - house $\mathrm{N}_{2}$ is repeated to obtain reduction-oxidation recycles. Samples are ground into powder for cyclic weight measurements as a function of time. 


\section{Results and Discussion}

\subsection{Images of Prepared Materials}



(a) Wet Gel with Varying Iron Content; From L to R: Fe20, Fe50, and Fe250
6

3

(b) Aerogel with Varying Iron Content after Calcination; From T to B: Fe20cal, Fe50cal and Fe250cal

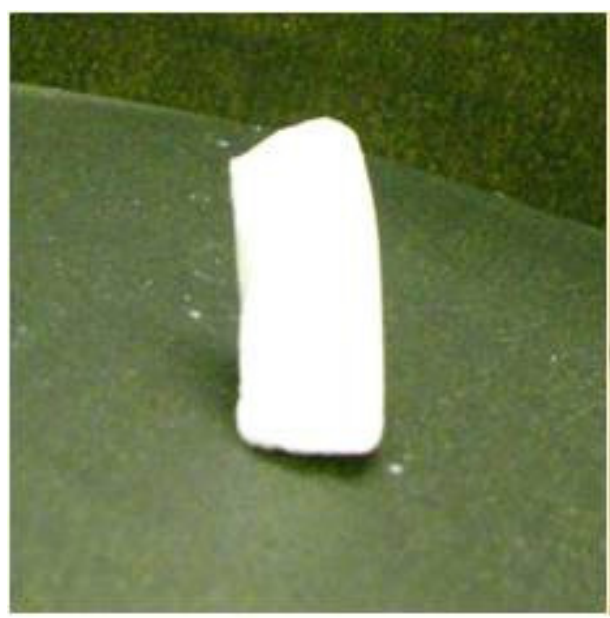

(c) Aerogel maintains Cylinder Shape after CPD

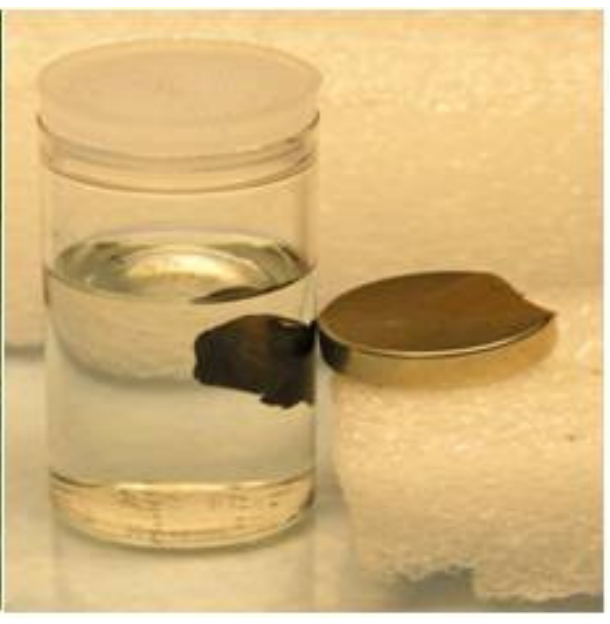

(d) Magnetic Cobalt-containing Alumina Silica Aerogel

Figure 4-1. Pictures of pure aerogel and aerogel with metal particles

Figure 4-1 shows photographs of pure and nanoparticle-containing gels, before and 
after drying. In Figure 4-1a, wet alumina-silica gels with different iron concentrations (from right to left, Fe250, Fe50, and Fe20) are shown. The gels are darkly colored by the presence of the nanoparticles both inside and on the outside of the gels. In Figure 4-1b, the same samples as shown in (a) after drying and calcination at $800{ }^{\circ} \mathrm{C}$ in air for 5 hours. As seen between Figures 4-1a and 4-1b, after grinding and calcination, the gel takes on a lighter red-brown color compared to the gel with nanoparticles freshly deposited. This suggests that the the ground gel is more homogeneous, and that iron particles have become fully oxidized due to the color being visually similar to that of $\mathrm{Fe}_{2} \mathrm{O}_{3}$. Figure 4-1c shows that after CPD the shape of the gel is retained. Some shrinkage and distortion are observed, but the gel is consolidated and uniform in structure. Figure 4-1d shows a wet gel with deposited cobalt being attracted to a permanent magnet, indicating that the cobalt present in the gel is magnetic.

The materials were characterized to determine surface morphology and the aerogel structure, as well as composition, using several techniques. The efficiency of oxygen capture and release were assessed by TGA, and cyclic, high pressure TGA with these materials was used to simulate the CLC system.

\subsection{Structure and Composition of Aging Aerogels}

We used multiple techniques to characterize the structure and nature of the gel without the addition of metal to the gel. SEM was used to visualize the morphology of the sample and to observe significant features of the sample. BET surface area analysis and XRD gave indications of structural changes after the aging process. TEM showed some aspects of aerogel structure. XPS provided insight into the composition and structure of aerogels during aging steps.

Aging is an important process in aerogel formation - the process strengthens the gels, changes the surface structure, and can modify the surface chemistry as well. To 
study the changes in the aerogel as aging was carried out with both alumina and silica, scanning electron microscopy, BET analysis, X-Ray diffraction, and transmission electron microscopy studies were performed on aged aerogels.

X-ray diffraction is an extremely powerful technique for determining the crystalline phase of materials to identify changes in structure as reactions occur. Powder X-ray diffraction is the technique most commonly used to characterize the crystallographic structure and crystallite size of powdered or particulate solid samples. It is commonly used to identify unknown substances or structural information by comparing the experimentally determined pattern with a database. Aged materials were tested by XRD to confirm the crystal structure and observe any changes in structure as aging occurred.

As a highly porous material, aerogels are known to have extremely high surface areas. Brunauer-Emmett-Teller Theory (or BET theory) allows the determination of specific surface area of a material by characterizing the adsorption of gas molecules onto surfaces and into pores. This and similar theories of gas adsorption analysis are very well-defined, and can be used to determine surface area as well as pore structure, shape, and size. In this work, BET analysis has been carried out to determine the surface area of the aerogel at various stages in the production, before and after metals were added, and after calcination of the metal-aerogel composite.

Scanning Electron Microscopy (SEM) allows direct imaging of surfaces and morphology. For aerogels, the SEM has some limitations - first, the aerogel components are very small and may be below the resolution limits of the SEM; second, the aerogel is non-conductive, and must be sputter-coated with a conductive metal to obtain high quality images. This metallic coating (usually gold or gold/palladium) may distort or obscure important features of the aerogel. SEM imaging was therefore approached cautiously, to observe those features which might provide insight into the overall 
structure and morphology of the material. In particular, porosity and gel structure were of interest in the pristine aerogels, for comparison to the same gels after the addition of metals.

Transmission Electron Microscope (TEM) is a characterization method for morphology as well as crystallographic information. TEM imaging can provide great insight into interactions between components of a material, as well as directly observing differences in structure or morphology that might arise in a composite. Although the TEM used for the data collection in this work was low resolution model (and hence cannot provide atomic scale information), the available results were able to shed some insight into the structure of the aerogel.

X-ray photoelectron spectroscopy (XPS) is a surface technique to quantitatively measures the elemental composition, empirical formula, chemical state and electronic state of the target material. A beam of X-rays irradiates the material while simultaneously the kinetic energy and number of electrons that escape from the top 1 to $10 \mathrm{~nm}$ of the material were measured. A material in its "as received" state can be analyzed directly by XPS, or after some treatment.

As described in the experimental design section, two aging steps were adopted to strengthen the gel: alumina aging and TEOS aging. Generally, gelation is a time-consuming process; depending on the material, minutes to several days may be needed to form a consolidated structure. Just after the gelation point, the physical properties of the raw gel probably are not optimal, so an aging step was introduced to allow improvement of the structure of the gel. In our preparation, just after gelation, the gel forms a solid structure from the high viscosity solution, but is still very soft. By allowing time for alumina aging, the gel becomes stronger and more resistant to fracture, based on results from handling. The formation of silica on alumina aerogels through TEOS aging has been demonstrated to increase the stability of alumina aerogels at high 
temperature, in addition to increasing the strength and stiffness of the aerogel. To understand the changes in the aerogel as the aging processes are carried out, alumina aging was performed in the original gelation solution for 1-4 days, and TEOS aging was performed in a TEOS/EtOH solution for 6-24 hrs to deposit a silica layer on the surface of aerogel. After drying by CPD, the gels were examined by multiple techniques.

Figure 4-2a is the X-Ray diffraction pattern for a single batch of gel subdivided into samples which were aged at room temperature in the original solution (alumina aging) for increasing amounts of time. As aging time increases, the wet gel particles may aggregate together or grow larger through condensation processes, increasing the particle size. The pattern shows the peaks becoming much sharper after 2 days when compared to the original broad peaks, indicating that the particle size is increasing. The diffraction pattern agrees with that of $\mathrm{AlOOH}$ (boehmite). Considering the aging time versus the crystallinity, two days of alumina aging shows good crystallinity and was selected as the standard alumina aging - further growth would be expected to reduce pore size.

The XRD pattern in Figure 4-2b shows samples from a single batch of silica-alumina wet gel, each after different TEOS aging times (0, 6, 8, 10 and $24 \mathrm{hrs})$. The aerogel with no TEOS aging shows the same boehmite peaks as seen in Figure 4-2a above. After TEOS aging, no obvious peaks due to silica are observed. This suggests that the silica that is being deposited is amorphous silica rather than a crystalline material. The sharp peaks at $2 \theta=72^{\circ}$ are an artifact from the sample holder. 

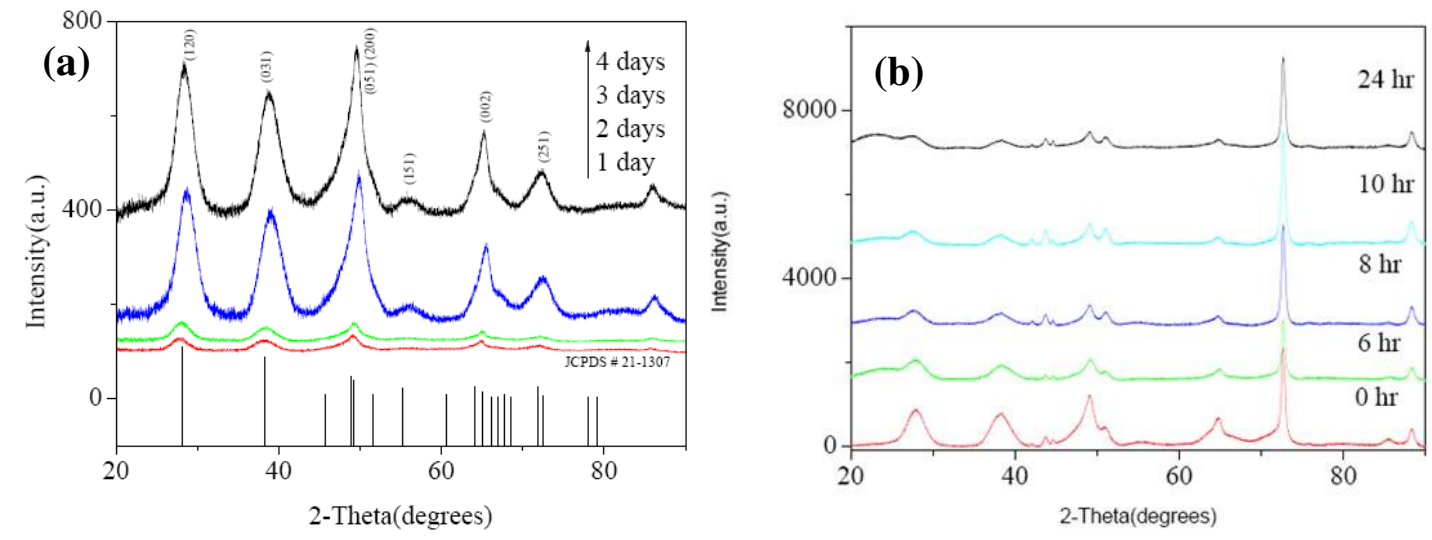

Figure 4-2. XRD patterns from aged aerogels. a) After indicated alumina aging times; boehmite peak pattern at bottom. b) After indicated TEOS aging times.

As TEOS aging time was varied from 6 to 24 hours, the surface area was measured. BET analysis by $\mathrm{N}_{2}$ adsorption/desorption shows that the surface area increases during the TEOS aging process (Figure 4-3). As aging time lengthens, the surface area increases linearly from 360 to $750 \mathrm{~m}^{2} / \mathrm{g}$. In TEOS aging, small silica particles deposited

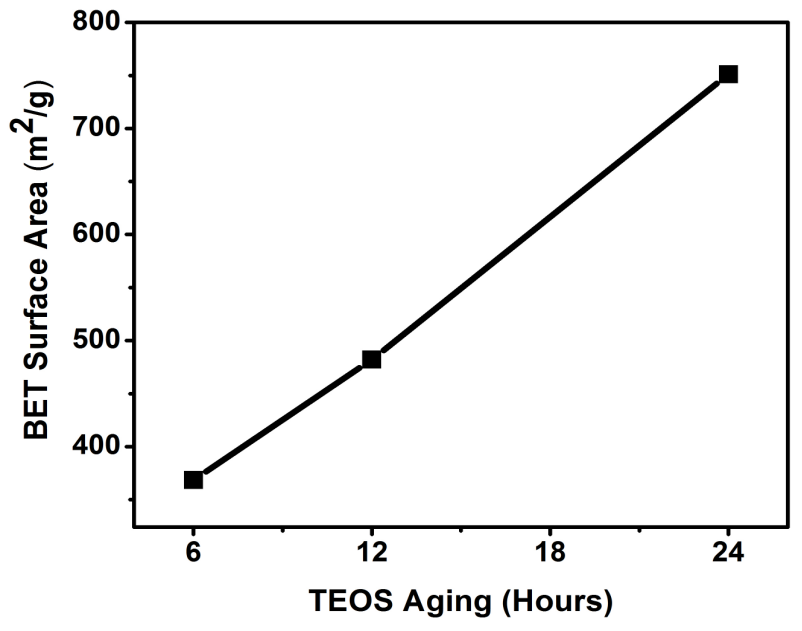

Figure 4-3. Surface area of aerogel as TEOS aging time increases. onto the surface of the gel could act as potential sites for metal nanoparticle binding. The dramatic surface area increase indicates that these deposited silica particles are very small, probably nanometer scale or smaller. The presence of increased surface area is beneficial for our proposed application, providing extensive sites for metal nanoparticle adsorption. Based on the XRD and BET analysis of the aged aerogels, two days for alumina aging and $24 \mathrm{hrs}$ for TEOS aging were selected for all subsequent metal deposition studies.

SEM images were obtained of aerogel after first gelation and after TEOS aging. 
Pure aerogel and aerogel after TEOS aging were dried through CPD, and then attached to silica wafer with carbon tape and sputter coated with $10 \mathrm{~nm}$ of platinum. The as-formed aerogel in Figure 4-4a shows a very porous monolithic structure before TEOS aging, with a structure that appears to be sponge-like. As described in the experimental design section, the TEOS aging procedure deposits silica particles onto the aerogel surface. Extensive deposition of silica particles should be expected to decrease the size of pores that might be visible by SEM. In Figure $4-4 b$ the gel appears to have lost some of spongelike porosity visible in Figure 4-4a. However, while deposition of silica onto the alumina does reduce the pore volume, it does not reduce the overall surface area, since the deposited
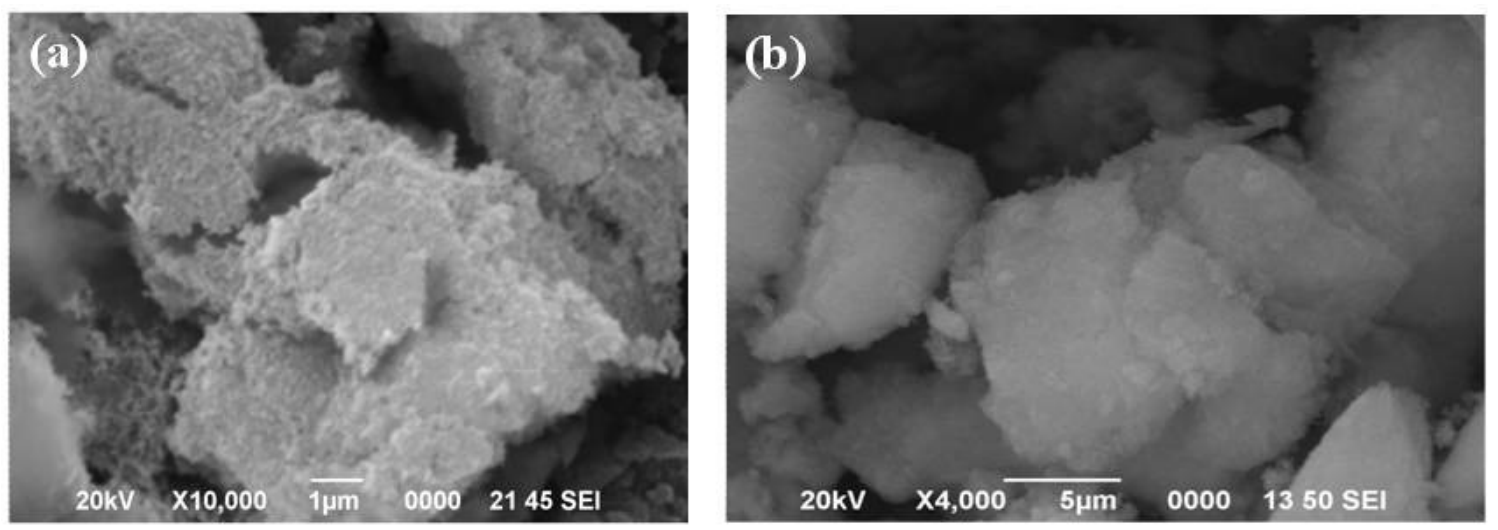

Figure 4-4. SEM images of alumina-silica aerogel before (a) and after (b) 24hrs TEOS aging

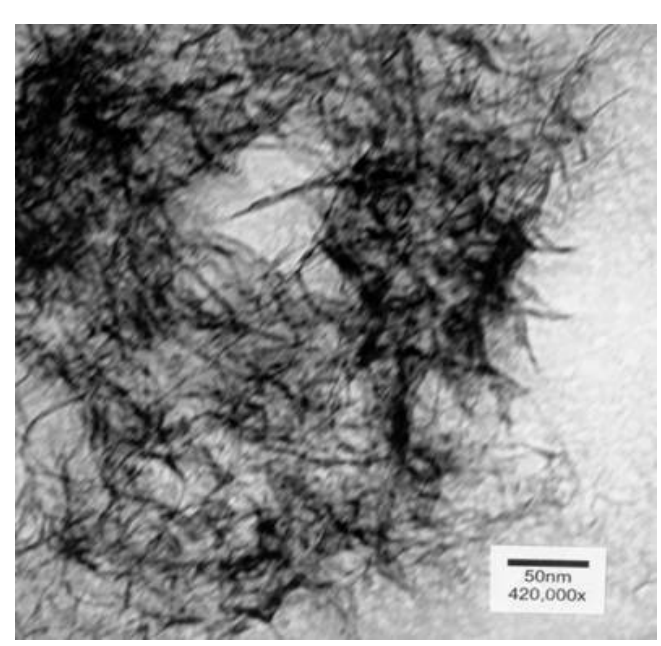

Figure 4-5. TEM image of alumina-silica aerogel particles may be very small.

By TEM imaging, the skeleton structure of the aerogel is still discernable, even at low resolution. Figure 4-5 shows the aerogel structure to be needlelike aggregate structures less than $10 \mathrm{~nm}$ in length, consistent with the formation of boehmite. No distinct silica particles are visible, suggesting that the particles are smaller than 
can be resolved with the TEM. The general grey obscurity of the image could be attributed to the formation of an overlayer of silica, though other causes cannot be discounted.

The aged aerogel samples were also examined by XPS to determine compositional details. Figure 4-6 shows a survey scan for aerogel after CPD with and without TEOS aging. The sample with zero hours of TEOS aging shows a weak

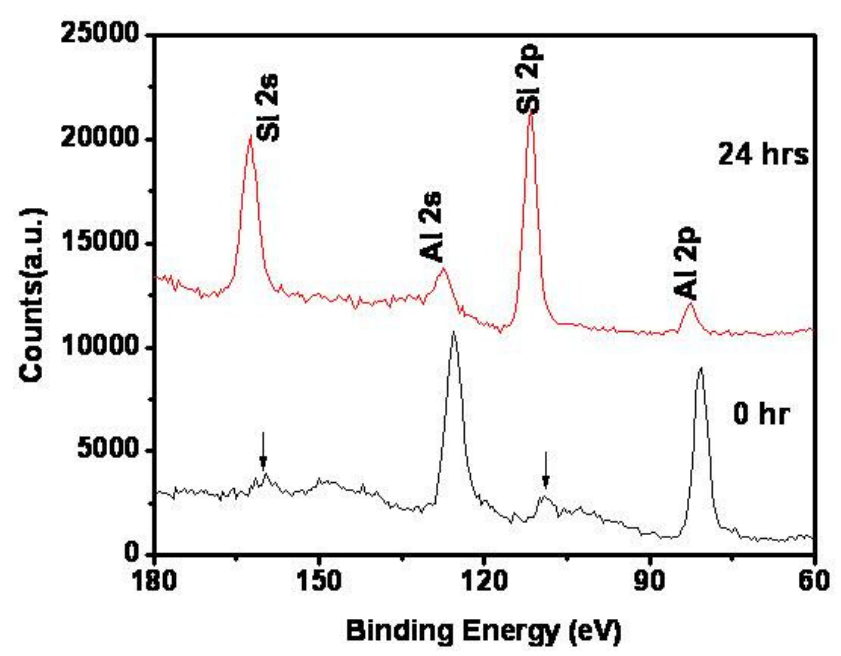

Figure 4-6. XPS spectra for aerogel. The figure shows a comparison between no TEOS aging and 24 hours TEOS aging silica peak. This indicates that either the silica is a very small component of the aerogel, or the silica signal is attenuated by an interfering material. Since the two are gelled together, the silica signal attenuation by alumina is the more likely scenario. In the TEOS aged sample, the peak due to silicon increased greatly at the same time that the intensity of the $\mathrm{Al}$ peak is decreased. This indicates that the TEOS aging deposited a silica layer on the surface of the alumina gel. The Al response was attenuated due to the silica layer growing on top of it. Due to the fact that XPS is a surface measurement (with a probe depth of only a few nanometers), we cannot probe the interior of the gel (the alumina skeleton) after TEOS aging using a simple survey scan. XPS, therefore, cannot provide information to determine if the inner composition of the aerogel changed.

When we consider all of the data from the examination of aerogels as they are grown and age, we can conclude that after two to three days of aging, the alumina has a distinct crystalline boehmite structure, while after 24 hours of TEOS aging, the silica has no sharply defined crystalline structure. XPS data indicate that the silica initially is a 
minimal component of the composite, but silica aging produces a significant effect on the surface of the aerogel, increasing the surface area by almost a factor of two. Examination of the XRD data in Figure 4-2(b), above, also clearly indicates that the alumina structure does not change during silica aging. XRD would not be sensitive enough to identify superficial changes to the boehmite, but since it shows no overall changes to the crystal structure, we conclude that the alumina is largely unchanged by silica adsorption.

\subsection{Aerogels Containing Iron and Cobalt}

As described in the Experimental Section, cobalt or iron was deposited into the aerogel by thermolytic decomposition of organometallic compounds at high temperature. After the gels were dried using CPD, they were calcined. The calcined gels were examined by many of the same techniques used to examine the metal-free aerogels. Thermal treatments (including the metal deposition process and calcination) would be expected to produce significant changes in the aerogel, leading to coarsening and dramatic loss of surface area. However, the use of silica and alumina aerogels was predicted to maintain gel crystal structure and surface area, minimizing the effects of the

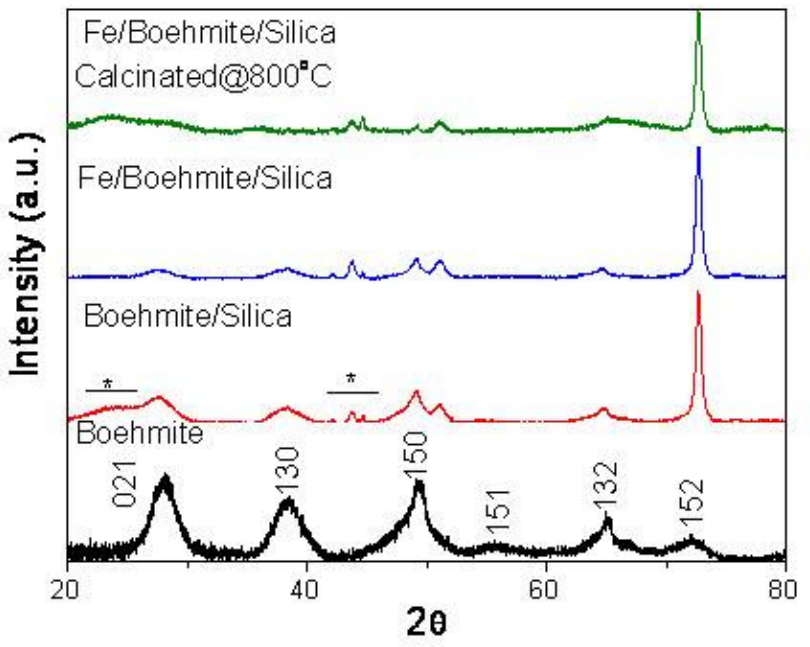

Figure 4-7. XRD patterns for gel undergoing alumina aging (boehmite) - TEOS aging (Boehmite/ Silica)- adding Fe particles (Fe/Boehmite/Silica)- calcined at $800{ }^{\circ} \mathrm{C}$ hours TEOS aging thermal exposures

Figure 4-7 shows XRD of four samples, all from the same batch of gel. Each of the four samples was carried through one further step in the gel and metal composite 
preparation process. All four samples were alumina aged for 2 days, and one sample was separated for XRD. The remaining three samples were TEOS aged for $24 \mathrm{hrs,} \mathrm{with} \mathrm{one}$ sample separated for XRD. The remaining two samples were used as supports for thermally-induced deposition of iron from iron pentacarbonyl, with one sample separated for XRD. Finally, the last sample was calcined, and then separated for XRD. The highest temperatures that the gels in each step were exposed to were $90{ }^{\circ} \mathrm{C}, 70{ }^{\circ} \mathrm{C}, 255{ }^{\circ} \mathrm{C}$ and $800{ }^{\circ} \mathrm{C}$. Analysis of the $\mathrm{XRD}$ data shows that the crystal structure of the gel is most consistent with that of boehmite. After TEOS aging, an amorphous silica layer is deposited onto the gel's surface. After the deposition of iron, there are no significant changes in the XRD pattern. The iron concentration is quite low, probably less than 5\%, and therefore cannot be observed in the XRD, unless there were extremely crystalline regions. XPS and ICP-MS results (discussed below) verify the presence of iron in the aerogel. After calcination, there are few changes in peaks corresponding to the aerogel as well. If the aerogel coarsened extensively at high temperature due to conversion from boehmite to $\delta-\mathrm{Al}_{2} \mathrm{O}_{3}$ or another alumina phase, peaks due to the alumina would be expected to increase in intensity, grow sharper, and shift. Since this did not occur, or at most, occurred only a little, a reasonable conclusion is that the alumina-silica gel is more thermally stable than alumina alone. The sharp peak at 72 degrees is an artifact from the sample holder.

After metals were deposited onto the aerogel surface, the surface area was determined by BET analysis. In every case, after the metal was deposited, the surface area decreased when compared to the aerogel alone (Table 4-1). This decrease in surface area could occur due to a number of causes. The temperature of metal deposition (250 $\left.{ }^{\circ} \mathrm{C}\right)$ is sufficiently high that it could induce dehydration, recrystallization, and overall coarsening in the alumina phase, decreasing the surface area. The overgrowth and aggregation of iron nanoparticles could also block pores or bridge nanometer scale 
components of the aerogel, also reducing surface area. From examples in the literature, a complete recrystallization should result in a dramatic reduction in surface area. A 50\% reduction in surface area suggests some partial recrystallization.

For iron, as the amount of iron precursor was increased, the surface area also increased. The increase of the precursor concentration should produce a larger amount of particles being deposited into the gel, with an expected increase in surface area. With one exception, the surface area decreased after calcination at $800{ }^{\circ} \mathrm{C}$. Fe5cal (Fe5 after calcination) instead showed an increase in surface area after calcination, but the difference is quite small. Fe5cal, Fe20cal and Fe50cal have approximately the same surface area. It is possible that minute amounts of iron can serve to stabilize alumina like silica, supporting the aerogel structure at high temperatures. As the amount of iron increases, however, the iron will tend to form nanoparticles which do not stabilize alumina well, allowing an increase in surface area.

From the elemental composition results (shown below), the amount of cobalt in the aerogel is typically much higher than that of iron. At the same reaction temperature for the metal loading reaction, more cobalt deposition and more cobalt particles may be the primary factor for surface area change. Small pores could be blocked by the formed cobalt particles, hence from Co5 to Co30 there is a significant decrease in surface area as more and more pores are blocked, but from Co30 to Co150, the surface area is almost constant. Thus as the number of particles increased additional pores could not be blocked. The calcined cobalt samples show similar behavior to iron, stabilizing the surface area better than in the aerogel alone. Small amounts of the cobalt can stabilize the alumina, but when the concentration increases, nanoparticles begin to form, and the alumina is not stabilized well. Calcination can lead to the recrystallization of the alumina or sintering of the metal nanoparticles into lower surface area, larger particles. Note that, for both Fe250cal and Co150cal, the surface area dropped significantly compared to Fe50cal and 
Co30cal, which indicates that for higher metal concentrations exposure to $800{ }^{\circ} \mathrm{C}$, there is a significant increase in aggregation/sintering, or a decrease in alumina stabilization.

Table 4-1. Surface Area of Aerogel with Varying Metal Deposition

\begin{tabular}{cccccc}
\hline Sample name & $\underline{\text { Aerogel }}$ & $\underline{\mathrm{Fe} 5}$ & $\underline{\mathrm{Fe} 20}$ & $\underline{\mathrm{Fe} 50}$ & $\underline{\mathrm{Fe} 250}$ \\
Before Calcination $\left(\mathrm{m}^{2} / \mathrm{g}\right)$ & 751.12 & 315.48 & 390.83 & 418.51 & 442.33 \\
After Calcination $\left(\mathrm{m}^{2} / \mathrm{g}\right)$ & 284.57 & 351.96 & 349.99 & 354.24 & 282.08 \\
& & & & & \\
$\underline{\text { Sample name }}$ & & $\underline{\mathrm{Co5}}$ & $\underline{\mathrm{Co} 12}$ & $\underline{\mathrm{Co} 30}$ & $\underline{\mathrm{Co} 150}$ \\
Before Calcination $\left(\mathrm{m}^{2} / \mathrm{g}\right)$ & & 393.56 & 366.16 & $283.26 /$ & 289.91 \\
After Calcination $\left(\mathrm{m}^{2} / \mathrm{g}\right)$ & & 350.06 & 365.87 & 334.12 & 277.31 \\
\hline
\end{tabular}

Figure 4-8 shows a small piece of aerogel after the addition of the metal precursor, and thermal formation of the nanoparticles. The aerogel mass has been broken to reveal interior and exterior surfaces. The color variations on the aerogel, and the differences in the darkness of the aerogel inside the mass and the outside surface indicate a non-uniform distribution of metal in the aerogel. To investigate morphologically observable differences in the material, high resolution SEM images for the gels after metal ( $\mathrm{Fe}$ or $\mathrm{Co}$ ) deposition were collected. Two types of samples were examined by SEM cross-sectioned aerogel (where the aerogel was cut to expose surface and interior) and

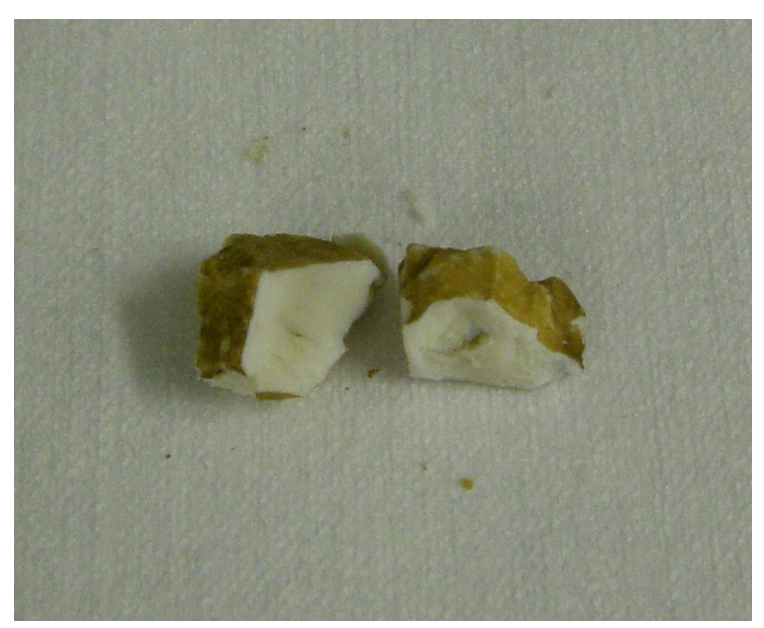

Figure 4-8. Aerogel with deposited iron. Cobalt-containing aerogels have the same general appearance. As is clearly observable from the image, the aerogel pieces have much higher metal concentration on the surface. 
aerogel which was ground in a mortar and pestle.

Figures 4-9 shows SEM images of ground aerogels with Iron (Fe250, a) and Cobalt $(\mathrm{Co} 150, \mathrm{~b})$. There are apparent differences between the two samples. Fe250 aerogel (Figure 4-9a) had a sponge-like surface structure, consistent with the typical picture of an aerogel. Particles forming the aerogel network appear to be very small (below the resolution of the SEM), with no obvious metal particles visible (with one possible exception at the bottom of Figure 4-9a - this will be considered below). Co150 aerogel (Figure 4-9b) appears to have a different morphology, showing a bulkier particulate surface without the spongelike appearance noted previously. Individual discrete particles are not visible, however, suggesting that the cobalt metal has been deposited into pores. Large amounts of discrete particles which might be ascribed to the deposited metal are visible in neither case.

Obvious metal nanoparticles cannot be seen in these SEM images from the interior of the aerogels. This may be due to the low average concentration of metals in the aerogel
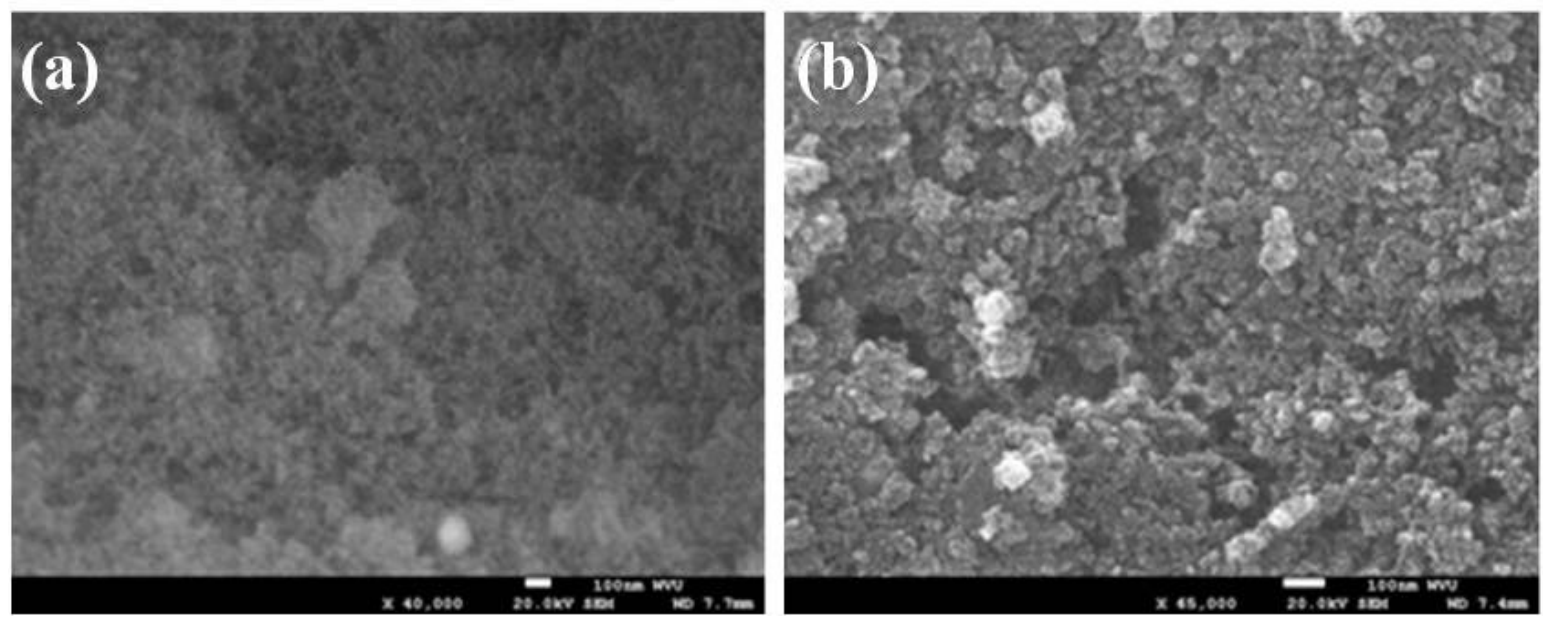

Figure 4-9. SEM images of aerogel with Iron loading (Fe250, ground, (a)) and Cobalt loading (Co150, ground, (b))

or due to extremely small particle size. To confirm that the metal was present in the aerogel, EDX provided some qualitative compositional information to aid in understanding the SEM results. The aerogel samples were nonconductive, and were 
therefore sputter-coated with Au-Pd before SEM-EDX. Figure 4-10 is the EDX spectrum of ground aerogel with iron (Fe250), and Figure 4-11 is ground aerogel with cobalt (Co150). Each spectrum shows energy signatures consistent with either iron or cobalt, as expected. The EDX spectra confirmed the major components of the aerogel materials are $\mathrm{O}, \mathrm{Si}, \mathrm{Al}$, and metal (Fe or $\mathrm{Co}$ ): $\mathrm{Au}$ and $\mathrm{Pd}$ peaks are from the conductive coating, and carbon is from environmental contamination and background from the carbon tape substrate. Due to the porosity of the gel, the low conductivity of the sample, and the non-flat surface, EDX could only give a qualitative elemental analysis. The surface would need to be polished to determine quantitative concentrations of each element, which is not feasible for these materials. From both Figure 4-10 and 4-11, the relative peak intensities of $\mathrm{O}, \mathrm{Al}$, and $\mathrm{Si}$ are much greater than those of the metal ( $\mathrm{Fe}$ or $\mathrm{Co})$, implying a large difference in concentration between the aerogel components and the deposited metal. Other techniques have been used for quantitative analysis of composition, as described in later sections.

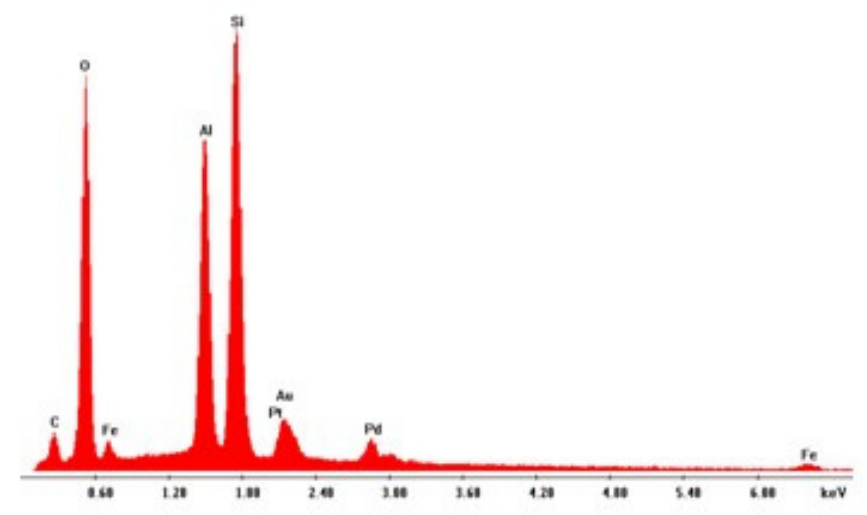

Figure 4-10. EDX image of aerogel with Iron loading (Fe250, ground) 


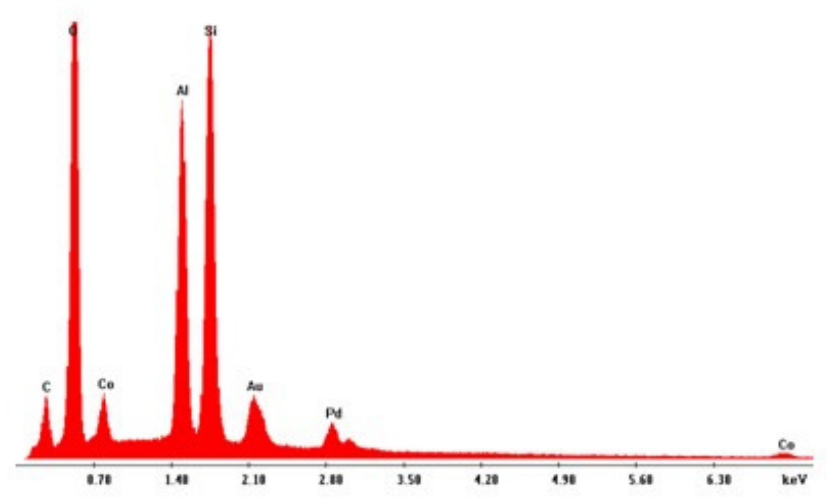

Figure 4-11. EDX image of aerogel with Cobalt loading (Co150, ground)

Due to the lower average concentration for the ground samples, cross-sectioned samples were prepared which allowed examination of both the exterior surface of the aerogel with presumably high metal deposition, as well as the interior surface of the aerogel. These samples were analyzed with high resolution SEM-EDX to image the presence of metal particles. From the image in Figure 4-8, the metal deposition seems to be concentrated on the surface of the gel. EDX for the external surfaces of Fe250 and Co150 are shown in Figure 4-12 and Figure 4-13 respectively. Even with Au/Pd coating, Fe250 showed extreme susceptibility to charging, making simultaneous SEM imaging and EDX analysis impossible. The cobalt-containing gel was more easily imaged. In Figure 4-13, round particles can be observed which are distributed widely on the surface. From Figures 4-12 and 4-13, the EDX results of the exterior surface of both the iron and cobalt gels show much higher relative intensities for the metal peaks (Fe or Co) compared to the EDX results of ground samples. This result confirms (at least qualitatively) that the surface has a high metal concentration compared to the interior of the gel. Examination of aerogel exterior surfaces reveals no discrete particle structures, suggesting that the particles observed on the exterior of the cobalt gel are cobalt or cobalt oxide particles. Particle size was approximately $250 \mathrm{~nm}$ for these materials. This particle size is also consistent with the single particle observed in Figure 4-9a, suggesting that either contamination occurred between cobalt and iron, or that iron has similar particles on the 
external of the aerogel. The contamination issue can occur in the SEM during imaging charging in the SEM causes fragments of aerogel to move easily, and could potentially eject a loosely-bound particle from one sample to another.

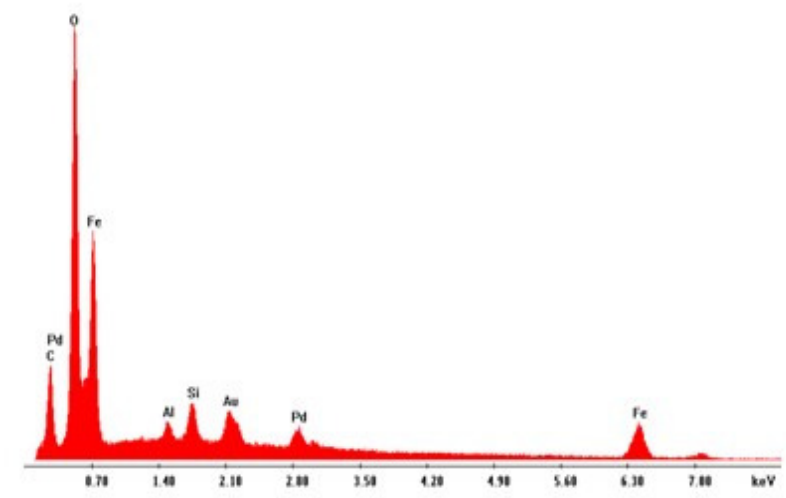

Figure 4-12. EDX for Fe250 surface (cross section)
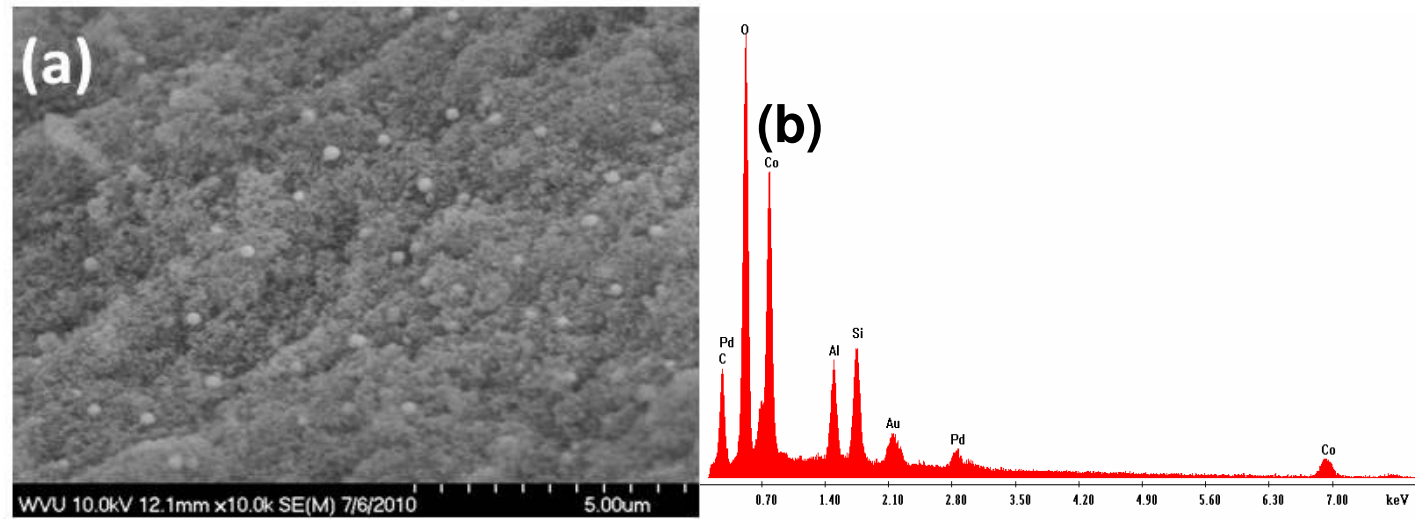

Figure 4-13. SEM-EDX result for Co150 surface (cross section)

TEM images shown in Figure 4-14 of the alumina-silica aerogel after iron deposition clearly indicate the presence of needlelike aggregate structures which are less than $10 \mathrm{~nm}$ in length, as observed in the TEM in Figure 4-5, above. After the deposition of metal

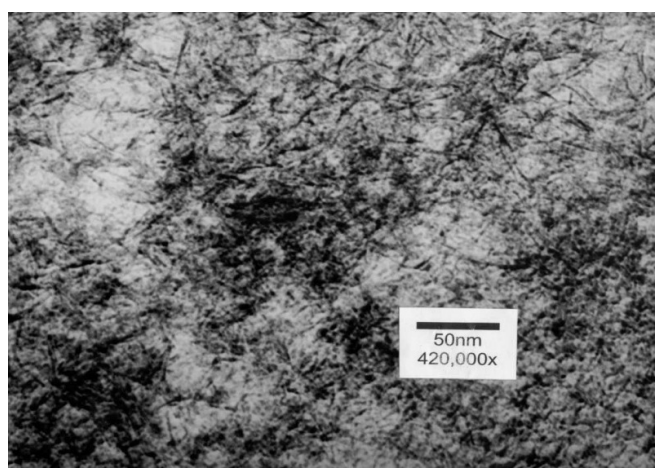

Figure 4-14. TEM image of alumina-silica aerogel after iron deposition into the gel, small black dots can be observed in TEM image. Though the TEM images 
are not high enough resolution to determine lattice constants or unequivocally measure particle sizes, these images do support the contention that the metal is deposited into the gel, ultimately in the form of nanoparticles. High Resolution TEM will be done in future work to exhibit how the nanoparticles interact with the aerogel structure.

XPS analysis of iron-containing aerogels was used to consider the form of the iron on the aerogel and to precisely determine composition of the metal containing aerogels. Analysis of composition of the iron-containing aerogel by XPS and ICP-MS were compared to understand formation mechanisms and compositional variations. The XPS survey scan shown in Figure 4-15 of both the pure aerogel (with no metal deposition) and the aerogel after deposition of iron shows the presence of $\mathrm{Al}(73.6 \mathrm{eV}), \mathrm{Si}(102 \mathrm{eV})$, and $\mathrm{O}$ with $\mathrm{Fe}(710.51 \mathrm{eV})$ peaks. According to literature sources, ${ }^{70}$ the dominant binding energy peaks for $\mathrm{Fe}^{0}, \mathrm{Al}^{0}$ and $\mathrm{Si}^{0}$ are $707.0 \mathrm{eV}, 72.9 \mathrm{eV}$, and $99.3 \mathrm{eV}$, and oxidized states occur at 709.1-711.9 eV, 73.6-74.7 eV, 103.3 eV respectively. The iron peak is not very intense in the survey scan due to the low relative concentration, but it can be clearly observed with high resolution scanning (Figure 4-16).

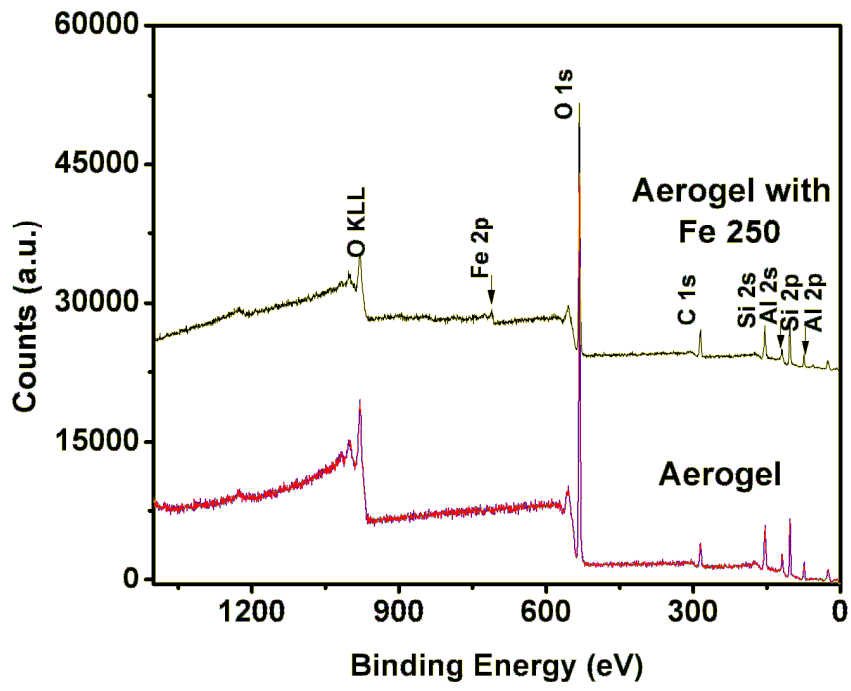

Figure 4-15. XPS survey scan for aerogel with and without deposition of iron
The binding energy for elemental iron is $707.0 \mathrm{eV}$. As shown in the high resolution XPS scan in Figure 4-15, none of the iron appears to be at $707.0 \mathrm{eV}$. XPS peaks from elements in higher oxidation states occur at higher binding energies compared to pure elements. The peak at 710.51 and $723.5 \mathrm{eV}$ correspond to, respectively, the 


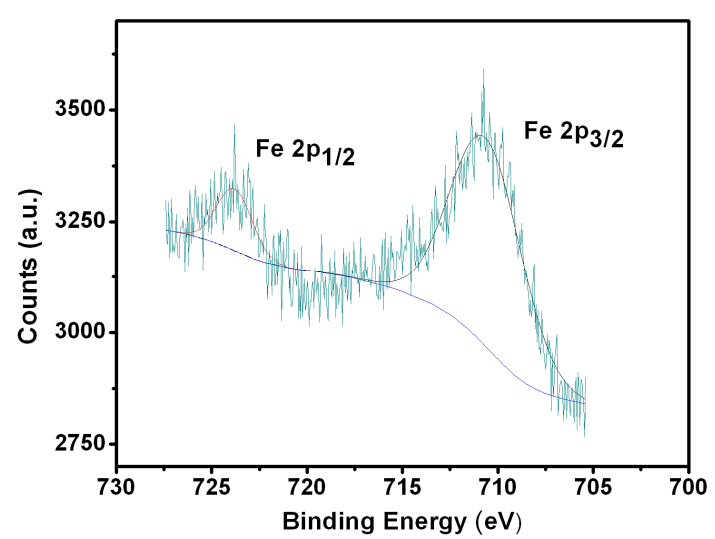

Figure 4-16. High resolution XPS spectrum for Iron peak iron $2 \mathrm{p}_{3 / 2}$ and $2 \mathrm{p}_{1 / 2}$ peaks, indicating, respectively, the $\mathrm{Fe}^{+2}$ and $\mathrm{Fe}^{+3}$ oxidation states. These oxidized iron species indicate the formation of iron oxides in the aerogel.

The composition of the aerogels with varying metal

content can be determined by XPS. Table 4-2 shows the atomic percentage composition of the aerogel as determined by XPS, as well as the overall percent mass of iron in each sample. For comparison, the iron content was also determined by ICP-MS. This table shows both values in target metal concentration. The two techniques provide very similar results. Clearly, increasing the amount of the precursor presented in the thermal decomposition reaction results in greater iron concentration in the aerogel. However, we must keep in mind that the ICP-MS will determine the concentration of Fe in the bulk matrix while the XPS gives the composition of the scanning area surface. XPS is not accurate for an atom ratio lower than $\sim 1 \%$, and ICP-MS is not accurate for the weight percent higher than $\sim 1 \%$. Even so, these two results corroborate one another and provide a frame of reference from which to compare the metal concentration in the aerogel

Figure $4-17$ is $\mathrm{XPS}$ survey scan for Co150. From

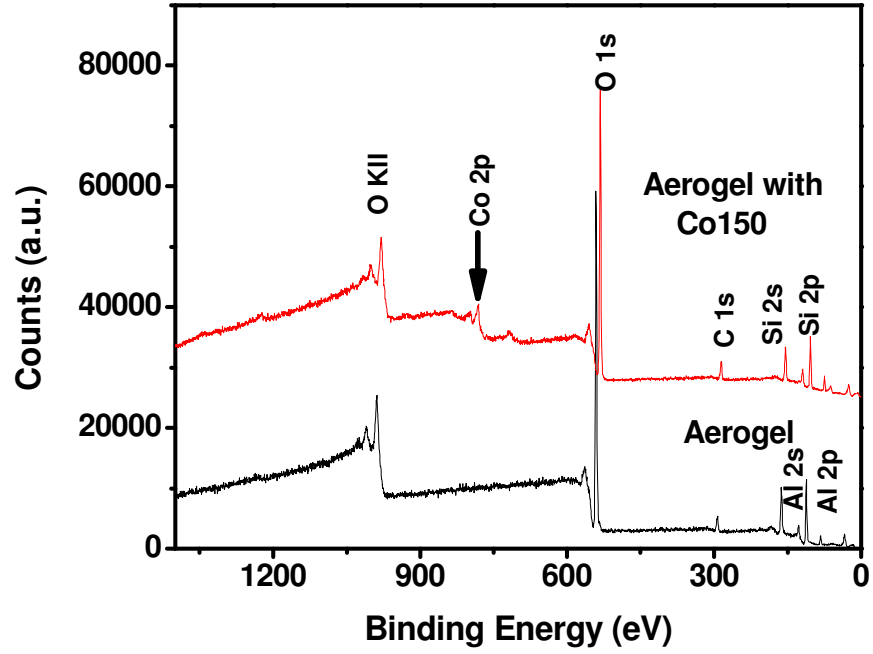

Figure 4-17. XPS survey scan for Co150 
the survey scan spectrum, there are visible peaks belonging to cobalt, which indicates that cobalt has a higher concentration than iron. The element composition for Co series samples are $\mathrm{Si}, \mathrm{Al}, \mathrm{O}, \mathrm{Co}$. From the atom ratio \%, the calculated weight percent for Co in Co150 is $10.78 \%$, much higher than iron, consistent with the conclusions from SEM.

Table 4-2. Elemental Composition of Iron-containing Aerogels by XPS and ICP-MS

\begin{tabular}{|c|c|c|c|c|c|c|c|}
\hline \multirow[b]{2}{*}{$\underline{\text { Sample }}$} & \multirow{2}{*}{$\begin{array}{l}\text { Binding Energy } \\
\underline{F e ~} 2 p_{\underline{3 / 2}}(\mathrm{eV})\end{array}$} & \multicolumn{4}{|c|}{ Atom Ratio \% (XPS) } & \multirow{2}{*}{$\begin{array}{l}\underline{\text { XPS }} \\
(\mathrm{Fe} \mathrm{wt} \%) \\
\end{array}$} & \multirow{2}{*}{$\begin{array}{l}\underline{\mathrm{ICP}-\mathrm{MS}} \\
(\mathrm{Fe} \mathrm{wt} \%) \\
\end{array}$} \\
\hline & & $\underline{\mathrm{Al}}$ & $\underline{\mathrm{Si}}$ & $\underline{\mathrm{O}}$ & $\underline{\mathrm{Fe}}$ & & \\
\hline Fe 5 & 710.59 & 8.05 & 19.9 & 71.82 & 0.23 & 0.67 & 0.19 \\
\hline Fe 20 & 710.54 & 8.2 & 20.27 & 71.28 & 0.26 & 0.75 & 0.53 \\
\hline Fe 50 & 710.28 & 7.34 & 19.1 & 73.21 & 0.44 & 1.29 & 0.87 \\
\hline Fe 250 & 710.62 & 7.74 & 20.24 & 71.2 & 0.82 & 2.38 & 2.65 \\
\hline
\end{tabular}

The XPS and ICP-MS results suggest a much lower concentration of iron is present in the aerogel than predicted from the amount of starting materials. From the optical image in Figure 4-8, and the SEM and EDX results, it is obvious that there are greater concentrations of metals on the surface of the gel chunks than inside the gel. Aerogels containing metal (Fe and $\mathrm{Co}$ ) deposited with the thermal decomposition method described were studied by XPS mapping and line scan techniques to address differences in the distribution of metal in and on the aerogel. Figure 4-18 is XPS mapping and line-scan on a Secondary X-ray Image (SXI) for Fe250, and Figure 4-19 is the same technique applied to Co150. SXI can clearly distinguish the sample edge from the sample holder, assisting in the search to find a suitable scanning position for both mapping and line-scan. Usually an area including the sample edge for scanning was chosen to obtain the relative concentration of target element from surface to interior. For both Fe250 and Co150, the edge of the sample was clearly distinguishable in SXI (Figure 4-18a, 4-19a, and c). The line-scan curves show the intensity of the metal of interest (iron in Figure 
4-18 and cobalt in figure 4-19) distribution extending along the scanning line. For line-scan, distance from 0 to the end, corresponding to the SXI from top to bottom.

For the iron-containing sample (Figure 4-18), the line scan plots the intensity of the peak at $710.51 \mathrm{eV}$, corresponding to the $\mathrm{Fe} 2 \mathrm{p}_{2 / 3}$. The intensity of this peak correlates to the concentration of the metal at a given location. In Fe250, the concentration of iron reaches a maximum at a location corresponding to the edge of the sample. In addition, there is another local maxima at $600 \mu \mathrm{m}$ from the surface. The maximum concentration of iron at the surface of the sample is expected, given that the samples are dark on the outside (from the deposition of metal) and light on the inside. For the cobalt-containing sample, the line scan plots the intensity of the peak at $781.4 \mathrm{eV}$, corresponding to the Co $2 \mathrm{p}_{2 / 3}$. In Co150 (Figure 4-19), the maximum concentration of the metal also corresponded to the edge of the gel.

In XPS mapping, the intensity of the same peaks as considered in the line scan are plotted for an $\mathrm{X}-\mathrm{Y}$ sequence of points generating an image which shows the intensity of the peak at a given location. Higher intensity, means higher concentration, and corresponds with brighter color in mapping images. In the Fe250, the highest intensity region corresponds clearly with the edge of the sample, and therefore the sample surface. There is also other higher intensity regions that do not show occur at the edge of the sample. The origin of these features is discussed below. In the Co150, the intensity map shows a maximum some distance from the edge of the sample (the surface of the aerogel). However, in general, the intensity which corresponds to Co decreases towards the center of the sample.

There are a number of notable maxima that stand out as possible anomalies in the XPS mapping data, including the secondary maximum in the Fe250 line scans, and noted maxima in the Fe250 and Co150 mapping. We can propose at least two possible causes for these additional maxima. One likely possibility is that the brittle aerogel cracked 
during the thermal decomposition - aerogel is very brittle, and cracks can easily form on the aerogel. If this happens, the surface of the inner crack is equivalent to another outer surface directly touching the solution, leading to the higher concentration by mechanisms that we describe below. A second very likely possibility is that the surface being analyzed in the XPS is not flat. The intensity of an XPS signal is extremely sensitive to the electron take-off angle. If the surface being analyzed is not flat, the intensity will vary as the electron take-off angle changes. A small bump in the sample due to a miscut during sectioning could give rise to wide variations in intensity. This would explain the variation observed at an angle parallel with the surface in the Fe250 mapping and the variation of the Co150 sample in the mapping. In future work where mapping might be used on non-flat substrates, instead of directly plotting intensity of one peak, the ratio between two peaks could be used. Such data does not exist for these samples, or the ratio between peak intensities would be used.

Although there are some caveats that must be stated with regard to the XPS mapping/line scan data, it is important to note that they do corroborate the observation through visual inspection and SEM/EDX analysis that the concentration of metal at the surface is significantly higher than within the aerogel. Two possible explanations can be proposed to account for this difference in metal deposition: diffusion of metal precursors from the interior of the aerogel to the exterior solution before decomposition, reducing the concentration of material in the interior; and direct deposition of solution-generated nanoparticles on the surface of the aerogel (which presumably happens early in the nanoparticle formation process).

Diffusional Loss - During sample preparation, extensive time is provided for the solvated metal precursors to diffuse into the wet gel. Assuming the metal precursors distribute evenly with the same concentration both in the solution and gel, during the reaction at $250{ }^{\circ} \mathrm{C}$, the precursors could evaporate from the solution, leading to higher 
metal precursor concentrations in the gel but lower in the solution. This particularly likely in the case of $\mathrm{Fe}(\mathrm{CO})_{5}$, which is a volatile organometallic compound. Diffusional processes of the metal precursor would tend to transport it from the interior of the gel into the solution. Once the metal precursor in the gel decomposed to form the metal, the concentration of the metal is lower than expected.

Solution-generated Nanoparticles - The gels are immersed in a high boiling point solvent and the metal precursors are added and allowed to permeate the gel and solution. The metal precursors that are in solution can thermally decompose, generating nanoparticles that grow in solution and diffuse about until they reach the surface, either the flask wall or the aerogel. These nanoparticles can pick up material and grow larger (thus the $250 \mathrm{~nm}$ particles observed in the Co250 sample by SEM), resulting in a much
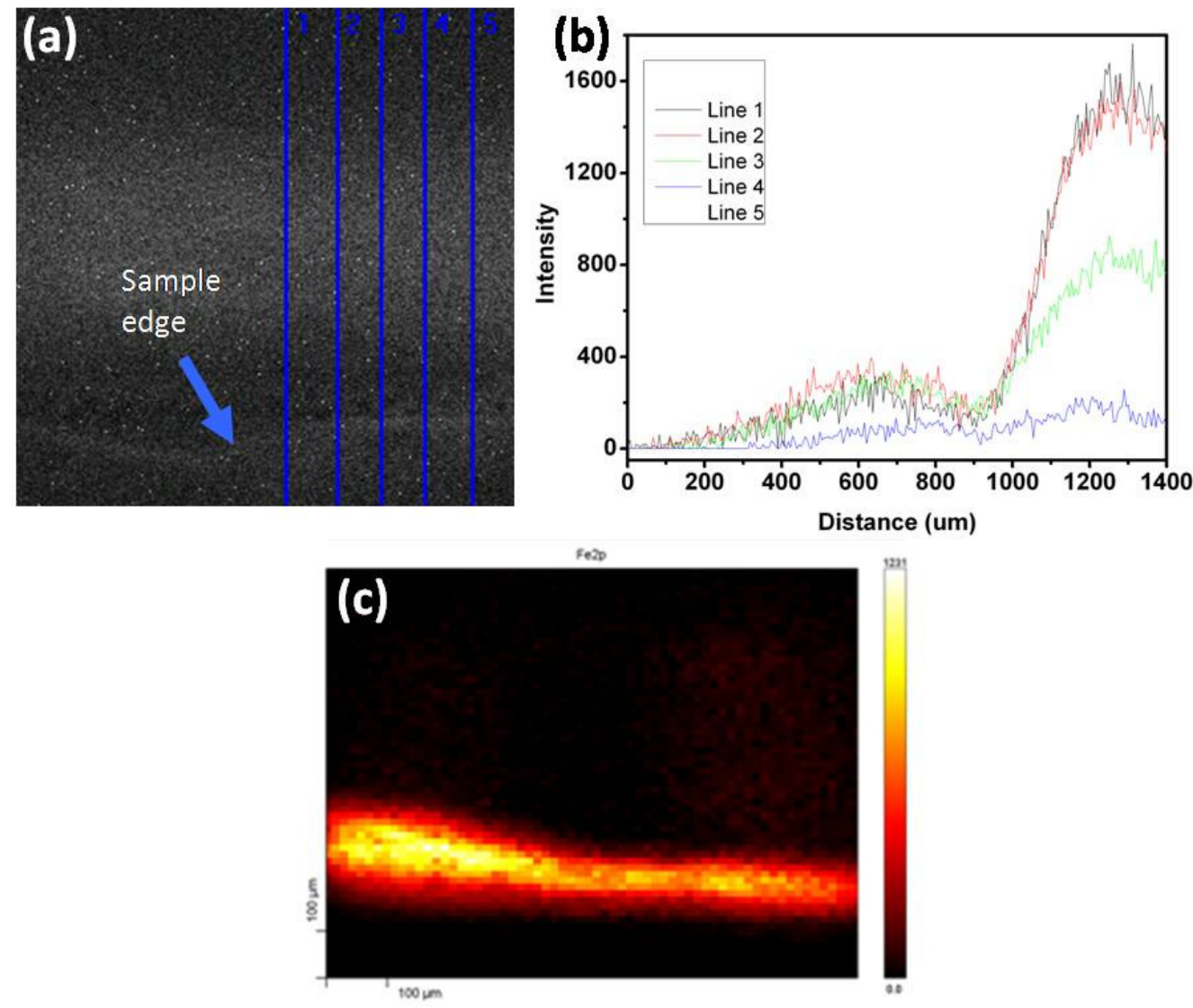

Figure 4-18. For Fe250 (a) XPS SXI showing linescan locations, (b) XPS Line-Scan distribution curves, and (c) XPS Mapping image 
higher concentration of metal at the surface of the aerogel.
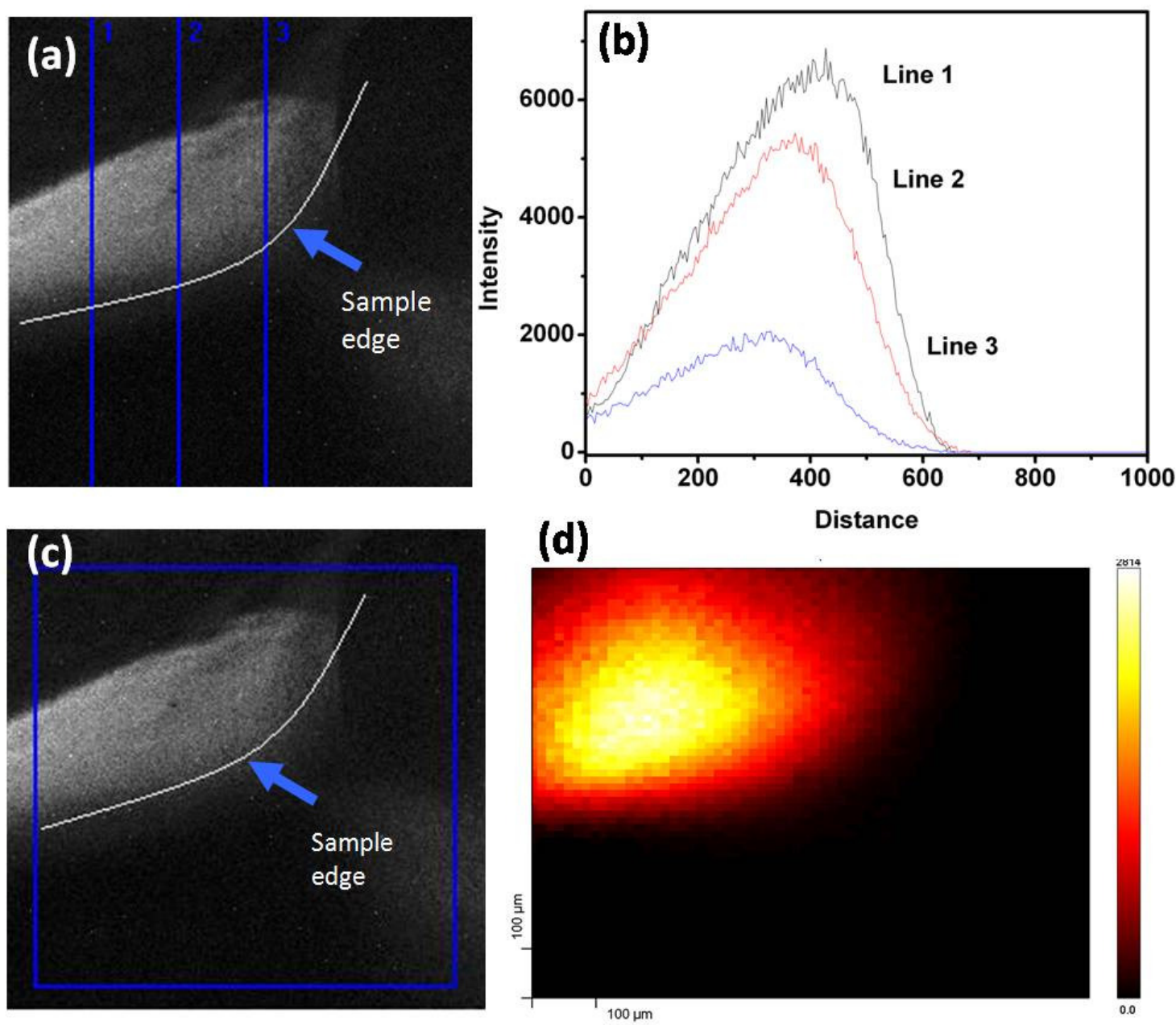

Figure 4-19. For Co150 (a) XPS linescan SXI showing linescan locations, (b) XPS linescan distribution curves, (c) XPS Mapping SXI, and (d) XPS Mapping image.

From the above studies, several conclusions can be drawn about the deposition of metals into gels by thermal decomposition. Aerogels with iron and cobalt were synthesized using identical procedures, the only difference being the metal precursors and their concentrations. The estimation of theoretical yield from the amount of metal precursors used (shown in Table 3-1) predicted that the iron concentration in the gel should be higher than cobalt in the gel. The results of the characterization methods used to determine concentration (shown in Table 4-3), consistently indicated that cobalt had a 
much higher concentration than iron. This data is synopsized here, in Table 4-3.

Table 4-3. Metal Concentrations from Different Characterization Methods

\begin{tabular}{cccc}
\hline & Ideal Metal Concentration in & & $\underline{\text { ICP-MS }}$ \\
$\underline{\text { Sample }}$ & $\underline{\text { Aerogel (wt } \%)}$ & $\underline{\text { XPS (wt } \%)}$ & $\underline{(\mathrm{wt} \%)}$ \\
Fe250 & 26.85 & 2.38 & 2.65 \\
Co150 & 15.88 & 10.78 & 11.73 \\
\hline
\end{tabular}

To understand how the concentration of the iron can deviate so greatly from the theoretical value, consider the preparation (Scheme 4-1). The iron precursor is a volatile liquid, while the cobalt precursor is a solid and stable in the solution. The reaction temperature is $250{ }^{\circ} \mathrm{C}$ for one hour. The most likely explanation is that some of the $\mathrm{Fe}(\mathrm{CO})_{5}$ evaporated from the mixture while heating to the reaction temperature. The boiling point of $\mathrm{Fe}(\mathrm{CO})_{5}$ is $103{ }^{\circ} \mathrm{C}$, and

the heating process up to $250{ }^{\circ} \mathrm{C}$ was carried out for almost two hours to get the required temperature, resulting that the $\mathrm{Fe}(\mathrm{CO})_{5}$ was above boiling point around 60 minutes before significant thermal decomposition occurred. Another possible explanation stems for the fact that the iron

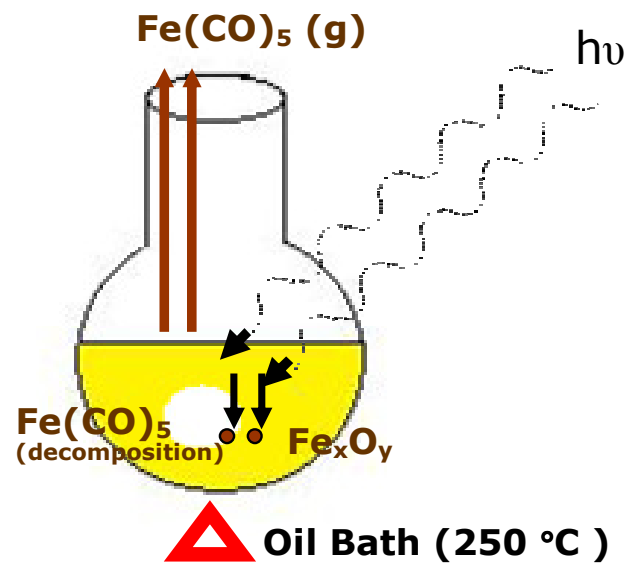
precursor is sensitive to light. During the reaction, no effort was made to isolate the Scheme 4-1. Loss reactions in iron-gel formation reaction from ambient lighting, which could have contributed to increased decomposition and solution deposition on the flask, which would not have been deposited in the gel. Both explanations would also have decreased the precursor concentration in the solution, forming a metal precursor gradient 
from the interior of the gel to the surface. As described above, this would increase precursor diffusion out of the gel, leading to the iron concentration decreasing in the aerogel.

\subsection{Thermal Analysis of Iron-containing Aerogel}

The materials that have been prepared during this work were studied by thermal techniques to assess their behavior at temperatures and in environments similar to those that occur in catalytic processes, such as chemical looping combustion.

Temperature-programmed reduction (TPR) was used to determine the most efficient reduction conditions for these materials. In TPR, the analyte is exposed to a hydrogen atmosphere while the temperature is controllably raised and the disappearance of the hydrogen is monitored. By observing the temperature at which reduction occurs, insights can be gained as to potential structural or mechanistic details of the material, and conclusions can be drawn as to the stability of the material.

Thermogravimetric analysis (TGA) was used for multiple purposes in these experiments. A TGA monitors the mass of a sample as the thermal and reactive conditions around the sample are changed. By observing mass changes at various temperatures or in reactive environments, conclusions can be drawn about composition, behavior, etc. of a material. A Chemical-Looping Combustion (CLC) system can be simulated by TGA. In a typical CLC system, there are two reactors: fuel-reactor and air-reactor. The metal/metal oxides react with fuel gas in the fuel reactor to be reduced; this reduced species is transferred to the air-reactor to react with air to be reoxidized, and

then back to the fuel-reactor again in order to complete the loop. This is a reduction-oxidation process for the metal nanoparticles. A TGA developed for multiple gas control can inject syngas and air alternately reacting with metal oxides and at the 
same time maintaining the high temperature, essentially imitating a CLC system. Such a TGA system is in use at NETL and was used for some of the studies below. We also modified a TGA system in our laboratory to allow single cycles of oxidation and reduction to assess the capabilities of the aerogel composites.

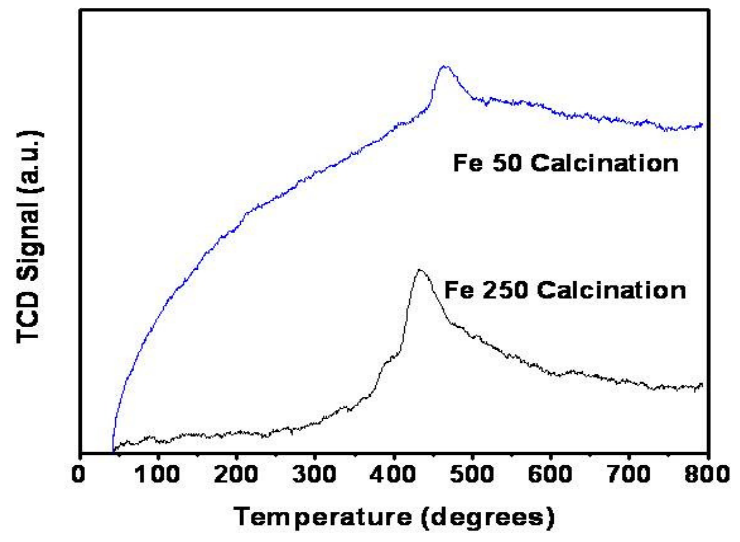

Figure 4-20. TPR spectra for Fe-aerogel
TPR was used to test the relative stability of aerogels containing higher or lower concentrations of iron. Figure 4-20 shows that the reduction temperature for Fe250 shifted to a lower temperature compared to Fe50. Reduction occurred at $435^{\circ} \mathrm{C}$ for the Fe250 calcined sample and at $470{ }^{\circ} \mathrm{C}$

for the Fe50 calcined sample. This result could indicate that the iron oxide nanoparticles are more stable within the aerogel structure at a low concentration compared to a higher. This can be explained by considering the surface area measurements for the Fe50 and Fe250 samples before and after calcination (Table 4-1 above). The surface area of the Fe250 sample changed the most during calcination. This indicates that the iron, either in the form of oxide nanoparticles or an oxide film, did not stabilize the alumina-silica aerogel as well in the Fe250 sample as it did in the Fe50 sample. It is reasonable to conclude that in the Fe250 sample, there is less interaction between the iron/iron oxide and the alumina than there is in the Fe50 sample. In the Fe50 sample, the iron may interact with alumina or silica through a more strongly bonding route. This may be similar to the action of the silica on the alumina. In any case, it is also reasonable to conclude that greater iron concentration in the aerogel will be more useful for CLC due to the slightly lower thermal requirements and the increased mass of iron to accept and contribute oxygen. 
The program for the TGA in our laboratory (referred to as TGA-7) was set up as follows. First, the temperature was increased from $30{ }^{\circ} \mathrm{C}$ to $800{ }^{\circ} \mathrm{C}$ at a rate of $20{ }^{\circ} \mathrm{C}$ /min in Argon; second, the temperature was maintained at $800{ }^{\circ} \mathrm{C}$ for 135 minutes. During the first 30 minutes of the second step, Argon atmosphere was maintained so that the sample could reach a constant weight. The gas was then switched to $2 \% \mathrm{H}_{2}$ in Argon for 45 minutes to reduce the sample. During this period, the sample mass decreased. After the sample mass reaches a minimum indicating complete reduction, the gas was switched to Argon again for 15 minutes to purge hydrogen out of the system. Finally, for the last 45 minutes, the gas was changed to compressed air to reoxidize the material during which the sample mass increases. All TGA-7 tests followed the same program, and the sample weights were all around $4 \mathrm{mg}$.

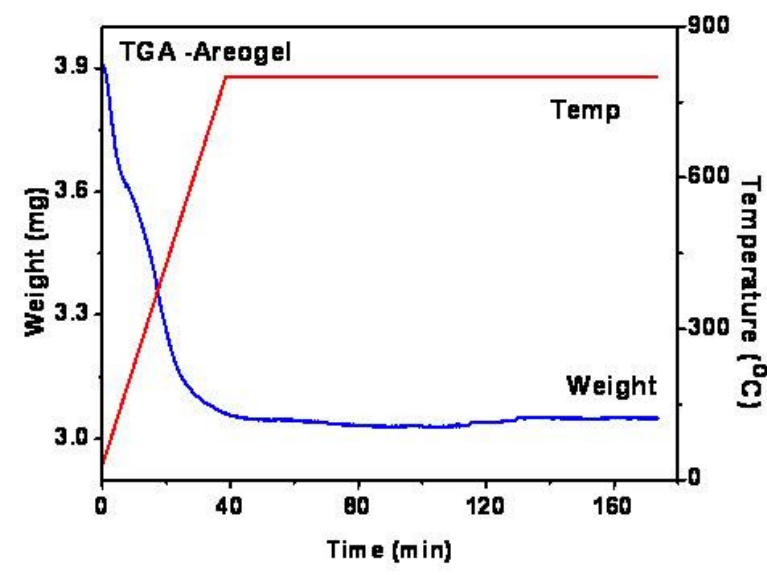

Figure 4-21. TGA-7 result for pure gel

Thermomogravimetric analysis for pure aerogel was obtained by TGA-7 (Figure 4-21) as the control sample. The aerogel, which is a fragile white solid, was ground into powder for the test. The experimental time course is plotted for both temperature $\left({ }^{\circ} \mathrm{C}\right)$ and mass $(\mathrm{mg})$ vs. time (min). As temperature increased from $30{ }^{\circ} \mathrm{C}$ to $800{ }^{\circ} \mathrm{C}$, the mass of pure aerogel decreased. Ultimately, $\sim 22.75 \%$ of the starting mass was lost during this procedure. The mass lost can be split into two regions: first, under $150{ }^{\circ} \mathrm{C}$ attributed to evolution of physically adsorbed water; second, changes occurring between $200-600{ }^{\circ} \mathrm{C}$ correspond to condensation-dehydration of boehmite-alumina $(\mathrm{AlOOH})$, converting it to $\mathrm{Al}_{2} \mathrm{O}_{3}$ with the loss of chemically bound water. The mass was approximately constant 
during the reduction-reoxidation process at $800{ }^{\circ} \mathrm{C}$ indicating that the aerogel has some stability at high temperature.

All the metal content samples increased in mass when Argon flows into the system to purge out hydrogen after the reduction step. The mass tends to re-stabilize shortly and increases again at the start of the reoxidation step. We hypothesized that this increase in mass upon exposure to Argon was due to an oxygen contaminant in the Argon tank. To test this hypothesis, the trials were repeated with high purity argon. The high purity Argon test followed the same program as the rest of the TGA-7 samples, except all the Argon flows were replaced by Zero Grade high purity Argon. Co150cal was used as the trial sample. During the test, the mass once again increased while during the Argon flow. This anomaly has not yet been addressed and will be considered in future work.

Fe250 (that is, without calcination) was tested by TGA-7 as well (Figure 4-22). As the temperature increased, Fe250 showed the same two mass-loss regions as pure aerogel, again because of the evaporation of adsorbed water (below $150{ }^{\circ} \mathrm{C}$ ) and the boehmite-alumina conversion $\left(200-800{ }^{\circ} \mathrm{C}\right)$. The mass then decreased upon the reduction mixture introduction, indicating that iron particles are very sensitive to reduction by hydrogen gas. After 45 minutes of reduction, Argon flows into the system to purge the system and prepare for reoxidation. The mass increased at this point, as described above. When air flow was initiated, iron reoxidation occurred, and the mass increased again.

After the temperature reached $800{ }^{\circ} \mathrm{C}$ and the mass lost stabilized, $20.4 \mathrm{wt} \%$ of the original mass was lost during the temperature ramp, close to the mass change of a pure aerogel sample. This is likely because the limited amount of iron in the gel will not affect the total mass percent significantly. $2 \%$ hydrogen was then introduced into the system for reduction. The reduction-reoxidation part for each sample is enlarged beside the TGA results. In Figure 4-23s, just after switching the Argon to Hydrogen at 
approximately $70 \mathrm{~min}$, there is a valve signal shift, and then the sample mass decreased promptly, indicating the iron was very sensitive to the presence of a reducing atmosphere. After the mass line reached its minimum and stabilized, $0.5 \mathrm{wt} \%$ loss was recorded from the original mass, which is the $\mathrm{O}$ from $\mathrm{Fe}_{\mathrm{x}} \mathrm{O}_{\mathrm{y}}$ working as oxygen carrier. The increased mass during the Argon purge and oxygen reoxidation steps were considered as one process for mass change calculations. The reoxidized mass level in Fe250 is even higher

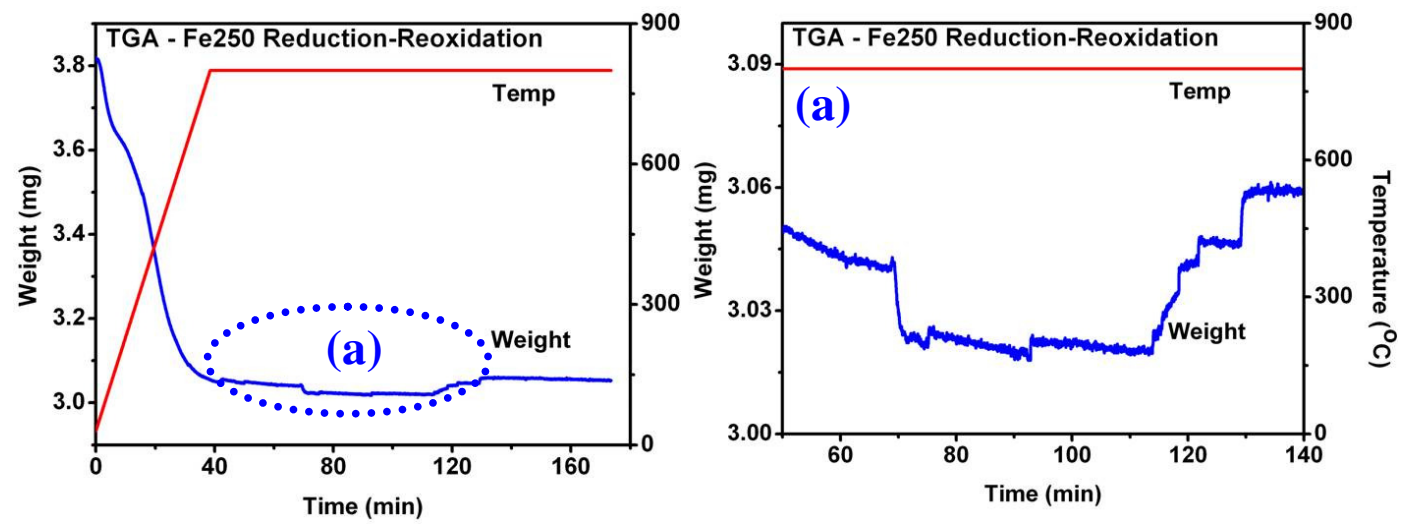

Figure 4-22. TGA-7 result for Fe250 reduction-reoxidation

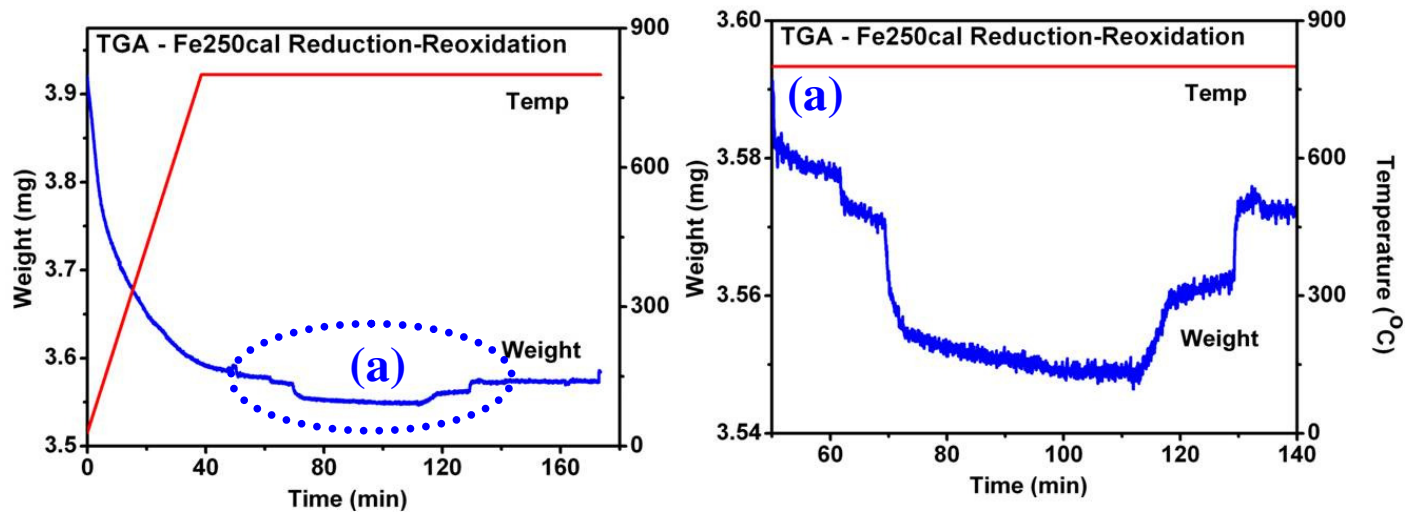

Figure 4-23. TGA-7 result for Fe250cal reduction-reoxidation

than before reduction, suggesting that iron in Fe250 is only partially oxidized to start with, but after reduction-reoxidation it is fully oxidized, hence the mass increase. Due to the low concentration of iron it was not possible to match the diffraction pattern to a standard as was done with cobalt, but based on this analysis, we believe that the iron in Fe250 initially is $\mathrm{Fe}_{3} \mathrm{O}_{4}$. Iron particles are sensitive to both reductive and oxidative reactions. 
Another possibility is that the iron particles as produced in the aerogel may not completely oxidize. To produce the fully oxidized species which should maintain the same mass before reduction and after oxidation, samples were calcined in air at $800{ }^{\circ} \mathrm{C}$, the same temperature used in CLC. Figure 4-23 is the TGA result for the Fe250cal reduction. After calcination the sample still has a chance to absorb moisture from the atmosphere, so as temperature increased, the water will desorb first. A $0.6 \mathrm{wt} \%$ mass loss was seen in the reduction, which is a little bit higher compared to the uncalcined sample of Fe250, which is because of some mass loss during the calcination, the base line for calculation is different.

Co150 was tested by TGA-7 as well (Figure 4-24). The XPS result shows cobalt is $10.78 \mathrm{wt} \%$ this is much higher than iron and it is expected to see a much larger mass difference. After the temperature reached $800{ }^{\circ} \mathrm{C}$ and the mass stabilized (Figure 4-24a), $17.2 \%$ mass lost was observed from the temperature increasing process, which is a little bit lower than pure aerogel and aerogel with iron because cobalt accounts for a higher mass percentage than iron, and this mass will not be lost in calcination. Figure 4-24a is the reduction-reoxidation cycle of the Co150. After switching Argon to Hydrogen, the sample mass decreased rapidly, indicating the sensitivity of cobalt particles to a reductive enviroment. When the mass level reached the minimum and became stable, the system was purged with argon and the gas changed to oxygen for reoxidation. The sample mass increased, and stabilized at the same level as before. In the XRD results for cobalt series samples before TGA, the XRD pattern agrees with $\mathrm{Co}_{3} \mathrm{O}_{4}$. After reoxidation at $800{ }^{\circ} \mathrm{C}$ it should be fully oxidized with mass greater than the originally partial-oxidized material. The reason this does not occur probably is probably because at this oxidation situation, $\mathrm{Co}_{3} \mathrm{O}_{4}$ is the most stable status than $\mathrm{Co}_{2} \mathrm{O}_{3}$ or any other kinds of oxides. After reoxidation, the primary composition of the sample still is $\mathrm{Co}_{3} \mathrm{O}_{4}$. Cobalt particles are sensitive to both reduction and oxidation as well. Ultimately, a mass loss of $1.55 \%$ was observed after 
the reduction, presumably as the $\mathrm{O}$ from $\mathrm{Co}_{\mathrm{x}} \mathrm{O}_{\mathrm{y}}$ working as an oxygen carrier.

Co150 was also calcined at $800{ }^{\circ} \mathrm{C}$, and tested by TGA-7 for reduction-reoxidation (Figure 4-25). As with the iron sample, aerogel with cobalt after calcination still has the chance to absorb moisture, so as temperature increased, the part of absorbed water will evaporate first, that is the mass loss as temperature increasing. A $2 \%$ mass loss in reduction was observed, as the same reason of calcined iron, and is higher than Co150.

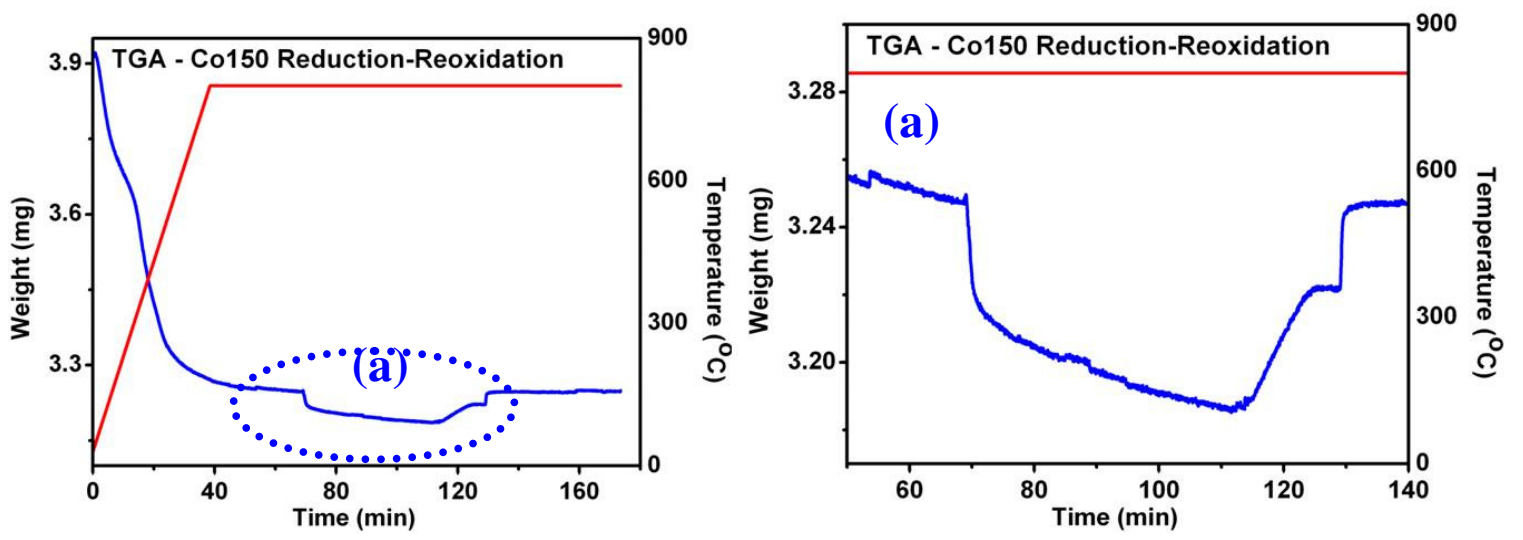

Figure 4-24. TGA-7 result for Co150 reduction-reoxidation
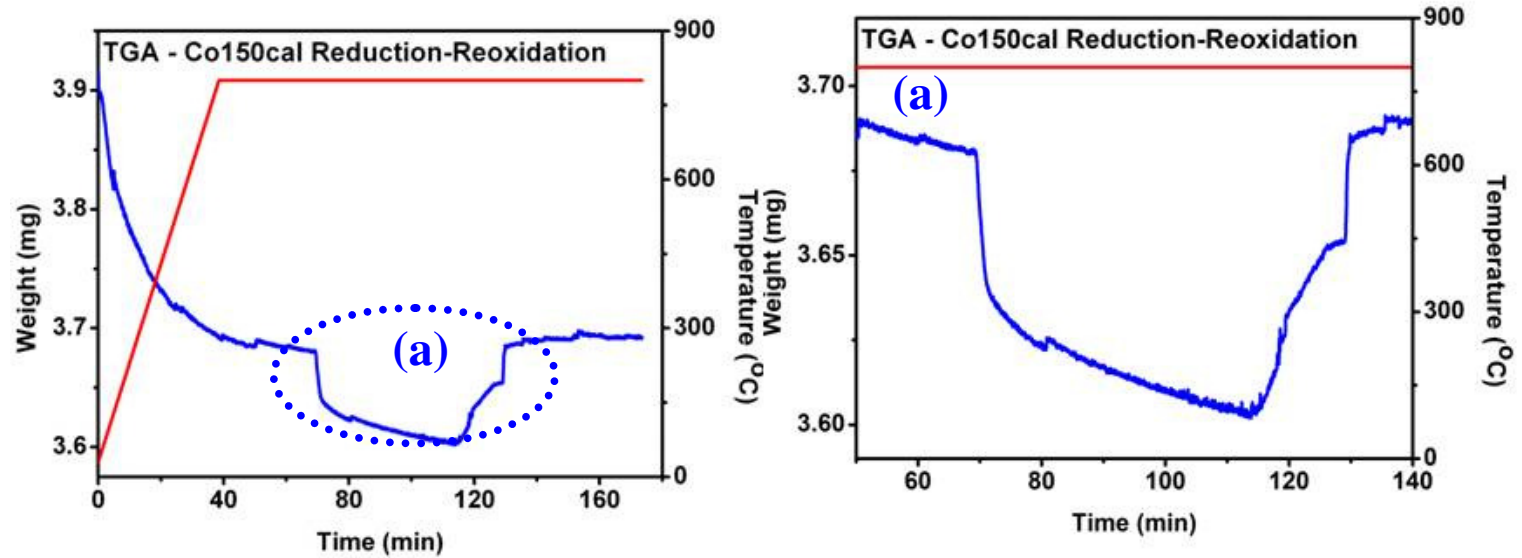

Figure 4-25. TGA-7 result for Co150cal reduction-reoxidation

Since the mass increase during Argon flow cannot be presently explained, it is not reasonable to estimate the metal concentration from the mass change. For easy comparison, the mass loss just before reduction occurs is compared with the final mass. 
This excludes interference from the absorbed water and the only difference for these four samples (since they all originated from the same batch of alumina-silica gel) is the type and concentration of the metal oxide. The mass loss for Fe250, Fe250cal, Co150 and Co150cal accounts for $0.67 \mathrm{wt} \%, 0.66 \mathrm{wt} \%, 1.87 \mathrm{wt} \%$, and $2.13 \mathrm{wt} \%$, respectively. From these results we can conclude that Co150cal did the best job as oxygen carrier. Obviously, increasing the amounts of iron and cobalt to increase the amount of oxygen available for oxidation would be a clear improvement.

As a proof of concept, the materials were tested by cyclic TGA at NETL (Figure 4-26) to study the behavior of these materials under multiple cycles of reduction-reoxidation. In these tests, the aerogel composites were cycled through the reduction-oxidation cycle six times. The program was as follows: The temperature is gradually increased from room temperature to $800{ }^{\circ} \mathrm{C}$ at the rate of $10{ }^{\circ} \mathrm{C} /$ minute, and then maintained isothermally. A mixture typical of the synthesis gas available in CLC (CO 36\%, $\mathrm{H}_{2} 27 \%$, $\mathrm{He} 25 \%$, and $\mathrm{CO}_{2} 12 \%$ ) was cycled with house $\mathrm{N}_{2}$ and house air to obtain reduction-oxidation cycles. The procedural details are described here, and indicated in the cyclic TGA trace in Figure 4-27. House Nitrogen is flowing during the ramp of temperature from room temperature to $800{ }^{\circ} \mathrm{C}$. Shown in Figure 4-27 is one cycle after the temperature reaching $800{ }^{\circ} \mathrm{C}$. When house air flows into the system (step A), the material is reoxidized, showing a mass increase. Nitrogen then flows through to purge the system (step B) before the reduction flow. In the next step (step C), syngas is introduced into the system, reducing the metal oxide, decreasing the total mass. Finally, nitrogen flows again (step D) to purge before the next reoxidation cycle.

Under typical cyclic TGA conditions, the mass during nitrogen flow should remain stable after the materials have been reoxidized, because no reaction should happen here in Nitrogen. However, for all our samples, in each Nitrogen step, the mass decreases. This is 
believed to be a possible problem with the instrument, the easiest explanation of which is that a pressure change as nitrogen flows into the system causes the mass fluctuation, perhaps due to buoyancy. To mitigate the effect, and to consider the total mass drop for reduction, the mass at oxidation and reduction were considered, ignoring the mass drop that occurred during in Nitrogen step.

Our materials (both iron and cobalt particles) do have reduction-reoxidation behaviors in multiple cycles TGA test simulating the real situation for a CLC system. But the weight loss for reduction is very small, even less than $1 \%$. And this part of weight loss is the capability for oxygen delivery from air to syngas as oxygen carriers, higher is expected. Comparing with others work, for instance, Dr. Tian's work ${ }^{71}$ in NETL, their materials even can lose more than $10 \mathrm{wt} \%$ for reduction loss in TGA test. Up to now our materials may be not the best choice for CLC, lower metal concentration probably is the primary reason, but we can still consider about the improvements and some other applications. Increasing the metal amounts, employing different kinds of metal precursors, and metal loading methods, even changing the shape of aerogel (i.e. thin film) are the ways we can go further to improve our materials, or utilize the materials as a catalyst in other systems.
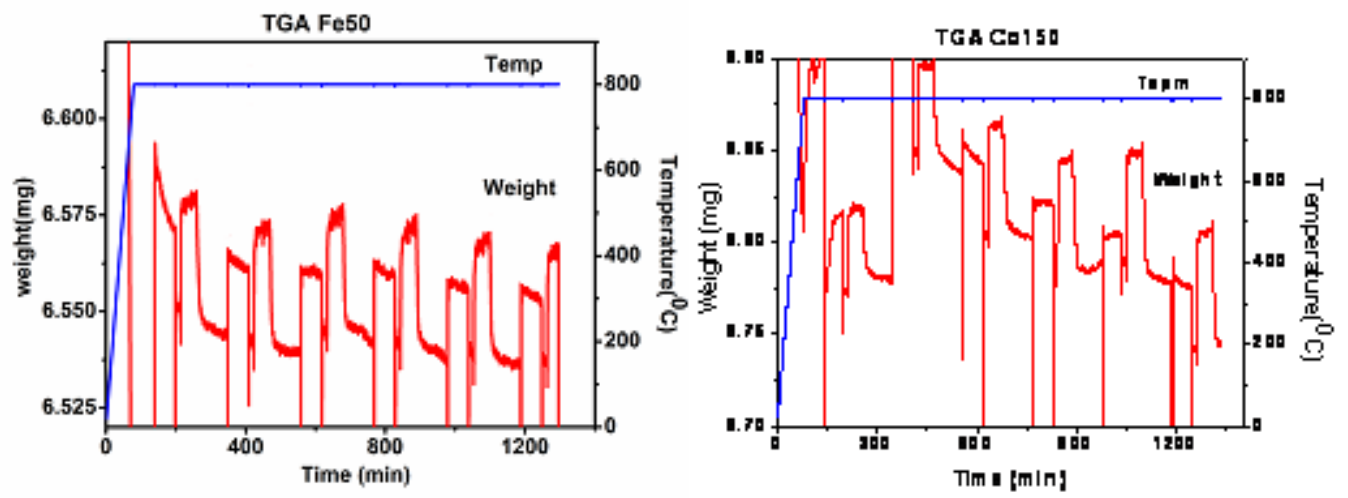

Figure 4-26. Cyclic cycles TGA test for Fe50 (left) and Co150 (right) 


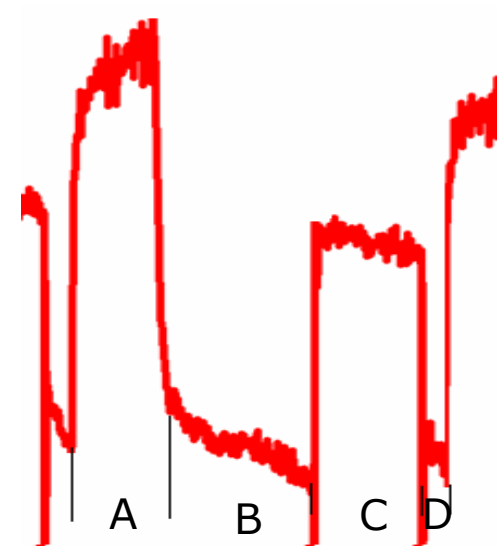

Figure 4-27. One oxidation-reduction cycle in cyclic TGA system

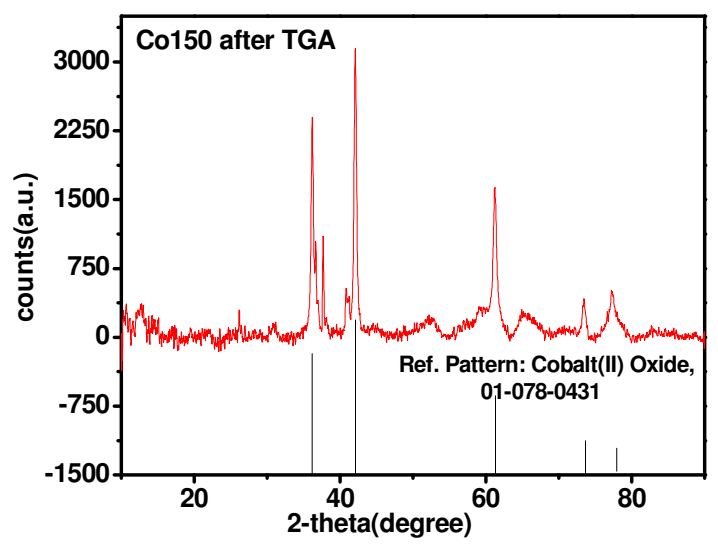

Figure 4-28. XRD pattern for Co150 after reduction in TGA
The oxidation state and structure of the metal after cyclic TGA was studied by XRD. For the iron samples, the concentration for iron is too low (less than $5 \%$ ), and the aerogel is largely amorphous, producing very broad peaks which can cover the small iron peaks, making it difficult to figure out from XRD which form of iron is present after

TGA test. With the Co150 sample, however, we successfully obtained the XRD pattern for the cobalt-containing aerogel after the reduction step. Figure 4-28 is the Co150 XRD pattern after TGA. The crystal pattern at the bottom of the plot is that of Cobalt (II) Oxide, which matches the sample closely. From this result, we can conclude that the cobalt is fully oxidized during the CLC cycles. Further work is necessary to determine the reductive state. 


\section{Conclusion}

An easy to control procedure was employed to synthesize alumina-silica aerogels as the substrate for metal particles for use as an oxygen carrier in chemical looping combustion. The prepared aerogel undergoes both alumina and TEOS aging processes to increase the strength and stiffness of the structure. The alumina aging step increased the crystallinity of the gel, and the silica aging step adjusted the ration of silica to alumina, with both of them affecting the net structure of aerogel. Alumina aerogel with a significant silica content exhibited more stable structure at high temperature. TEOS aging to deposit the silica on the aerogel increased surface area, increasing also the potential sites for metal loading. The surface area for pure aerogel after alumina aging and $24 \mathrm{hrs}$ TEOS aging, could reach as much as $750 \mathrm{~m}^{2} / \mathrm{g}$. Iron and cobalt were added to aerogels through thermal decomposition methods. For many studies, samples were ground into powder to obtain the average information about the sample. Some samples were also cross-sectioned and used to study the morphology of the original samples. The samples were characterized for structure and composition extensively. The results indicate that aerogel has a needlelike net structure, uniform monolithic surface, and appears very porous. Iron is in lower concentration, forming particles or films which cannot be resolved unequivocally with SEM or TEM, producing an aerogel surface which appears sponge-like and similar to pure aerogel. Cobalt, however, forms particles of much larger size (around $250 \mathrm{~nm}$ ) and higher concentration than iron forming a bulkier particulate surface. In some cases, the cobalt particles could be observed evenly distributed on the aerogel surface using SEM. Metal particles (both iron and cobalt) have a distribution gradient with highest concentration at the surface and decreasing to the center of the aerogel, which is supported by visual inspection of aerogels with metal content and by XPS Mapping and Linescan techniques. The composition of these materials was studied 
qualitatively by SEM-EDX, while XPS and ICP-MS indicate the quantitative concentration of the target metals - the two methods largely agree with one another. The elemental composition of the aerogel includes $\mathrm{O}, \mathrm{Si}, \mathrm{Al}$ and the specific metal (iron or cobalt). The other three elements have the relative higher concentrations than metal. Though following the same general deposition methods, cobalt has a higher concentration within the aerogel compared to iron, mainly due to different properties of the iron and cobalt precursors. It was also observed that iron oxide at low concentration stabilizes the aerogel structure better than at high concentration of the metal.

Chemical-Looping Combustion was simulated by TGA and both iron and cobalt-containing aerogels have reduction-reoxidation behaviors in TGA system, but with different efficiency. In addition, our materials are very sensitive with reduction and reoxidation flows, which is a good feature for a catalyst. Preliminary tests in cyclic TGA supported that these materials demonstrate the cyclic reduction-oxidation properties necessary to act as oxygen carriers in CLC.

From all the results we got now, we can conclude that our materials may be not the best candidate for CLC, but aerogel could be a good oxygen carrier support for CLC. To improve these materials, one of the most obvious routes would be to increase the amount of metal within the aerogel. Other kinds of metal precursors (that are perhaps less volatile), or modifications to the metal deposition approach are also practicable. Although our material may not be perfectly suitable for CLC, future work will examine their possible application as catalysts in other systems. 


\section{$\underline{\text { 6. References }}$}

1. Husing, N.; Schubert, U., Aerogels airy materials: Chemistry, structure, and properties. Angewandte Chemie-International Edition 1998, 37, (1-2), 23-45.

2. Human Development Report 2007/2008.

3. Carbon Dioxide capture from existing Coal-Fired power plants. DOE/NETL-401/110907.

4. BP Statistical Review of World Energy. British Petroleum 2006.

5. "Renewables, Global Status Report 2006. Renewable Energy Policy Network for the 21 st Centur.

6. Schon, S. C.; Small, A. A., Climate change and the potential of coal gasification. Geotimes 2006, 51, (9), 20-23.

7. Jenkins, S., IGCC 101 for Public Utilities Commission of Colorado URS Corporation.

8. Adanez, J.; Garcia-Labiano, F.; de Diego, L. F.; Gayan, P.; Celaya, J.; Abad, A., Nickel-copper oxygen carriers to reach zero $\mathrm{CO}$ and H-2 emissions in chemical-looping combustion. Industrial \& Engineering Chemistry Research 2006, 45, (8), 2617-2625.

9. Hossain, M. M.; de Lasa, H. I., Chemical-looping combustion (CLC) for inherent CO2 separations-a review. Chemical Engineering Science 2008, 63, (18), 4433-4451.

10. Ishida, M.; Jin, H., A Novel Combustor Based on Chemical-Looping Reactions and Its Reaction Kinetics. Journal Of Chemical Engineering Of Japan 1994, 27, (3), 296-301.

11. Ishida, M.; Jin, H., A Novel Chemical-Looping Combustor without NOx Formation. Industrial \& Engineering Chemistry Research 1996, 35, (7), 2469-2472.

12. Ishida, M.; Zheng, D.; Akehata, T., Evaluation of a chemical-looping-combustion power-generation system by graphic exergy analysis. Energy 1987, 12, (2), 147-54.

13. Richter, H. J.; Knoche, K. F., Reversibility of Combustion Processes. ACS Symp. 1983, 235, 71-85

14. Mattisson, T.; Lyngfelt, A., In Scandinavian-Nordic Section of Combustion Institute. 2001.

15. Mattisson, T.; Lyngfelta, A.; Cho, P., The use of iron oxide as an oxygen carrier in chemical-looping combustion of methane with inherent separation of CO2. Fuel 2001, 80, (13), 1953-1962.

16. Mattisson, T.; Johansson, M.; Lyngfelt, A., The use of $\mathrm{NiO}$ as an oxygen carrier in chemical-looping combustion. Fuel 2006, 85, (5-6), 36-747.

17. Corbella, B. M.; Palacios, J. M., Titania-supported iron oxide as oxygen carrier for chemical-looping combustion of methane. Fuel 2007, 86, (1-2), 113-122.

18. Corbella, B. M.; de Diego, L. F.; Garcia-Labiano, F.; Adanez, J.; Palacios, J. M., Performance in a fixed-bed reactor of titania-supported nickel oxide as oxygen carriers for the chemical-looping combustion of methane in multicycle tests. Industrial \& Engineering Chemistry Research 2006, 45, (1), 157-165.

19. de Diego, L. F.; Garcia-Labiano, F.; Adanez, J.; Gayan, P.; Abad, A.; Corbella, B. M.; Palacios, J. M., Development of Cu-based oxygen carriers for chemical-looping combustion. Fuel 2004, 83, (13), 1749-1757. 
20. Guise, M. T.; Hosticka, B.; Earp, B. C.; Norris, P. M., An experimental investigation of aerosol collection utilizing packed beds of silica aerogel microspheres. Journal of Non-Crystalline Solids 2001, 285, (1-3), 317-322.

21. Hirashima, H.; Kojima, C.; Imai, H., Application of alumina aerogels as catalysts. Journal of Sol-Gel Science and Technology 1997, 8, (1-3), 843-846.

22. Anderson, M. L.; Morris, C. A.; Stroud, R. M.; Merzbacher, C. I.; Rolison, D. R., Colloidal gold aerogels: Preparation, properties, and characterization. Langmuir 1999, 15, (3), 674-681.

23. Carta, D.; Casula, M. F.; Falqui, A.; Loche, D.; Mountjoy, G.; Sangregorio, C.; Corrias, A., A Structural and Magnetic Investigation of the Inversion Degree in Ferrite Nanocrystals MFe2O4 $(\mathrm{M}=$ Mn, Co, Ni). Journal of Physical Chemistry C 2009, 113, (20), 8606-8615.

24. Bae, J. W.; Kim, S. M.; Kang, S. H.; Chary, K. V. R.; Lee, Y. J.; Kim, H. J.; Jun, K. W., Effect of support and cobalt precursors on the activity of Co/AlPO4 catalysts in Fischer-Tropsch synthesis. Journal of Molecular Catalysis a-Chemical 2009, 311, (1-2), 7-16.

25. Lapidus, A. L.; Pavlova, V. A.; Chin, N. K.; Eliseyev, O. L.; Gushchin, V. V.; Davydov, P. E., Aluminosilicate-supported cobalt catalysts in the Fischer-Tropsch synthesis. Petroleum Chemistry 2009, 49, (4), 301-305.

26. Prieto, G.; Martinez, A.; Concepcion, P.; Moreno-Tost, R., Cobalt particle size effects in Fischer-Tropsch synthesis: structural and in situ spectroscopic characterisation on reverse micelle-synthesised Co/ITQ-2 model catalysts. Journal of Catalysis 2009, 266, (1), 129-144.

27. Pirola, C.; Bianchi, C. L.; Di Michele, A.; Diodati, P.; Vitali, S.; Ragaini, V., High Loading Fe-supported Fischer-Tropsch Catalysts: Optimization of the Catalyst Performance. Catalysis Letters 2009, 131, (1-2), 294-304.

28. Tavasoli, A.; Irani, M.; Nakhaeipour, A.; Mortazavi, Y.; Khodadadi, A. A.; Dalai, A. K., Preparation of a Novel Super Active Fischer-Tropsch Cobalt Catalyst Supported on Carbon Nanotubes. Iranian Journal of Chemistry \& Chemical Engineering-International English Edition 2009, 28, (1), 37-48.

29. Dunn, B. C.; Cole, P.; Turpin, G. C.; Ma, Z. R.; Pugmire, R. J.; Ernst, R. D.; Eyring, E. M.; Shah, N.; Huffman, G. P., Silica aerogel supported catalysts for Fischer-Tropsch synthesis. Abstracts of Papers of the American Chemical Society 2004, 227, 146-FUEL.

30. Dunn, B.; Turpin, G. C.; Cole, P.; Webster, M. C.; Ma, Z. R.; Pugmire, R. J.; Ernst, R. D.; Eyring, E. M.; Shah, N.; Huffman, G. P., Cobalt and ruthenium Fischer-Tropsch catalysts supported on silica aerogel. Abstracts of Papers of the American Chemical Society 2004, 228, U178-U178.

31. Blancharda;, F.; Reymonda, P.; Pommiera, B.; Teichner, S. J., On the mechanism of the Fischer-Tropsch synthesis involving unreduced iron catalyst. Journal of Molecular Catalysis 1982, 17, (2-3), 171-181.

32. Group, M. M. Silica Aerogels.

33. Kocona, L.; Despetisb, F.; Phalippou, J., Ultralow density silica aerogels by alcohol supercritical drying. Journal of Non-Crystalline Solids 1998, 225, (1), 96-100.

34. Bommela, M. J. v.; Haan, A. B. d., Drying of silica aerogel with supercritical carbon dioxide. Journal of Non-Crystalline Solids 1995, 186, 78-82.

35. Suh, D. J.; Par, T.-J., Sol-Gel Strategies for Pore Size Control of High-Surface-Area Transition-Metal Oxide Aerogels. Chem. Mater. 1996, 8, (2), 509-513. 
36. Gash, A. E.; Satcher, J. H.; Simpson, R. L., Strong Akaganeite Aerogel Monoliths Using Epoxides: Synthesis and Characterization. Chemistry of Materials 2003, 15, (17), 3268-3275.

37. Fu, R.; Baumann, T. F.; Cronin, S.; Dresselhaus, G.; Dresselhaus, M. S.; Satcher, J. H., Formation of Graphitic Structures in Cobalt- and Nickel-Doped Carbon Aerogels. Langmuir 2005, 21, (7), 2647-2651.

38. Anderson, M. L.; Morris, C. A.; Stroud, R. M.; Merzbacher, C. I.; Rolison, D. R., Colloidal Gold Aerogels: Preparation, Properties, and Characterization. Langmuir 1999, 15, (3), 674-681.

39. Casas, L.; Roig, A.; Rodriguez, E.; Molins, E.; Tejada, J.; Sort, J., Silica aerogel-iron oxide nanocomposites: structural and magnetic properties. Journal of Non-Crystalline Solids 2001, 285, (1-3), 37-43.

40. Leventis, N.; Sotiriou-Leventis, C.; Zhang, G.; Rawashdeh, A.-M. M., Nanoengineering Strong Silica Aerogels. Nano Letters 2002, 2, (9), 957-960.

41. Hunt, A. J.; Ayers, M. R., Investigations of silica alcogel aging using coherent light. Journal of Non-Crystalline Solids 2001, 285, (1-3), 162-166.

42. Saegusa, T., Organic Polymer-Silica Gel Hybrid: A Precursor of Highly Porous Silica Gel Journal of Macromolecular Science, Part A 1991 28, (9), 817 - 829.

43. Chujo, Y.; Saegusa, T., Organic polymer hybrids with silica gel formed by means of the sol-gel method. Macromolecules: Synthesis, Order and Advanced Properties 1992, 100, 11-29.

44. Okamoto, Y.; Honda, S.; Okamoto, I.; Yuki, H.; S.Murata; Noyori, R.; Takaya, H., Novel packing material for optical resolution: (+)-poly(triphenylmethyl methacrylate) coated on macroporous silica gel. Journal of the American Chemical Society 1981, 103, (23), 6971-6973.

45. Alexander, G. B.; Broge, E. C., Process of Making Reinforced Sillica Gel and Esterified Sillica Gel. United State Patent Office 1952.

46. Einarsrud, M. A.; Nilsen, E.; Rigacci, A.; Pajonk, G. M.; Buathier, S.; Valette, D.; Durant, M.; Chevalier, B.; Nitz, P.; Ehrburger-Dolle, F., Strengthening of silica gels and aerogels by washing and aging processes. Journal of Non-Crystalline Solids 2001, 285, (1-3), 1-7.

47. Tsukada, T.; Segawa, H.; Yasumori, A.; Okadab, K., Crystallinity of boehmite and its effect on the phase transition temperature of alumina. Journal of Materials Chemistry 1998.

48. Dwivedi, R. K.; Gowda, G., Thermal stability of aluminium oxides prepared from gel. Journal of Materials Science Letters 1985, 4, 331-334.

49. Pajonk, G. M., Catalytic aerogels. Catalysis Today 1997, 35, (3), 319-337.

50. Hirashima, H.; Kojima, C.; Imai, H., Application of alumina aerogels as catalysts. Journal of Sol-Gel Science and Technology 1997, 8, 1-3.

51. Shi, G.; Mo, C. M.; Cai, W. L.; Zhang, L. D., Photoluminescence of ZnO nanoparticles in alumina membrane with ordered pore arrays. Solid State Communications 2000, 115, (5), 253-256.

52. Morris, C. A.; Anderson, M. L.; Stroud, R. M.; Merzbacher, C. I.; Rolison, D. R., Silica sol as a nanoglue: Flexible synthesis of composite aerogels. Science 1999, 284, (5414), 622-624.

53. Casula, M. F.; Corrias, A.; Paschina, G., FeCo-SiO2 nanocomposite aerogels by high temperature supercritical drying. Journal of Materials Chemistry 2002, 12, (5), 1505-1510. 
54. Dunna, B. C.; Colea, P.; Covingtona, D.; Webstera, M. C.; Ronald J. Pugmirea; Ernsta, R. D.; Eyringa, E. M.; Shahb, N.; Huffman, G. P., Silica aerogel supported catalysts for Fischer-Tropsch synthesis. Applied Catalysis a-General 2005, 278, 233-238.

55. Gayán, P.; Dueso, C.; Abad, A.; Adanez, J.; de Diego, L. F.; García-Labiano, F., NiO/Al2O3 oxygen carriers for chemical-looping combustion prepared by impregnation and deposition-precipitation methods. Fuel 2009, 88, (6), 1016-1023.

56. Nakagawa, K.; Tanimoto, Y.; Okayama, T.; Sotowa, K.-I.; Sugiyama, S.; Takenaka, S.; Kishida, M., Sintering Resistance and Catalytic Activity of Platinum Nanoparticles Covered with a Microporous Silica Layer Using Methyltriethoxysilane. Catalysis Letters 2010, 136, (1), 71-76.

57. Shen, L.; Wu, J.; Gao, Z.; Xiao, J., Reactivity deterioration of NiO/Al2O3 oxygen carrier for chemical looping combustion of coal in a $10 \mathrm{~kW}$ th reactor. Combustion and Flame 2009, 156, (7), 1377-1385.

58. Opila, E. J.; Smialek, J. L.; Robinson, R. C.; Fox, D. S.; Jacobson, N. S., SiC Recession Caused by $\mathrm{SiO}_{2}$ Scale Volatility under Combustion Conditions: II, Thermodynamics and Gaseous-Diffusion Model. Journal of the American Ceramic Society 1999, 82, (7), 1826-1834.

59. Himmel, B.; Gerber, T.; Bürger, H.; Holzhüter, G.; Olbertz, A., Structural characterization of SiO2---A12O3 aerogels. Journal of Non-Crystalline Solids 1995, 186, 149-158

60. Horiuchi, T.; Chen, L.; Osaki, T.; Sugiyama, T.; Suzuki, K.; Mori, T., A novel alumina catalyst support with high thermal stability derived from silica-modified alumina aerogel. Catalysis Letters 1999, 58, (2-3), 89-92.

61. Castro, R. H. R.; Ushakov, S. V.; Gengembre, L.; GouvÃa a, D.; Navrotsky, A., Surface Energy and Thermodynamic Stability of $\hat{\mathrm{I}}^{3}$-Alumina:â€\%o Effect of Dopants and Water. Chemistry of Materials 2006, 18, (7), 1867-1872.

62. Hdacha, H.; Woigniera, T.; Phalippoua, J.;Scherer, J. W., Effect of aging and pH on the modulus of aerogels. Journal of Non-Crystalline Solids 1990, 121, (1-3), 202-205.

63. Dutoit, D. C. M.; Schneider, M.; Fabrizioli, P.; Baiker, A., Vanadia-Silica Low-Temperature Aerogels: Influence of Aging and Vanadia Loading on Structural and Chemical Properties. Chemistry of Materials 1996, 8, (3), 734-743.

64. Hyun, S. H.; Kim, J. J.; Park, H. H., Synthesis and characterization of low-dielectric silica aerogel films. Journal of the American Ceramic Society 2000, 83, (3), 533-540.

65. Gan, L. H.; Xu, Z. J.; Feng, Y.; Chen, L. W., Synthesis of alumina aerogels by ambient drying method and control of their structures. Journal of Porous Materials 2005, 12, (4), 317-321.

66. Yoda, S.; Ohshima, S., Supercritical drying media modification for silica aerogel preparation. Journal of Non-Crystalline Solids 1999, 248, (2-3), 224-234.

67. Cao, S. L.; Yeung, K. L.; Yue, P. L., Preparation of freestanding and crack-free titania-silica aerogels and their performance for gas phase, photocatalytic oxidation of VOCs. Applied Catalysis B-Environmental 2006, 68, (3-4), 99-108.

68. Moner-Girona, M.; Martinez, E.; Roig, A.; Esteve, J.; Molins, E., Mechanical properties of silica aerogels measured by microindentation: influence of sol-gel processing parameters and carbon addition. Journal of Non-Crystalline Solids 2001, 285, (1-3), 244-250. 
69. Hyeon, T.; Lee, S. S.; Park, J.; Chung, Y.; Bin Na, H., Synthesis of highly crystalline and monodisperse maghemite nanocrystallites without a size-selection process. Journal of the American Chemical Society 2001, 123, (51), 12798-12801.

70. Moulder, J. F.; Stickle, W. F.; Sobol, P. E.; Bomben, K. D., Handbook of X-ray Photoelectron Spectroscopy. Physical Electronics Division: 1995.

71. Tian, H.; Chaudhari, K.; Simonyi, T.; Poston, J.; Liu, T.; Sanders, T.; Veser, G. t.; Siriwardane, R., Chemical-looping Combustion of Coal-derived Synthesis Gas Over Copper Oxide Oxygen Carriers. Energy \& Fuels 2008, 22, (6), 3744-3755. 